\title{
ADVANCED DISTILLATION FINAL REPORT
}

Award Number and Recipient: DE-FC36-04G014271

Velocys, Inc.

7950 Corporate Blvd.

Plain City, OH 43064

Project Title and name of Project Director:
Advanced Distillation
Tom Hickey
7950 Corporate Blvd.
Plain City, OH 43064
Tel: (614) 733-3380
FAX: (614) 733-3301
Email: hickey@velocys.com

Project Period $\quad 10 / 01 / 2004$ thru 12/31/2009

\section{PROTECTED RIGHTS NOTICE}

These protected data were produced under agreement no. DE-FC36-04G014271 with the U.S. Department of Energy and may not be published, disseminated, or disclosed to others outside the Government until December 31,2010 , unless express written authorization is obtained from the recipient. Upon expiration of protection set forth in this Notice, the Government shall have unlimited rights in these data. This Notice shall be marked on any reproduction of these data, in whole or in part. 



\section{EXECUTIVE SUMMARY}

The Advanced Distillation project was concluded on December 31, 2009. This U.S. Department of Energy (DOE) funded project was completed successfully and within budget during a timeline approved by DOE project managers, which included a one year extension to the initial ending date. The subject technology, Microchannel Process Technology (MPT) distillation, was expected to provide both capital and operating cost savings compared to conventional distillation technology. With efforts from Velocys and its project partners, MPT distillation was successfully demonstrated at a laboratory scale and its energy savings potential was calculated. While many objectives established at the beginning of the project were met, the project was only partially successful. At the conclusion, it appears that MPT distillation is not a good fit for the targeted separation of ethane and ethylene in large-scale ethylene production facilities, as greater advantages were seen for smaller scale distillations.

Early in the project, work involved flowsheet analyses to discern the economic viability of ethaneethylene MPT distillation and develop strategies for maximizing its impact on the economics of the process. This study confirmed that through modification to standard operating processes, MPT can enable net energy savings in excess of $20 \%$. This advantage was used by ABB Lumus to determine the potential impact of MPT distillation on the ethane-ethylene market. The study indicated that a substantial market exists if the energy saving could be realized and if installed capital cost of MPT distillation was on par or less than conventional technology. Unfortunately, it was determined that the large number of MPT distillation units needed to perform ethane-ethylene separation for world-scale ethylene facilities, makes the targeted separation a poor fit for the technology in this application at the current state of manufacturing costs.

Over the course of the project, distillation experiments were performed with the targeted mixture, ethane-ethylene, as well as with analogous low relative volatility systems: cyclohexane-hexane and cyclopentane-pentane. Devices and test stands were specifically designed for these efforts. Development progressed from experiments and models considering sections of a full scale device to the design, fabrication, and operation of a single-channel distillation unit with integrated heat transfer. Throughout the project, analytical and numerical models and Computational Fluid Dynamics (CFD) simulations were validated with experiments in the process of developing this platform technology.

Experimental trials demonstrated steady and controllable distillation for a variety of process conditions. Values of Height-to-an-Equivalent Theoretical Plate (HETP) ranging from less than 0.5 inch to a few inches were experimentally proven, demonstrating a ten-fold performance enhancement relative to conventional distillation. This improvement, while substantial, is not sufficient for MPT distillation to displace very large scale distillation trains. Fortunately, parallel efforts in the area of business development have yielded other applications for MPT distillation, including smaller scale separations that benefit from the flowsheet flexibility offered by the technology. Talks with multiple potential partners are underway. Their outcome will also help determine the path ahead for MPT distillation. 


\section{TABLE OF CONTENTS}

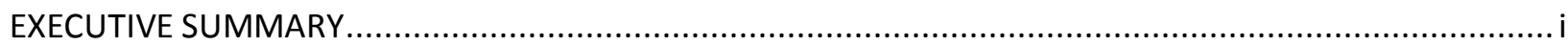

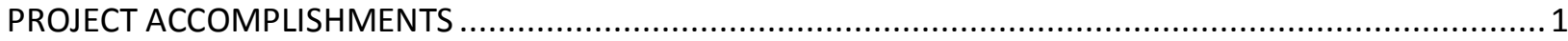

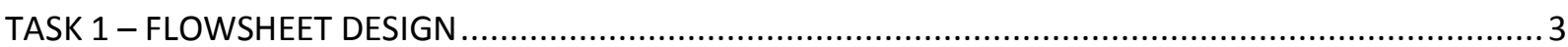

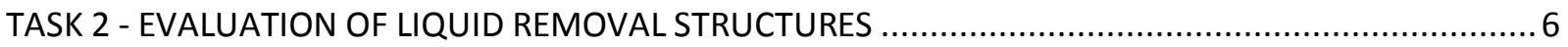

TASK 3 - SELECTION OF MICROCHANNEL GEOMETRY AND PROCESS CONDITIONS ............................ 10

3.1. Selection of a Chemical System for Scoping Experiments.................................................... 10

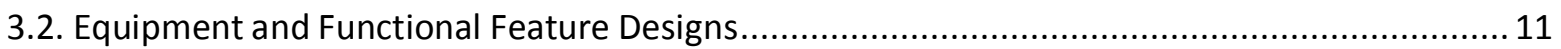

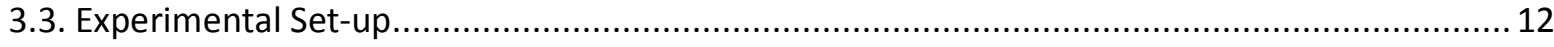

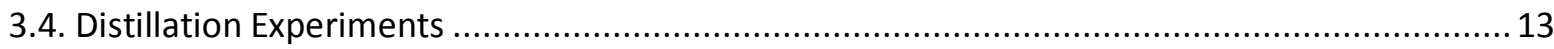

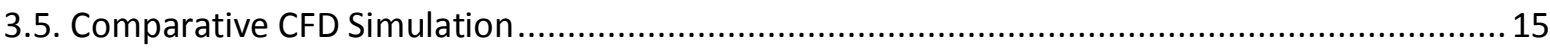

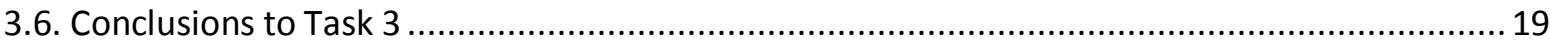

TASK 4 - VALIDATE DISTILLATION CODES BY FABRICATING AND OPERATING SINGLE-MICROCHANNEL

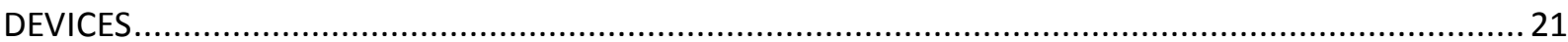

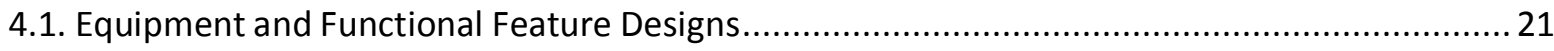

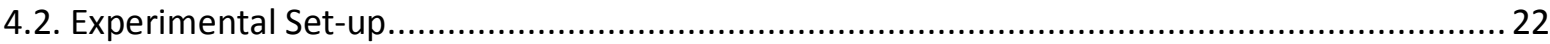

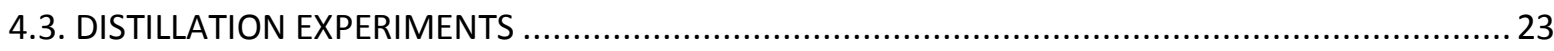

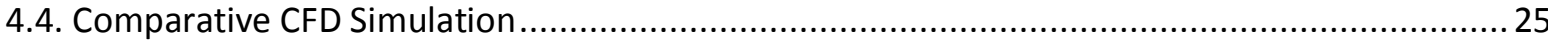

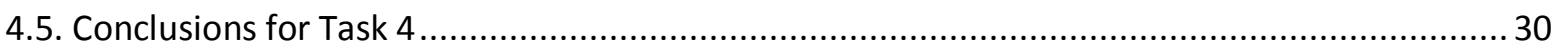

TASK 5 - DESIGN, FABRICATE AND TEST INTEGRATED SINGLE-CHANNEL DISTILLATION DEVICE .......... 32

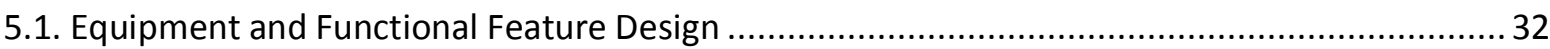

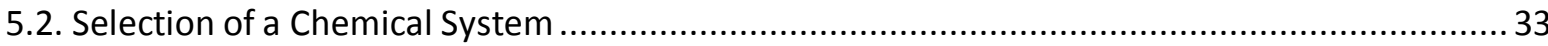

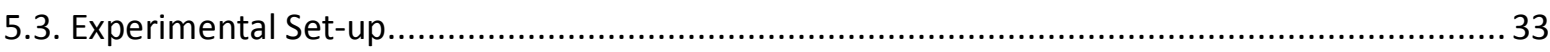

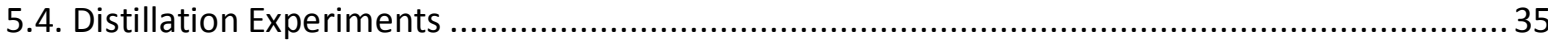

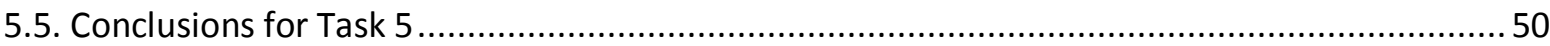

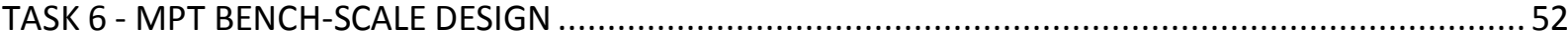

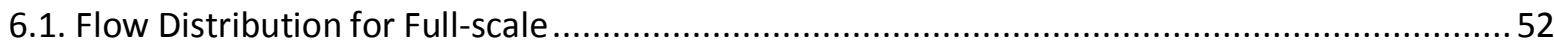

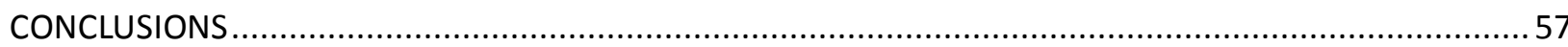

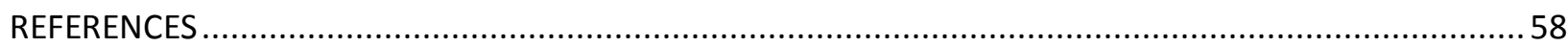

NOMENCLATURE

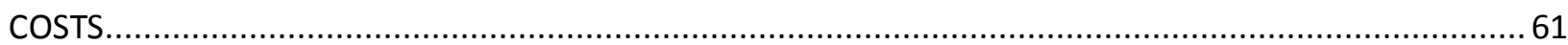

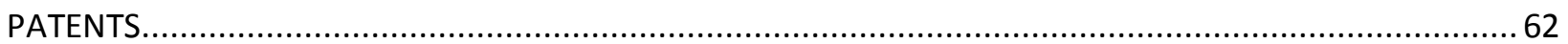

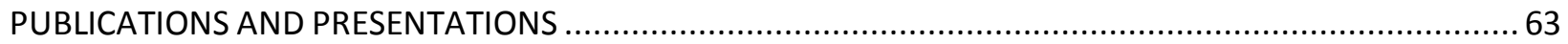




\section{TABLE OF FIGURES}

Figure 1-1. Probability distribution in the number of MPT units that will be deployed beginning in 2011.4 Figure 1-2. Potential USA energy savings for the years 2020 and 2030 with a 2011 MPT market entry.... 5

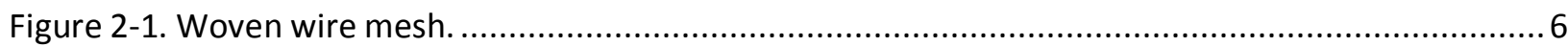

Figure 2-2. Liquid removal structure geometry for flow capacity comparison ....................................... 7

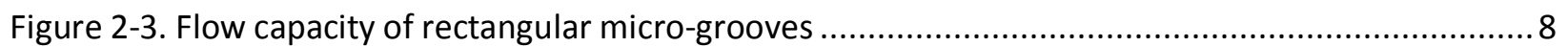

Figure 2-4. Flow capacity of triangular micro-grooves.............................................................. 8

Figure 2-5. Control volume in repeating unit model .................................................................... 9

Figure 3-1. Superposition of the vapor liquid equilibrium curves for the ethane-ethylene $\left(C_{2}\right)$ and hexanecyclohexane $\left(C_{6}\right)$ systems. The curves coincide very closely 10

Figure 3-2. Internal schematic of the microchannel distillation device used for hexane-cyclohexane separation. Dimension are not to scale.

Figure 3-3. Microchannel distillation devices used for hexane-cyclohexane separation. Pictures of the two device configurations are shown in the left and center views. The right most picture shows an internal view.

Figure 3-4. Simplified process and instrumentation diagram for the hexane-cyclohexane test stand. The circuit connected to the bulk nitrogen supply was only included in testing for the device configuration with heat exchange.

Figure 3-5. Schematics of the experimental microchannel distillation devices and corresponding distillation column separation section. Relative dimensions are not to scale.

Figure 3-6. Representative hexane concentration profiles (mole fraction) as a function of axial position with respect to the channel top for simulated Case 1a (falling film). Dotted lines represent liquidside, solid lines represent vapor-side profiles. A schematic of the channel, oriented horizontally to coincide with the plot axis, indicates liquid and vapor flow directions. Plot a presents interfacial concentrations, Plot $b$ presents concentrations in the cells adjacent to the interface, Plot $c$ shows the concentration difference driving the mass transfer at the interface (values in Plot $b$ minus values in Plot $a)$.

Figure 3-7. Representative surface area averaged concentration profiles and corresponding interfacial compositions for Cases 1a and 2a. Area averaged (bulk) concentration profiles were used to determine HETP values for each of the simulated runs

Figure 4-1. Microchannel distillation device used for ethane-ethylene separation. Flow channel width was 0.45 inch.

Figure 4-2. Phase separation screen/microporous contactor with 4-6 $\mu \mathrm{m}$ diameter laser drilled holes. . 22

Figure 4-3. Pressure differential for effective flow and interfacial interaction. Small holes in the screen allow interfacial contact and mass transfer while preventing breakthrough of one phase into the other.....

Figure 4-4. Simplified process and instrumentation diagram for the ethane-ethylene test stand. ..........23

Figure 4-5. Steady profiles over an approximate 3 hour period for operation at a flow ratio of 1.7 ....... 24

Figure 4-6. Steady temperature profiles over an approximate 3 hour period for operation at a flow ratio of 1.7. Color coding in the schematic corresponds to line color in the graphs. The temperature element at vapor outlet was malfunctioning and is not included in the graphs..... 24 
Figure 4-7. Steady outlet compositions measured over an approximate 3 hour period for operation at a flow ratio of 1.7 . 25

Figure 4-8. Cross sectional view of the microchannel distillation device used for ethane-ethylene separation. 25

Figure 4-9. Plot of overall and vapor and liquid HETP's for the simulated cases as a function of the corresponding experimental vapor flow rates. The stagnant value is for the overall HETP......... 28

Figures 4-10. Representative profiles of the concentration difference (light species in the bulk minus light species in the interface) across the interface for Run ID's 1-1d (a), 1-2d (b), and 0-1c (c). Positive differences, shown in black, correspond to the liquid gradient, negative differences, shown in red, correspond to the vapor gradient. Left-most plots show profiles across the width of the channel; right-most plots show profiles across the length of the channel. Liquid moves in the positive axial direction. The concentration differences drive the mass transfer at the

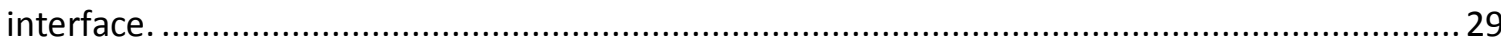

Figure5-1. Microchannel distillation device used for pentane-cyclopentane separation...................... 33

Figure 5-2. Superposition of the vapor liquid equilibrium curves for the three chemical separations experimentally tested with Velocys microchannel process technology. The curves coincide very closely, with the pentane and hexane systems having an exact overlap. As noted in the legend, temperature ranges for distillation of the analogous mixtures were very mild in comparison with the ethane distillation.

Figure 5-3. Simplified process and instrumentation diagram for the pentane-cyclopentane test stand. . 34

Figure 5-4. Pictures of the Flex Cell device mounted in the Thermotron cold box. Left-most picture shows the device with insulated level sensor housing, inlet and outlet lines. Right-most picture shows the same device with the insulation removed. .35

Figure 5-5. Time dependent level sensor, Coriolis flowmeter, and pressure profiles for operation over a 6 hour period at 1.0x flow rate. Profiles correspond to the 1st generation Flex Cell distillation run 1.

Figure 5-6. Time dependent temperature profiles for operation over a 6 hour period at 1.0x flow rate. Profiles correspond to the 1st generation Flex Cell distillation run 1...................................... 44

Figure 5-7. Time dependent sensor and valve response, pressure and temperature profiles for operation of the 1st generation Flex Cell over a 1 hour period at 1.0, 1.5, and 2.0x flow rates. Profiles correspond to the distillation runs of $8: 45,5 / 226,8: 42,6 / 2518$, and 16:00,6/2519, operated with condenser and reboiler temperatures ranging from 72 to $73^{\circ} \mathrm{C}$ and 86 to $88^{\circ} \mathrm{C}$, respectively.

Figures 5-8. McCabe-Thiele analysies plots for a representative 1st generation Flex Cell distillation caserun (5), run operated at the design flow rate on 5/20, at 10:55. Estimated stage numbers and HETP's are also shown, for clarification. a) Infinite reflux approximation. b) Approximation based on a reflux ratio 1.5 times minimum. 46

Figure 5-9. McCabe-Thiele analyses diagrams for three representative distillation runs $(6,18$, and 19) involving similar feed composition, reboiler and condenser temperatures but varying feed flow rates. Although performance of the stripping section of the tower was unchanged, the rectification performance was impacted by the change in process conditions, as is typical of 
standard distillation tower operation. Operation was stable and controllable for all conditions. Details can be found in Tables 5-2 through 5-5.

Figure 5-10. Plots of differential chiller feed and reboiler temperatures, and condenser chiller feed and reboiler process fluid temperatures as a function of distillate product purity. Measurements spanned the total operation period, including both the $1^{\text {st }}$ generation and $2^{\text {nd }}$ generation Flex Cells, FC1 and FC2, respectively. The label indicates the feed flow rate relative to the design point value $(1.0 \mathrm{X}, 1.5 \mathrm{X}, 2.0 \mathrm{X})$, whether the run set involved variation in reboiler or condenser temperature (ch rbl or ch cnd, respectively), and the collection dates for the data...................50

Figure 6-1. Schematic of an internal manifold and microchannels...................................................... 52

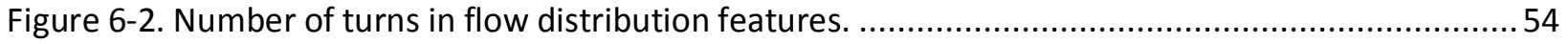

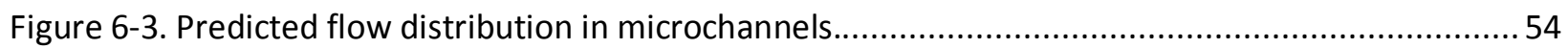

Figure 6-4. Channel pressure drop variation for design sensitivity analysis..........................................5 55

Figure 6-5. Mass flow distribution for design sensitivity analysis.................................................... 55

\section{TABLE OF TABLES}

Table 3-1. Experimental outlet conditions for hexane-cyclohexane separation and comparison with

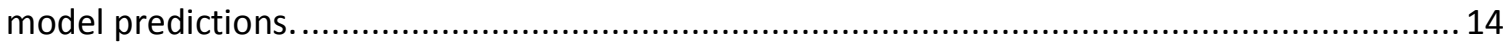

Table 3-2. Experimental outlet conditions for hexane-cyclohexane separation and comparison with

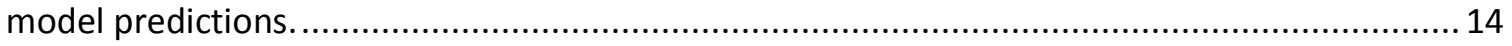

Table 3-3. Key measurables and performance estimates for operation of the hexane-cyclohexane separation devices. Reported runs did not include heat exchange. Tabulated predictions were made with the simple mathematical model from Task 2.

Table 3-4. Material properties and interfacial parameters used in the simulation involving hexanecyclohexane separation. Gas and liquid diffusivities were estimated adopting standard methodologies (Poling et al.).

Table 3-5. Key run parameters for the simulated cases. Vapor thickness was calculated by subtracting the assumed liquid film thickness from the overall internal device gap size, 0.058 inches. ........ 17

Table 3-6. Characteristic dimensionless numbers for the cases considered. Peclet Numbers were calculated as detailed in Section 4.4.3.

Table 3-7. Run results for the experimental and simulated hexane-cyclohexane separation cases. (Experimental values were estimated using ChemCAD.) ....................................................... 18

Table 4-1. Experimental run parameters and HETP values estimated using ChemCAD. ........................23

Table 4-2. Material properties and interfacial parameters used in the simulation involving direct comparison with the ethane-ethylene experiments. Gas and liquid diffusivities were estimated adopting standard methodologies (Poling et al.).

Table 4-3. Key parameters corresponding to the CFD simulations used to probe experimental system performance; inlet fluid velocities were defined to match experimental values. Run $0-1 \mathrm{c}$ corresponds to a preliminary run used to ensure adequate geometric configuration; this run has no direct experimental comparison. The preliminary run assumed an interfacial surface area $100 \%$ open to mass transfer; the latter runs assumed an interfacial surface area $14 \%$ open to 
mass transfer. The HETP's in the table reflect main channel values and are based on Hoy. Values in parenthesis for runs 1-3 and 1-4 correspond to the ratio of the stagnant to non-stagnant counterparts. All cases assumed a symmetric boundary condition at the channel sidewalls......27

Table 4-4. Comparisons of experimental and simulated model performance. Experimental HETP values were estimated using ChemCAD.

Table 5-1. Representative iterative design point calculations to size experimental column flows and gap dimensions. For the ChemCAD simulations, the feed stream and top stage temperatures were consistently held at 78.8 and $73{ }^{\circ} \mathrm{C}$, respectively. These values corresponded to pre-set $49 \mathrm{~mol} \%$ and $99 \mathrm{~mol} \%$ pentane feed and distillate compositions. Bottom stage temperatures was let fluctuate to achieve the predefined boil-up ratio and distillate purity. For the falling film calculations, void fraction was assumed to be 1.0 in all cases, the wall, perpendicular to the ground, was assumed to have a width of 1.0 inch.

Table 5-2. Pentane-cyclopentane distillation run summary for the 1st generation Flex Cell operated at a feed flow rate 1.0 times the design point. $T$ and $\mathrm{dT}$ correspond to temperature and temperature differentials, respectively...... 39

Table 5-3. Pentane-cyclopentane distillation run summary for the 1st generation Flex Cell operated at a feed flow rate 1.5 times the design point. $T$ and $\mathrm{dT}$ correspond to temperature and temperature differentials, respectively.

Table 5-4. Pentane-cyclopentane distillation run summary for the 1st generation Flex Cell operated at a feed flow rate 2.0 times the design point. $T$ and $\mathrm{dT}$ correspond to temperature and temperature differentials, respectively.

Table 5-5. Some key comparative run measures for pentane-cyclopentane distillation in the 1st generation Flex Cell. Data indicate long term and repeatable operating responses for the column. T indicates temperature.

Table 5-6. Comparative pentane-cyclopentane distillation performance for the 1st generation Flex Cell operated at varying feed flow rates. Details pertaining to each run can be found in Tables 10, 11, and 12 48

Table 5-7. Pentane-cyclopentane distillation run summary for the 2 nd generation Flex Cell operated at feed flow rates 0.8 and 1.0 times the design point. Comparative results for the 1 st generation device are also included, for reference.

Table 6-1. Dimensions used in the numerical model to simulate flow through distribution features. ..... 53 


\section{PROJECT ACCOMPLISHMENTS}

- A flowsheet design basis was completed for incorporating a MPT distillation unit within an ethylene plant, meeting the first project milestone. The economic potential was analyzed using a Monte Carlo simulation for target capital and operating costs for the MPT unit.

- Velocys MPT computation strategies were adapted to model mass, heat, and momentum transfer for twophase contacting in microchannels. The modeling strategy was validated in experiments with a cyclohexanehexane distillation system, and applied to the design of a microchannel device for ethane-ethylene separation.

- The first MPT experimental device for this project was designed and released for fabrication, meeting the second project milestone. The device was tested for cyclohexane-hexane separation, a close-boiling point separation analogous to ethane-ethylene separation. Experiments achieved a Height-to-an-Equivalent Theoretical Plate (HETP) of less than one inch, which is more than an order of magnitude less than typical conventional HETP of 18-24 inches.

- A fluid distribution scheme for scaling-up the single-channel MPT concept to a commercial module with many parallel channels was developed. This design was validated computationally to ensure that sufficiently uniform flow could be achieved within the tolerances of an as-manufactured commercial module, meeting the third project milestone.

- Testing equipment required for ethane-ethylene distillation was procured, installed, and commissioned for experiments with the first MPT device designed and fabricated for ethane-ethylene distillation.

- Ethane-ethylene separation was experimentally achieved using a microchannel device.

- The following patent applications have been filed in the US, as well as in the PCT office:

○ Distillation Process Using Microchannel Technology, filed 7/8/05 (11/177,941)

$\circ$ Multiphase Contacting Process Using Microchannels, filed 7/7/06 $(11 / 483,136)$

- For the further development of an integrated, single-feed distillation device:

- A detailed literature search was conducted to review governing physics in a falling film flow. The momentum and continuity equations were solved simultaneously to estimate the thickness and flow rate of liquid in a falling film flow.

- Two hydrocarbon mixtures were evaluated for the experimental demonstration of the device:

1. n-hexane and cyclohexane mixture

2. n-pentane and cyclopentane mixture - chosen as the working fluid for the demonstration because of operational advantages.

- The design concept of the integrated microchannel device was developed using a block assembly approach together with gaskets and bolts to provide flexibility for future design modifications and re-use. Each block in the assembly has a specific functionality, including feed distribution and heat transfer. The design was completed and two devices fabricated. The ethane-ethylene experimental test stand was modified to accommodate the integrated devices. The devices were successfully tested by distilling $\mathrm{n}$-pentane from a n-pentane-cyclopentane mixed feed. 
0 HETP's ranging from less than 0.5 inch to a few inches were measured for a variety of flow rates and reflux ratios. 


\section{TASK 1 - FLOWSHEET DESIGN}

The findings of a study by ABB Lummus Global Inc. are summarized in the following paragraphs. The entire nonproprietary version of the report is included in Appendix A. The projections drawn were based on MPT distillation achieving both energy and installed capital cost savings. Information uncovered in subsequent tasks revealed that it will likely be difficult for MPT distillation to reduce the capital cost of large distillation trains, such as those used for ethane-ethylene separations. So, the projections made below will be difficult, or impossible, to achieve. Furthermore, the development timeline for the technology will push the commercialization date past the projected 2011 market introduction.

For their analysis, ABB Lummus generated a process flow diagram for an ethylene plant fractionation section producing a high-purity ethylene suitable for polyethylene production. It was determined that the CPAT technology deployment algorithm was not entirely valid for the incremental processing step around the C2 splitter. Accordingly, a new model was developed based on the use of the CPAT logistics equation but modified for use in a Monte Carlo simulation. An initial cost estimating effort was completed to update the total installed capital cost of the base case C2 fractionation system that was presented in the original RFP response. The detailed conclusions of the study are listed below.

- $\quad$ Adoption of the MPT device as a heat and mass transfer contactor offers unique characteristics, allowing the ethylene fractionation section of a back-end acetylene hydrogenation flow scheme to be modified such that net energy savings will be in excess of $20 \%$. These characteristics, namely, low hoop stress across the microchannel walls and higher HETPs, allow economically attractive operation of the C2=/C2 separation at higher pressure, ca. 380 psia vs 236 psia. This in turn affords operation at a higher refrigerant temperature in the distillate condenser, which in turn requires less mechanical energy to drive the compressor circulating the refrigerant.

- $\quad$ At the $20 \%$ energy savings performance, MPT deployment in the USA ethylene industry is projected to save more than 20 Trillion (T) Btu/yr by 2020 and almost 50 T Btu/yr by 2030.

- $\quad$ By the year 2020, the MPT market is projected to correspond to some 32 units at ethylene capacity of 940 KMTA to meet a 49 KMTA ethylene market demand.

- $\quad$ The estimated total installed capital cost (ex royalties) for the MPT system based on the initial plants in entry year 2011 is projected to be about 13\% lower than that of a comparable conventional fractionation system. On an annualized operating cost basis, the MPT systems offer an estimated $\$ 4.5 \mathrm{MM} / \mathrm{yr}$ reduction in amortized capital costs plus natural gas costs (when natgas is priced at $\$ 6.00 / \mathrm{MM} \mathrm{Btu}$ ). As demand for MPT increases, fabrication costs per MPT assembly will decrease and by 2020 , it is projected that the total installed capital cost will be about $30 \%$ lower than that of conventional fractionation.

- MPT deployment was modeled using the same classical logistics equation in CPAT but with the Conversion Rate factor allowed to vary according to a probability distribution function that defines the most likely scenarios of deployment. The actual deployment values expressed in either total USA ethylene market demand; number of MPT units deployed; or total USA energy savings were computed using Monte Carlo simulation software.

- $\quad$ The results of the Monte Carlo simulations are tabulated below. 


\begin{tabular}{ccc} 
MPT US Deployment & \multicolumn{3}{c}{ World-Scale U } \\
year & $\mathbf{2 0 2 0}$ & $\mathbf{2 0 3 0}$ \\
95\% confidence & $>23$ & $>42$ \\
50\% confidence & $>30$ & $>55$ \\
25\% confidence & $>35$ & $>65$
\end{tabular}

$\begin{array}{ccc}\text { USA Energy Savings in T Btu/yr } \\ \text { year } & \mathbf{2 0 2 0} & \mathbf{2 0 3 0} \\ \text { 95\% confidence } & >15 & >27 \\ \text { 50\% confidence } & >21 & >39 \\ \text { 25\% confidence } & >26 & >47\end{array}$

- $\quad$ At the $20 \%$ MPT energy savings performance, there will be a corresponding reduction in USA emissions as tabulated below for year 2020 (with 50\% probability confidence):
- SOx reduction
$9.4 \mathrm{MT} / \mathrm{yr}$
- NOx reduction
$3.4 \mathrm{MT} / \mathrm{yr}$
- Carbon reduction
$0.36 \mathrm{~B} \mathrm{MT} / \mathrm{yr}$
- $\quad$ Particulates reduction
$0.16 \mathrm{MT} / \mathrm{yr}$

- $\quad$ The probability distribution in the number of MPT units that will be deployed beginning in 2011 is shown in the following Figure 1-1.

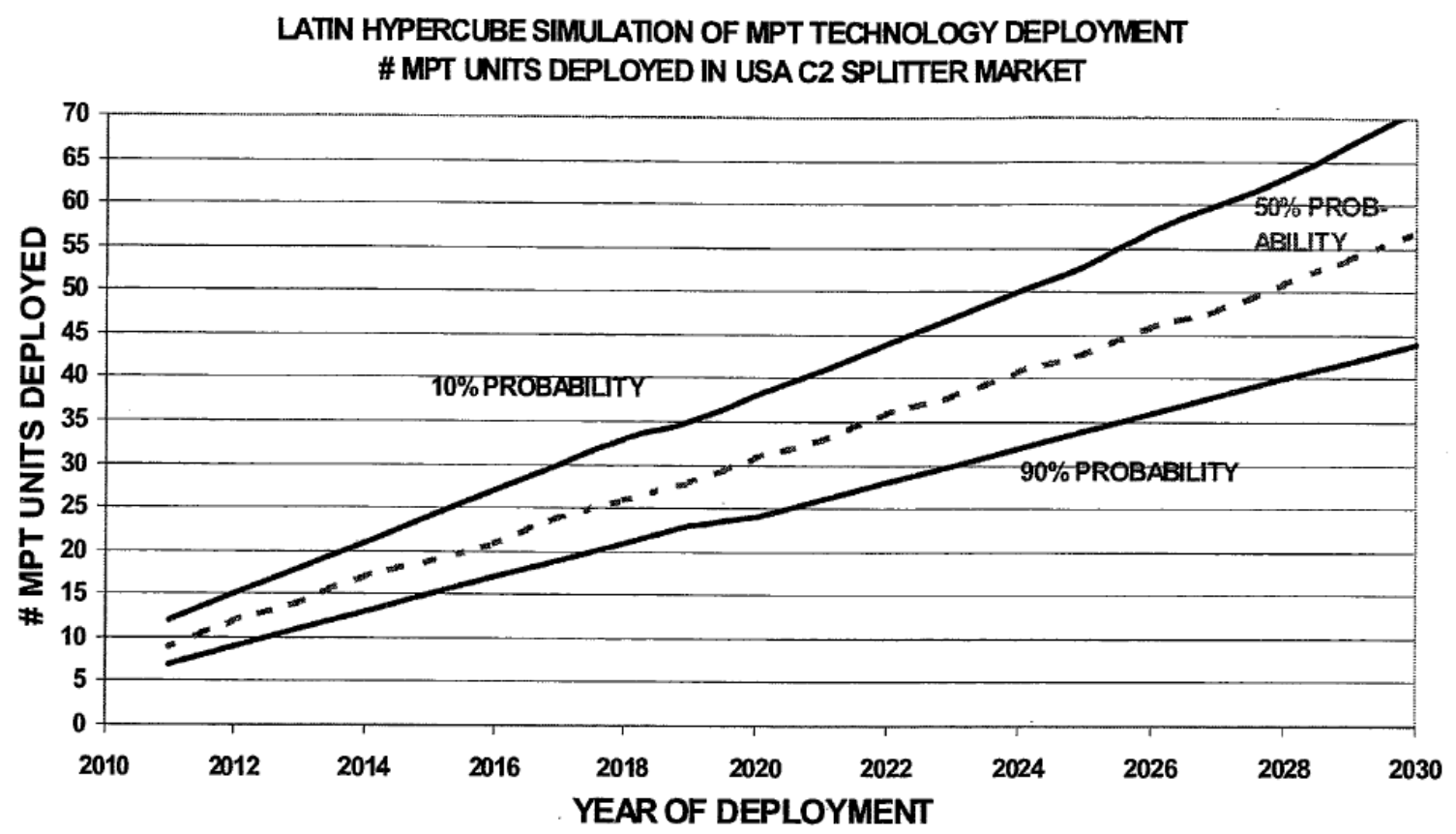

Figure 1-1. Probability distribution in the number of MPT units that will be deployed beginning in 2011.

- $\quad$ The probability distribution in the potential USA energy savings for the years 2020 and 2030 with a 2011 MPT market entry is shown in Figure 1-2. 


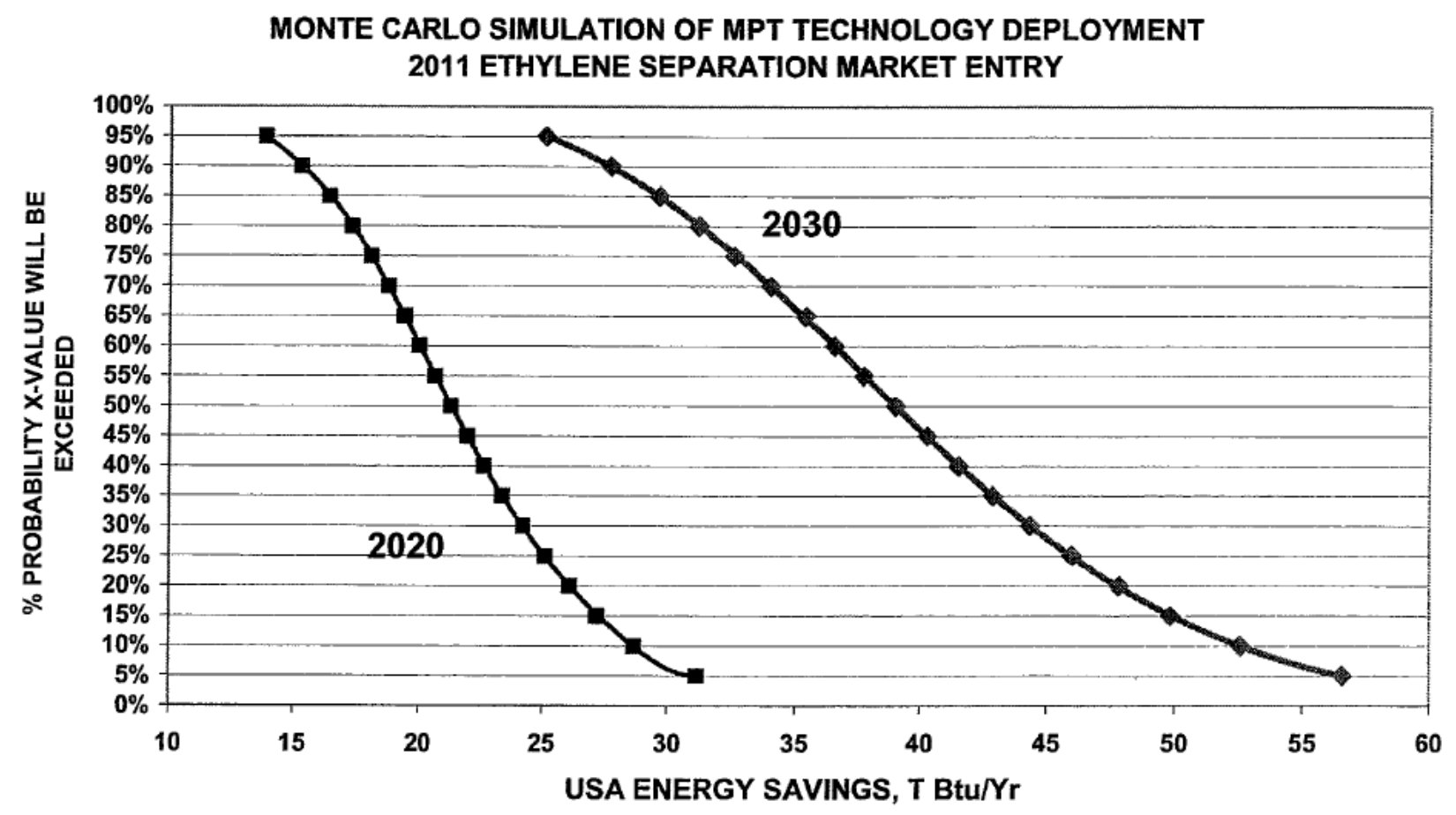

Figure 1-2. Potential USA energy savings for the years 2020 and 2030 with a 2011 MPT market entry. 


\section{TASK 2 - EVALUATION OF LIQUID REMOVAL STRUCTURES}

With the intent of maximizing process capacity and the effectiveness of gas-liquid separation in the distillation process, two mathematical models were developed to evaluate liquid removal structures and mass transfer performance.

Analysis of liquid removal structures highlighted the impact of surface geometry on liquid capacity. Shallow triangular micro-grooves were found to have greater liquid capacity than rectangular micro-grooves of the same width and height. At greater groove depths, relative capacity of rectangular and triangular micro-grooves of equal width and height was found to be more complex, with narrow rectangular microgrooves leading to significant capacity enhancement relative to their triangular counterparts. These findings can help design surface structures to maximize flow capacity in multiphase systems.

The mathematical simulation developed at this stage of the program was used in Task 3 to predict experimental observations in the first microchannel distillation experiments. This simulation helped clarify the fundamental phenomena that drive distillation. Details of these analyses follow.

\section{What is a liquid removal structure?}

A liquid removal structure promotes gas-liquid separation and allows facile mass transfer between multi-phase flow streams. Capillary force is the dominating force that preferentially retains the liquid in the structure from a gas-liquid flow stream. Some examples of these structures are:

1. Expanded metal foils

2. Wire mesh screen (shown in Figure 2-1)

3. Cotton cloth

4. Sintered metals

5. Metal foams

6. Polymer fibers

7. Grooved surfaces

- $\quad$ Triangular grooves (i.e. Fresnel lens)

- Rectangular grooves

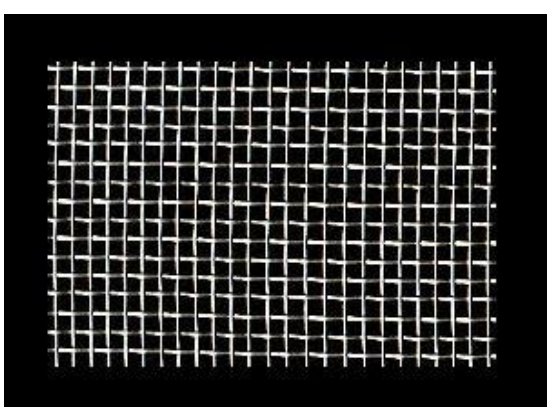

Figure 2-1. Woven wire mesh.

- $\quad$ Circular grooves

8. Any wetting, porous material

The desired characteristic dimension of a liquid removal structure is between $5 \mu \mathrm{m}$ and $200 \mu \mathrm{m}$.

\section{Evaluation method for liquid removal structure}

A mathematical modeling approach has been used to compare liquid removal structure geometries. The main transport physics involved in distillation process are momentum transfer, heat transfer and mass transfer. All the transport phenomena occur within and between the liquid and the vapor phases.

The criterion chosen for liquid removal structure evaluation was comparing the liquid flow capacity of different liquid removal structure geometries. A force balance model was developed to estimate the maximum flow rate through a liquid removal structure. Two geometries were compared with respect to maximum liquid flow capacity. The two geometries, as shown in Figure 2-2, were: rectangular micro-grooves and triangular microgrooves. 

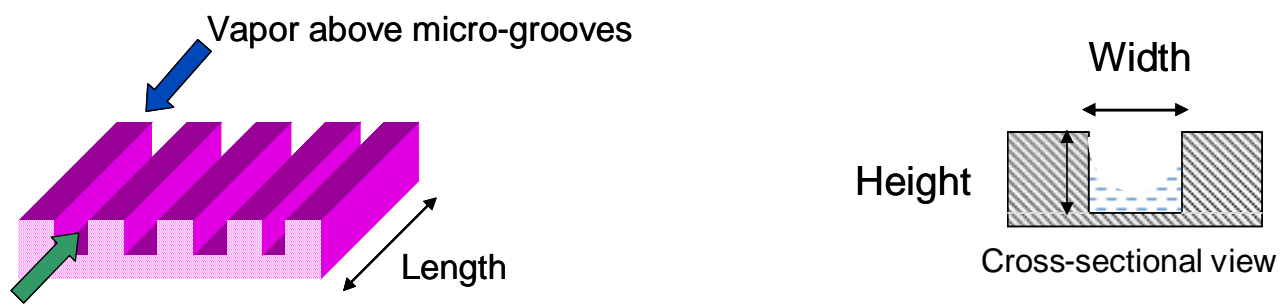

Liquid in micro-grooves

$(25 \mu \mathrm{m}-250 \mu \mathrm{m})$

\section{$\underline{\text { Rectangular micro-grooves }}$}

Liquid in micro-grooves

$(25 \mu \mathrm{m}-250 \mu \mathrm{m})$

$\underline{\text { Triangular micro-grooves }}$

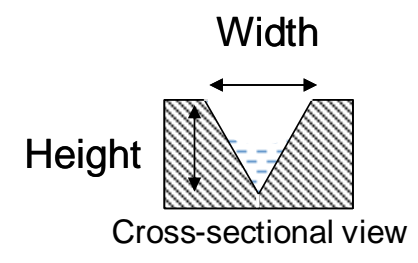

Figure 2-2. Liquid removal structure geometry for flow capacity comparison

The maximum flow rate through rectangular and triangular micro-grooves was estimated for a range of dimensions (width and height). Figures 2-3 and 2-4 show the effect of dimensions on maximum liquid flow capacity through the micro-grooves. The length of the micro-grooves was 5 inches for both geometries. The liquid flowing through the micro-grooves was assumed to be $\mathrm{n}$-hexane at $70^{\circ} \mathrm{C}$ and 10 psig pressure. Hexanecyclohexane (C6) mixture was selected as a surrogate chemical system for distillation trials. This mixture reflected the low relative volatility profiles of the ethane-ethylene (C2) system of primary interest while allowing testing at milder conditions.

For smaller groove-widths, rectangular grooves have larger liquid flow capacity than triangular grooves, as shown in Figures 2-3 and 2-4. For larger groove-width, triangular geometry has larger liquid flow capacity than rectangular geometry. 


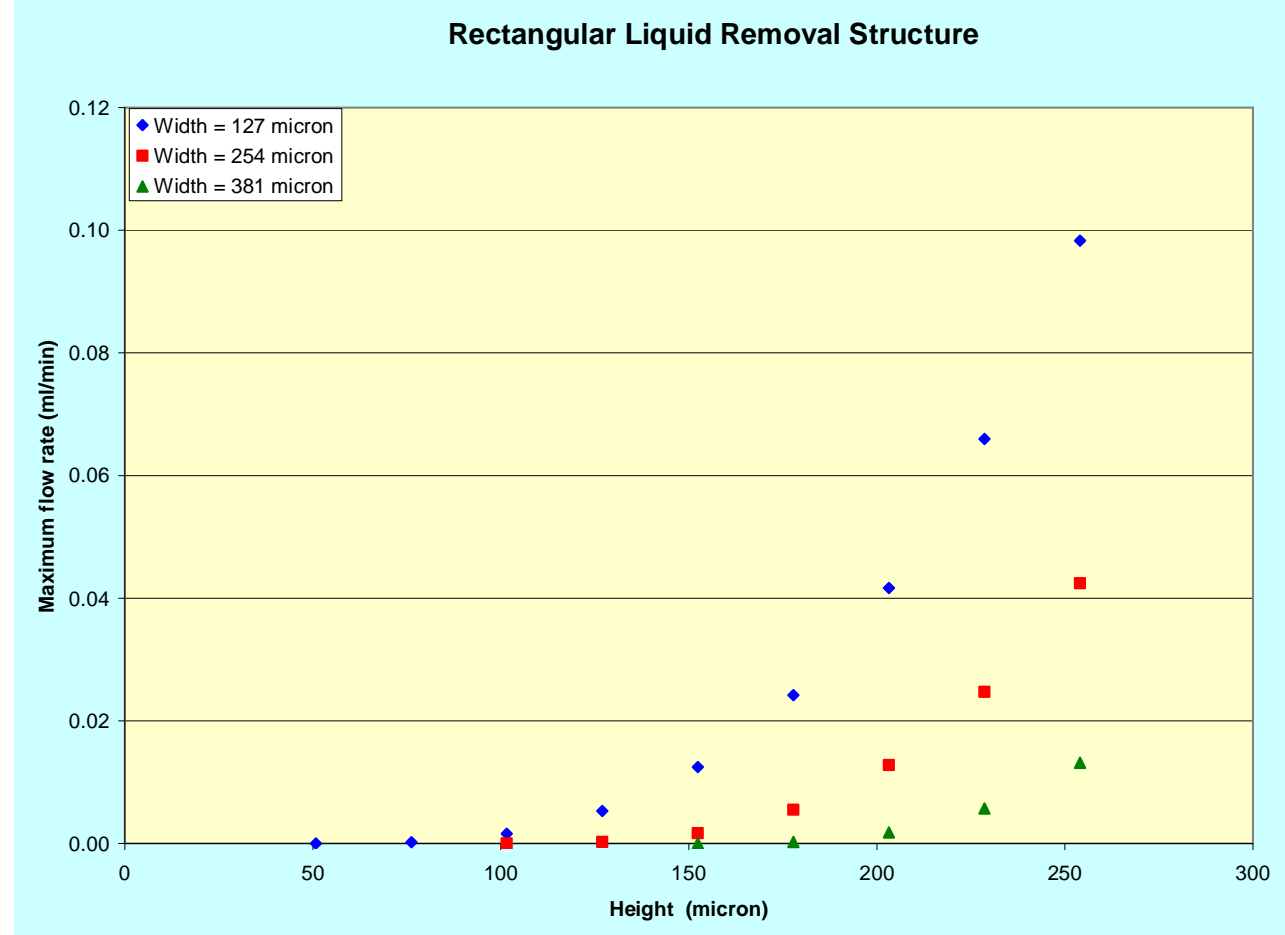

Figure 2-3. Flow capacity of rectangular micro-grooves

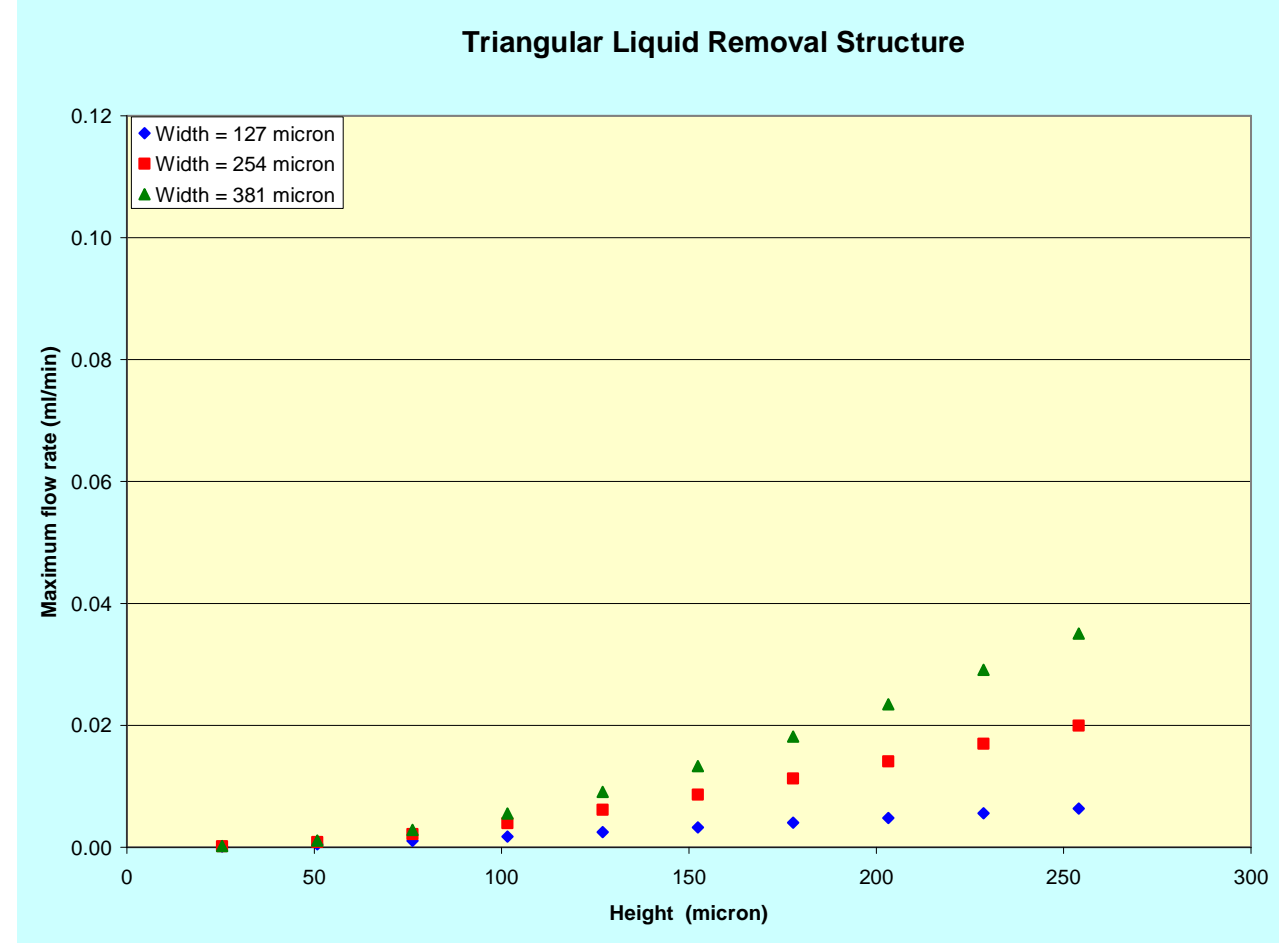

Figure 2-4. Flow capacity of triangular micro-grooves 


\section{Mathematical model for predicting distillation performance}

A simple mathematical modeling scheme was developed to simulate momentum, mass and heat transfer between liquid and vapor flow in micro-channels. The modeling involved discretizing the flow channel into small control volumes and solving momentum, mass and heat balance equations simultaneously. Figure 2-5 shows heat, mass and momentum balance for a control volume.

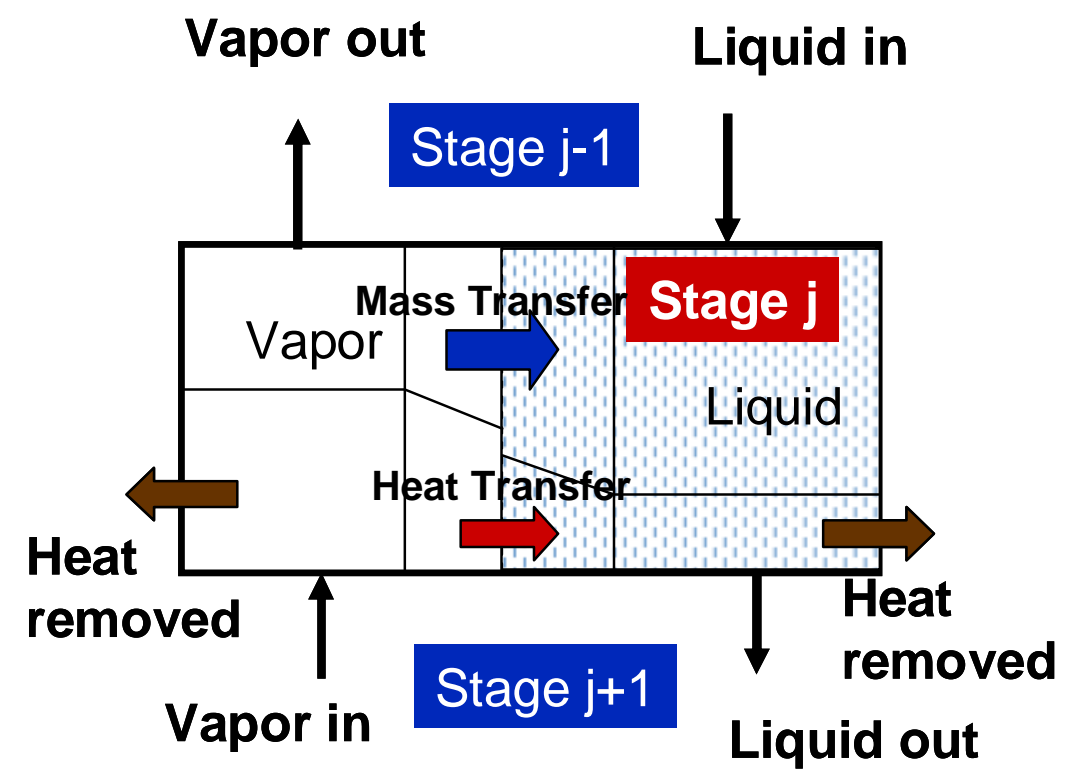

Figure 2-5. Control volume in repeating unit model

The main features in the model were:

- Species mass transfer between liquid and vapor phases

- Energy transfer between liquid and vapor phases

- Heat addition/removal to/from liquid or vapor phase

- Pressure drop

- Estimation of number of theoretical equilibrium stages

In Task 3, the model results were compared to the experimental performance of the $n$-hexane/cyclohexane system. These are summarized in Table 3-2 and 3-3. 


\section{TASK 3 - SELECTION OF MICROCHANNEL GEOMETRY AND PROCESS CONDITIONS}

A first set of distillation experiments and model validations were performed to highlight the enhanced performance achievable with microchannel distillation. Significantly smaller than typical HETP's (Height-to-anEquivalent Theoretical Plate) were observed experimentally, and numerical model predictions were validated through experimental observations.

Appropriate microchannel geometries were devised to allow simple visualization and distillation experiments and help map favorable flow regimes that do not result in flooding, liquid entrainment by vapor stream, or vapor breakthrough into the liquid outlet stream. Distillation experiments indicated that HETP's smaller than 1 inch were achievable. The simple mathematical model developed in Task 2 showed good agreement with experimental observations. A three-dimensional computational fluid dynamics simulation approach, based in Fluent, was developed following the experimental trials. This served as a refinement of the simple model, intended to capture the controlling system dynamics and serve as a guide towards future distillation system designs. Three-dimensional simulation results were very similar to experimental measures. Hence, the simulation was validated by direct comparison with experiments. The specifics of the tasks are detailed below.

\subsection{Selection of a Chemical System for Scoping Experiments}

As explained in Task 2, hexane-cyclohexane (C6) was selected as a surrogate chemical system for distillation trials. This mixture reflected the low relative volatility profiles of the ethane-ethylene (C2) system of primary interest while allowing testing at milder conditions and validation of models for future design. The similarity of the vapor liquid equilibrium curves for these two mixtures is evident in Figure 3-1, which also identifies the pressure and temperature ranges for operation.
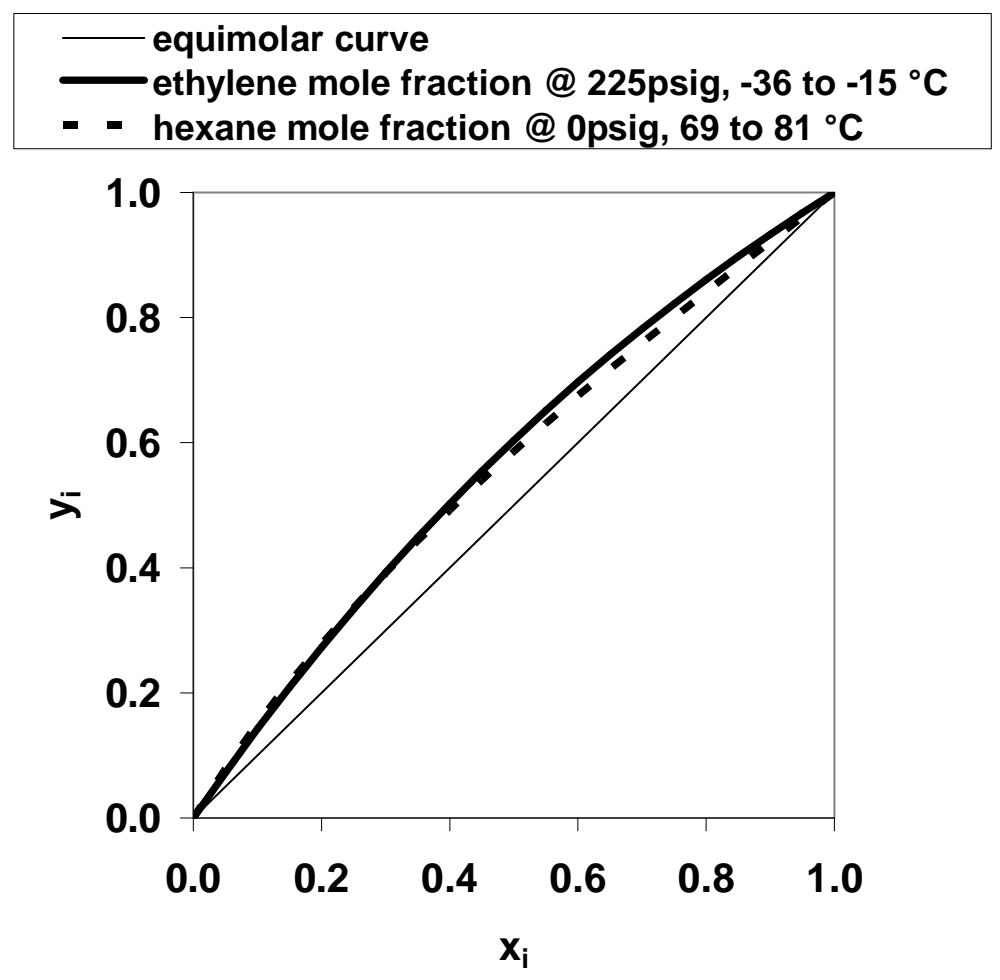

Figure 3-1. Superposition of the vapor liquid equilibrium curves for the ethane-ethylene $\left(C_{2}\right)$ and hexanecyclohexane $\left(\mathrm{C}_{6}\right)$ systems. The curves coincide very closely. 


\subsection{Equipment and Functional Feature Designs}

An experimental device was specifically designed for these distillation trials to allow verification of distillation potential in a microchannel system. The stainless steel distillation unit involved counter-currently flowing vapor and liquid phase mixtures of hexane and cyclohexane. Liquid flowed vertically downward along a 0.007 inch deep stainless steel mesh. Vapor was fed to the device from a lower port, opposite the liquid outlet port. Liquid inlet and vapor outlet ports and vapor inlet and liquid outlet ports were slightly offset relative to each other, with the liquid ports lower than the vapor counterparts. Figure 3-2 shows representative internal schematics of the experimental device, viewed from the top and side. The step in the cross section of the vapor channel, visible in the top view of the device, was a result of fabrication requirements. Two versions of the device were fabricated, the second configuration incorporated an external heat exchange channel, mounted on the back of the vapor plate. Figure 3-3 shows pictures of the assembled and open devices.

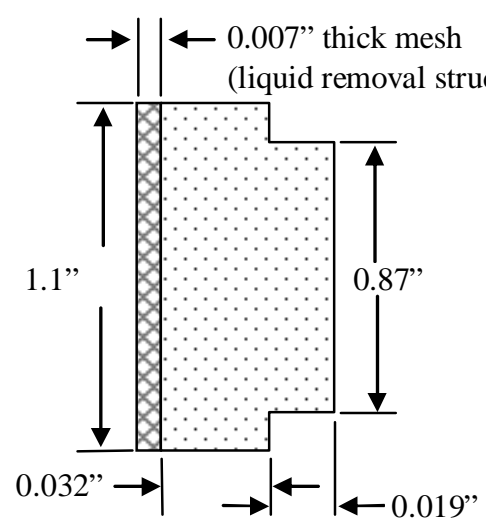

top view

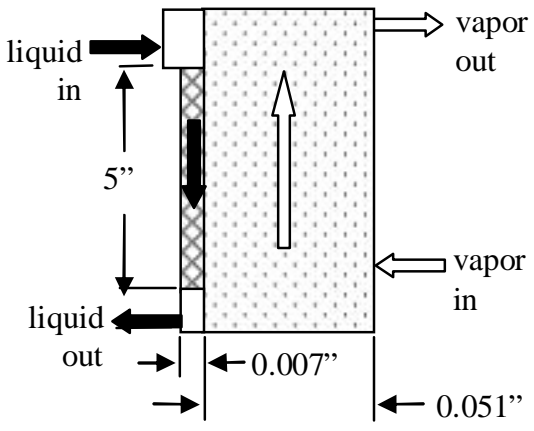

side view

Figure 3-2. Internal schematic of the microchannel distillation device used for hexane-cyclohexane separation.

Dimensions are not to scale.

heat exchange channel

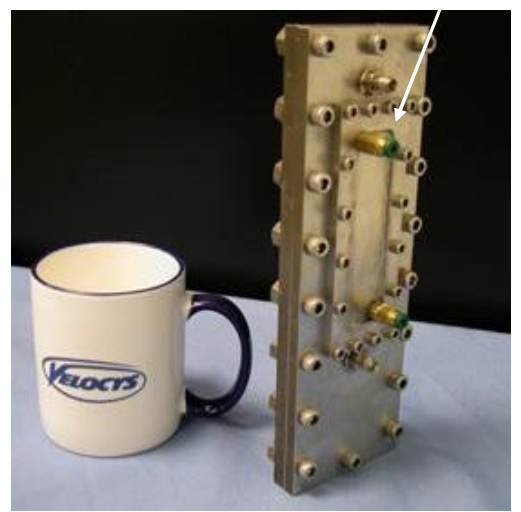

Assembled Device (with heat exchange)

liquid removal structure vapor channel

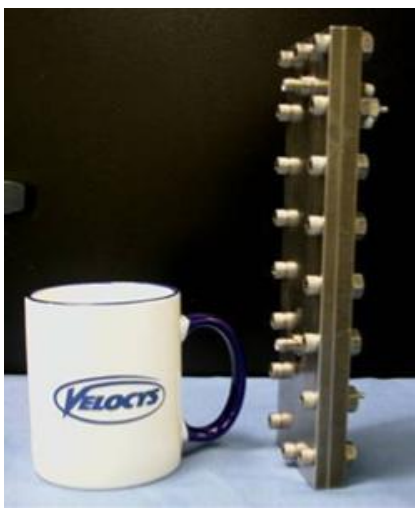

Assembled Device (without heat exchange)

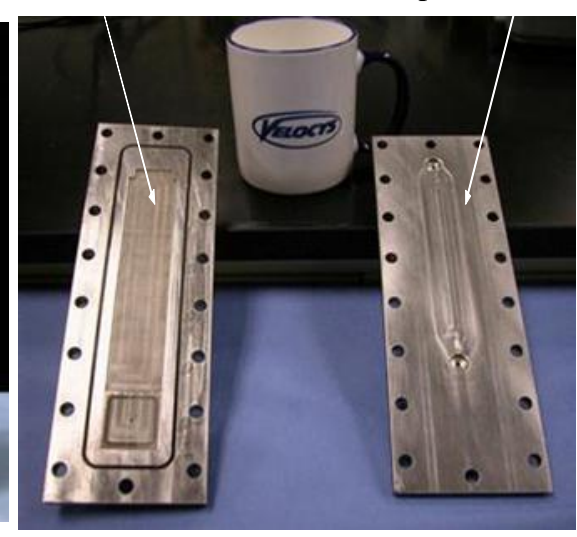

Internal Device View

Figure 3-3. Microchannel distillation devices used for hexane-cyclohexane separation. Pictures of the two device configurations are shown in the left and center views. The right most picture shows an internal view. 


\subsection{Experimental Set-up}

Testing infrastructure was prepared at Velocys' facility to conduct experiments for fluid separation demonstration in micro-channels and model validation. Pumps, flowmeters, temperature, pressure and heat sensors, and other equipment were specifically procured and assembled for the experiments. A computerized data collection system using Lab-view was set-up for experimental data recording.

A schematic of the process and instrumentation diagram (P\&ID) for the test configuration is shown below. As shown in the simplified P\&ID of Figure 3-4 syringe pumps were used to feed premixed liquid streams of the required concentrations of hexane and cyclohexane. Each mixed stream was heated to the operating temperature by a microchannel heater and fed to the test device.. The system was operated near ambient pressure. The device was heated and held at temperature with a dual, stacked ceramic heater assembly. A flowmeter measured the flow rate of the liquid stream exiting the device; the flow rate of the vapor stream was calculated to close the mass balance. The exiting vapor stream was condensed via an in-line tube-in-tube heat exchanger (not shown in the schematic), using water as the heat exchange fluid; the concentrations of the exiting fluids collected in beakers over the course of steady state operation were measured by gas chromatography. Initial testing was done without use of the integrated heat exchange channel. When testing the device configuration with the heat exchanger, a separate circuit was supplied with nitrogen to exchange heat with the distillation channel in the device. Testing was done with nitrogen flowing both cocurrently and countercurrently to the vapor flow to control fluid temperature in the distillation channel .

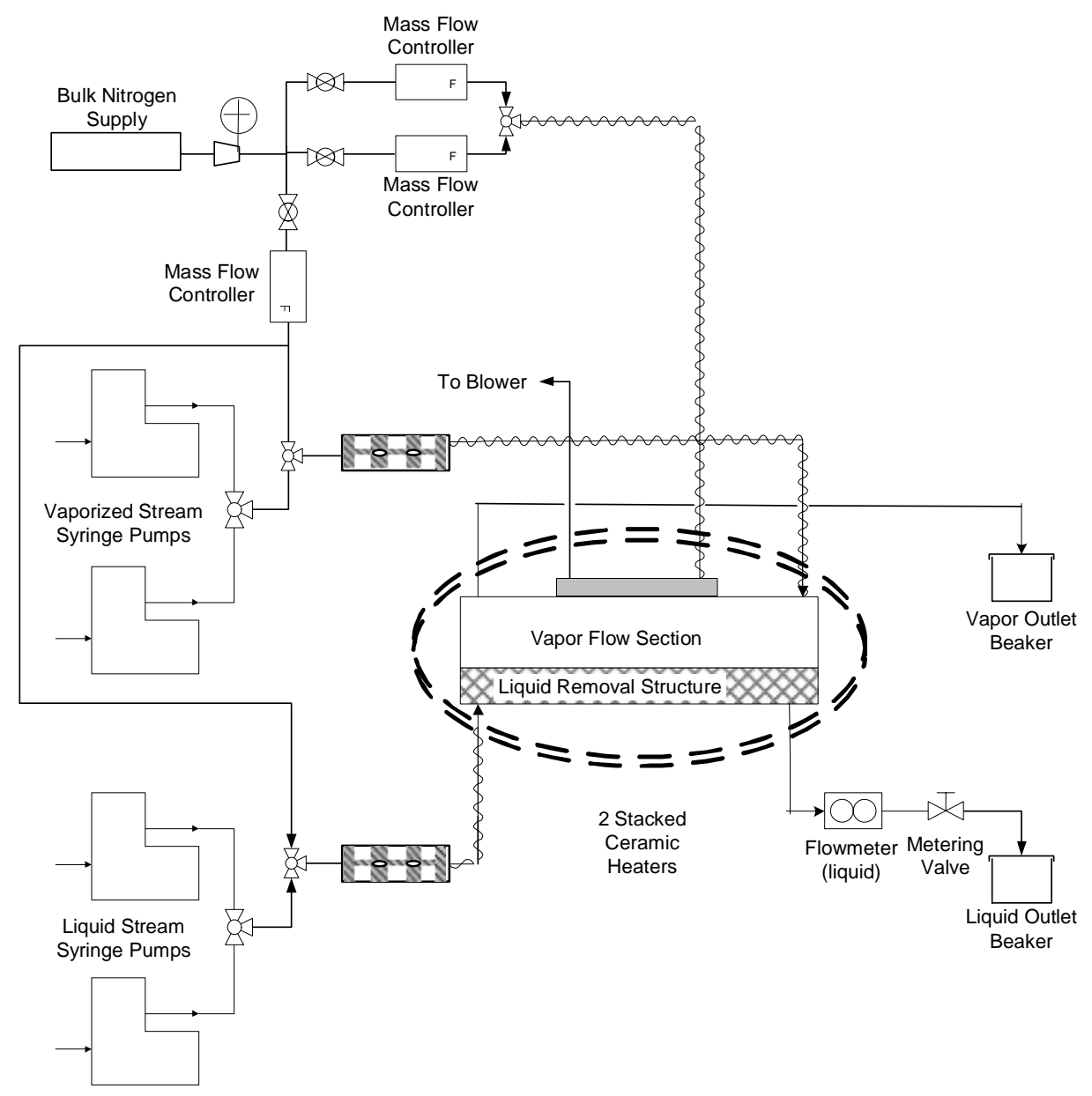

Page 12 of 63 
Figure 3-4. Simplified process and instrumentation diagram for the hexane-cyclohexane test stand. The circuit connected to the bulk nitrogen supply was only included in testing for the device configuration with heat exchange.

\subsection{Distillation Experiments}

Experiments were run with the hexane-cyclohexane system schematically shown in Figures 3-4 and 3-5 to evaluate the distillation performance in microchannels. A detailed flow visualization test study was conducted prior to the distillation testing to determine the operational flow rates for the device. A ChemCAD distillation model was used to calculate the number of theoretical plates corresponding to the achieved separation, with the liquid and vapor feeds input at the upper and lower plates, respectively. Hence, these experiments effectively matched internal column traffic, rather than a complete distillation column, as shown in Figure 3-5. The corresponding HETP for each run was calculated using the effective distillation length schematically shown in Figure 3-5.
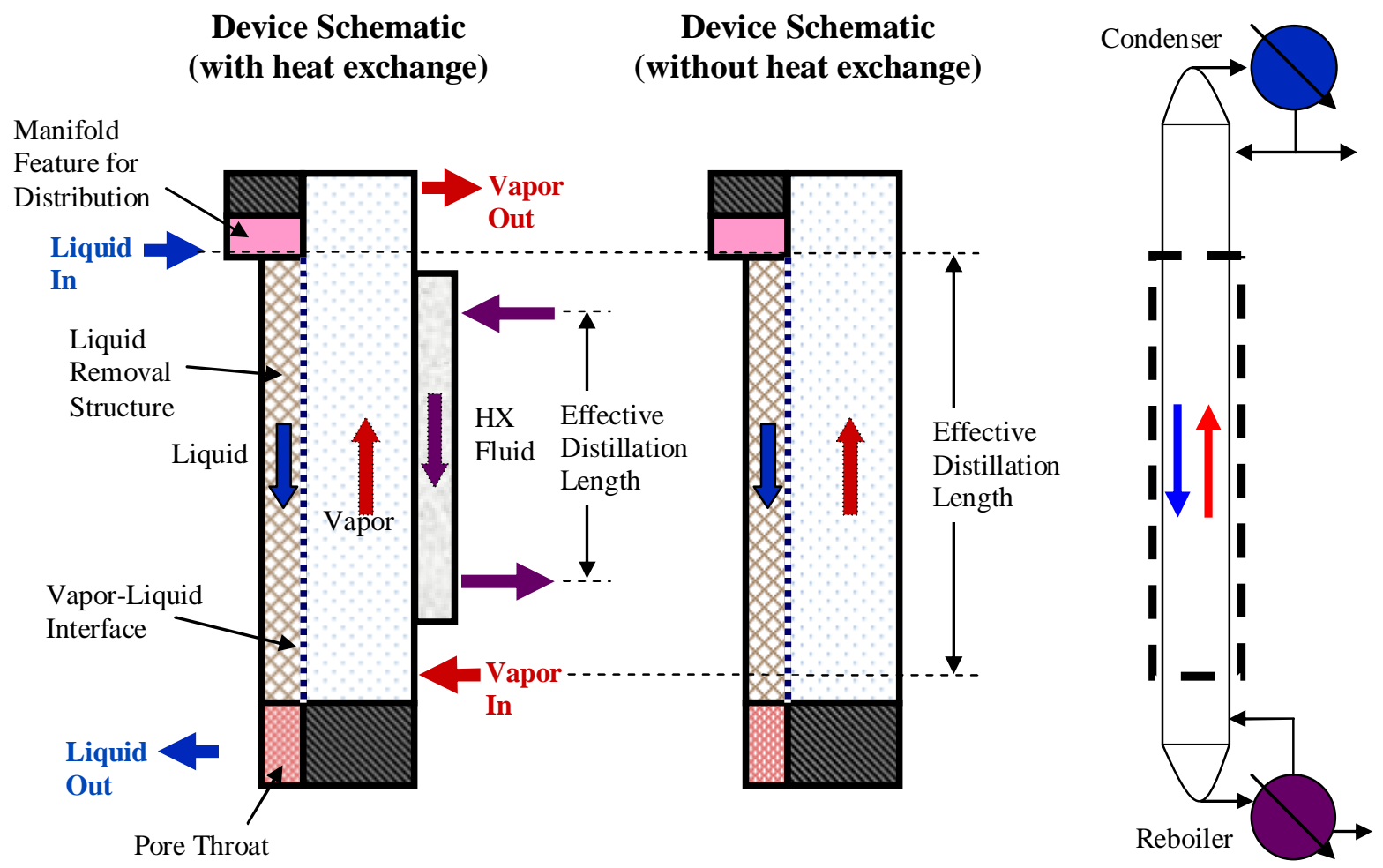

Figure 3-5. Schematics of the experimental microchannel distillation devices and corresponding distillation column separation section. Relative dimensions are not to scale.

\subsubsection{Experimental Results}

As evidenced in the small HETP estimates tabulated in Table 3-1 for two run conditions, microchannel distillation can lead to significant enhancement in mass transfer and distillation performance. The table also lists experimental outlet conditions and comparisons with the predictive simple heat and mass transfer model developed in Task 2. During the experiments difficulties were faced in the measurement of outlet liquid and vapor flow rates. Therefore, the outlet flow rates were calculated from the experimental inlet flow rate and inlet and outlet compositions. Results matched reasonably well with model predictions. 


\begin{tabular}{|r|c|c|}
\hline \multicolumn{1}{|c|}{ Experimental Run } & Run 1 & Model Predictions \\
\hline Temperature, ${ }^{\circ} \mathrm{C}$ & & $77^{\circ} \mathrm{C}$ \\
\hline Liquid Out & $76^{\circ} \mathrm{C}$ & $73^{\circ} \mathrm{C}$ \\
\hline Vapor Out & $69^{\circ} \mathrm{C}$ & $6 \%$ \\
\hline Liquid Out & $7 \%$ & $76 \%$ \\
\hline Vapor Out & $80 \%$ & $0.439 \mathrm{ml} / \mathrm{min}$ \\
\hline Flow Rate (L ml/min) & & $0.571 \mathrm{ml} / \mathrm{min}$ \\
\hline Liquid Out & $0.468 \mathrm{ml} / \mathrm{min}^{\star}$ & 15 \\
\hline Vapor Out & $0.542 \mathrm{ml} / \mathrm{min}^{\star}$ & \multicolumn{2}{|c|}{0.33 inches } \\
\hline \# Equilibrium Stages & & \\
\hline HETP, inches & & \\
\hline
\end{tabular}

* Calculated flow rate.

Table 3-1. Experimental outlet conditions for hexane-cyclohexane separation and comparison with model predictions.

\begin{tabular}{|c|c|c|}
\hline Experimental Run & Run 2 & Model Predictions \\
\hline \multicolumn{3}{|l|}{ Temperature, ${ }^{\circ} \mathbf{C}$} \\
\hline Liquid Out & $75^{\circ} \mathrm{C}$ & $76^{\circ} \mathrm{C}$ \\
\hline Vapor Out & $68^{\circ} \mathrm{C}$ & $74^{\circ} \mathrm{C}$ \\
\hline \multicolumn{3}{|l|}{ Mole \% hexane } \\
\hline Liquid Out & $9 \%$ & $13 \%$ \\
\hline Vapor Out & $73 \%$ & $71 \%$ \\
\hline \multicolumn{3}{|l|}{ Flow Rate (L ml/min) } \\
\hline Liquid Out & $0.854 \mathrm{ml} / \mathrm{min}^{*}$ & $0.889 \mathrm{ml} / \mathrm{min}$ \\
\hline Vapor Out & $1.160 \mathrm{ml} / \mathrm{min}^{*}$ & $1.128 \mathrm{ml} / \mathrm{min}$ \\
\hline \# Equilibrium Stages & \multicolumn{2}{|c|}{10} \\
\hline
\end{tabular}

Table 3-2. Experimental outlet conditions for hexane-cyclohexane separation and comparison with model predictions.

The results in Table 3-3 clearly show that a small HETP can be easily achieved in a microchannel distillation unit. The heat and mass transfer model developed in Task 2 provides a reasonable prediction for the distillation performance.

The achievement of small HETP with a heat exchange fluid demonstrated the ability to integrate heat exchanger with the distillation microchannels. The integration of distillation and process channel could provide controlled temperature profiles which could help to reduce the process energy requirements. 


\begin{tabular}{|c|c|c|c|c|}
\hline & \multicolumn{2}{|r|}{ Run 1} & \multicolumn{2}{|c|}{ Run 2} \\
\hline & Experiment & Model Prediction & Experiment & Model Prediction \\
\hline \multicolumn{5}{|l|}{ Flow rate (liquid ccm at ambient) } \\
\hline Liquid feed & 0.5 & 0.5 & 1.0 & 1.0 \\
\hline Vaporfeed & 0.5 & 0.5 & 1.0 & 1.0 \\
\hline Liquid product & $0.486 *$ & 0.439 & $0.854 *$ & 0.889 \\
\hline Vapor product & $0.542 *$ & 0.571 & $1.160 *$ & 1.128 \\
\hline \multicolumn{5}{|l|}{ Temperature $\left({ }^{\circ} \mathrm{C}\right)$} \\
\hline Liquid inlet & 69 & 69 & 68 & 68 \\
\hline Vapor outlet & 69 & 73 & 68 & 74 \\
\hline Liquid outlet & 76 & 77 & 75 & 76 \\
\hline Vapor inlet & 83 & 83 & 84 & 84 \\
\hline \multicolumn{5}{|l|}{ Hexane concentration (mol\%) } \\
\hline Liquid inlet & 84 & 84 & 84 & 84 \\
\hline Vapor outlet & 80 & 76 & 73 & 71 \\
\hline Liquid outlet & 7 & 6 & 9 & 13 \\
\hline Vapor Inlet & 8 & 8 & 8 & 8 \\
\hline Number of Equilibrium Stages & 10 & & 6 & \\
\hline HETP (in) & 0.50 & & 0.83 & \\
\hline
\end{tabular}

Calculated flow rate.

Table 3-3. Key measurables and performance estimates for operation of the hexane-cyclohexane separation devices. Reported runs did not include heat exchange. Tabulated predictions were made with the simple mathematical model from Task 2.

\subsection{Comparative CFD Simulation}

To help quantify the achievable microchannel performance and to help project and design future devices, another simulation methodology for the distillation phenomenon was developed using the FluentTM Computational Fluid Dynamics (CFD) package. The collected data were compared with the simulated results to validate the program. It should be noted that the simulation method allows relatively fast and direct estimation of distillation performance in a microchannel device. This method is not intended to be comprehensive. Its scope is to capture and model the primary phenomena that impact the distillation process with sufficient confidence for scoping analyses and future process refinement.

\subsubsection{Simulation Methodology}

The present simulation involved solution of species mass and momentum balances, but did not consider an energy balance or surface tension effects. Flow instability and heat transfer were not considered. The simulation was conducted under the following assumptions:

- a stationary interface, with no shear,

- interfacial concentrations based on ChemCAD provided distribution coefficients for each species (linearly interpolated between the column extremes),

- uni-directional equimolar counter-diffusion at the interface (Bird et al.),

- equal molecular weight for the two species (an average of the actual molecular weights, given their similarity),

- constant fluid properties within each phase. 
Height Equivalent to a Theoretical Plate (HETP) estimates for each phase were calculated using the number of transfer units for that phase, (determined by integration of cross-sectional area averaged concentration differences along the channel), and the length of the mass transfer channel, , such that

$$
\operatorname{HETP}_{x} \sim \frac{Z_{t o t}}{n_{x}}
$$

Overall HETP's were estimated by combining the HETP for each phase; i.e.,

$$
H E T P_{\text {total }}=H E T P_{\text {vapor }}+\frac{m G}{L} H E T P_{\text {liquid }}
$$

where $\mathrm{m}$ is the slope of the equilibrium line (with the liquid mole fraction in the abscissa, the vapor mole fraction in the ordinate), and $\mathrm{G} / \mathrm{L}$ is the ratio of the molar gas and liquid flow rates through the column (McCabe et al.; Taylor et al.). Results were analyzed in terms of change in concentration profile along the channel axial length.

\subsubsection{Simulated Configuration and Parameters}

Two potential channel configurations were simulated to evaluate the sensitivity to different flow geometries.

1. The "mesh flow" configuration assumed the liquid flowed along the width of the channel wall as a continuous, uniform film with a depth equivalent to the 0.007 inches supporting mesh thickness and the uniform feed velocity that would result with the imposed volumetric feed rate.

2. The "falling film" configuration assumed the liquid flowed as a freely falling film along the width of the vertical wall, with the thickness and velocity dictated by the imposed volumetric feed rate. Calculations were based on the analysis of Bird et al., according to which the liquid Reynolds number corresponded to fully laminar flow, with no ripples. The shearing effect of the flowing vapor phase was assumed to be insignificant.

For each configuration, the gap of the channel not filled with liquid was assumed to be filled with the countercurrently flowing vapor. Vapor and liquid flow regions were assumed to be rectangular in shape.

Physical properties were obtained from a ChemCAD distillation simulation of hexane-cyclohexane at the same temperature/pressure operating range as the experimental trials. Interfacial compositions were calculated from linear interpolation of the distribution coefficients (the ratio of vapor to liquid mole fractions of the species) between the column extremes Material properties were assumed constant (averaged from the corresponding phase in the ChemCAD simulation); they are listed in Table 3-4. The feed compositions and representative flow rates for the simulations matched experimental values.

\begin{tabular}{lcc}
\hline \multicolumn{1}{c}{ Material Property } & Liquid & Vapor \\
\hline density $\left(\mathrm{kg} / \mathrm{m}^{3}\right)$ & 660 & 3.2 \\
viscosity $(\mathrm{kg} / \mathrm{m} . \mathrm{s})$ & $3.0 \mathrm{E}-04$ & $8.0 \mathrm{E}-06$ \\
diffusivity $\left(\mathrm{m}^{2} / \mathrm{s}\right)$ & $5.0 \mathrm{E}-09$ & $4.5 \mathrm{E}-06$ \\
Schmidt Number (Section 4.4.3) & 91 & 0.56 \\
\hline & Hexane & Cyclohexane \\
\hline
\end{tabular}

Page 16 of 63 


\begin{tabular}{lcc}
\hline molecular weight $(\mathrm{g} / \mathrm{mol})$ & 85 (86 actual) & 85 (84 actual) \\
distribution coefficients at the column top & 0.79607 & 1.06210 \\
distribution coefficients at the column bottom & 0.94510 & 1.50565 \\
\hline
\end{tabular}

Table 3-4. Material properties and interfacial parameters used in the simulation involving hexane-cyclohexane separation. Gas and liquid diffusivities were estimated adopting standard methodologies (Poling et al.).

The channel was assumed to be long and rectangular, and although the simulations were 3-dimensional, they were effectively run as 2-dimensional problems by defining the sidewalls as symmetric boundary conditions. The key parameters for the cases considered (named to correspond with the experimental runs) are listed in Table 3-5.

\begin{tabular}{lcccccc}
\hline $\begin{array}{c}\text { Case } \\
\text { ID }\end{array}$ & $\begin{array}{c}\text { Assumed } \\
\text { Flow } \\
\text { Type }\end{array}$ & $\begin{array}{c}\text { Liquid Film } \\
\text { Thickness } \\
\text { (in) }\end{array}$ & $\begin{array}{c}\text { Vapor } \\
\text { Thickness } \\
\text { (in) }\end{array}$ & $\begin{array}{c}\text { Full Channel } \\
\text { Flow Rate } \\
\text { (liquid ml/min) }\end{array}$ & $\begin{array}{c}\text { Liquid } \\
\text { Velocity } \\
\text { (m/s) }\end{array}$ & $\begin{array}{c}\text { Vapor } \\
\text { Velocity } \\
\text { (m/s) }\end{array}$ \\
\hline 1b & mesh flow ** & 0.007 & 0.051 & 0.5 & 0.0017 & 0.051 \\
2a & falling film * & 0.0017 & 0.0563 & 1.0 & 0.0136 & 0.091 \\
2b & mesh flow ** & 0.007 & 0.051 & 1.0 & 0.0033 & 0.102 \\
\hline$*$ & Liquid thickness calculated from given liquid flow rate and physical properties, \\
& by assuming falling film flow over a flat wall (Bird et al.). & & \\
$* *$ & Liquid thickness assumed to match mesh thickness.
\end{tabular}

Table 3-5. Key run parameters for the simulated cases. Vapor thickness was calculated by subtracting the assumed liquid film thickness from the overall internal device gap size, 0.058 inches. 


\begin{tabular}{|c|c|c|c|c|}
\hline \multirow{2}{*}{$\begin{array}{c}\text { Case } \\
\text { ID }\end{array}$} & \multicolumn{2}{|c|}{$\begin{array}{l}\text { Peclet } \\
\text { Number }\end{array}$} & \multicolumn{2}{|c|}{$\begin{array}{l}\text { Convective/Viscous Effects } \\
\text { (Peclet/Schmidt) }\end{array}$} \\
\hline & liquid & vapor & liquid & vapor \\
\hline $1 a$ & 61 & 14 & 0.7 & 26 \\
\hline $1 b$ & 60 & 15 & 0.7 & 26 \\
\hline $2 a$ & 117 & 29 & 1.3 & 52 \\
\hline $2 b$ & 117 & 29 & 1.3 & 53 \\
\hline
\end{tabular}

Table 3-6. Characteristic dimensionless numbers for the cases considered. Peclet Numbers were calculated as detailed in Section 4.4.3.

\subsubsection{Simulated Results and Discussion}

HETP's for the experimental and simulated cases are summarized in Table 3-7 and taken as key indicators of performance. As confirmed by the close correspondence of experimental and simulated values, the current simulation methodology is an acceptable tool for predicting microchannel distillation performance.

Comparison of the simulated cases shows there is little impact of assumed liquid film gap on HETP, but the mesh flow assumption leads to:

- slightly better performance,

- closer adhesion to experimental results.

This suggests that mesh flow was a more valid representation of the physics of the system. Closer scrutiny of the concentration profiles for representative cases can shed light on these observations.

\begin{tabular}{cclllll}
\hline $\begin{array}{c}\text { Flow } \\
\text { Rate } \\
\text { (liquid } \mathrm{ml} / \mathrm{min} \text { ) }\end{array}$ & $\begin{array}{c}\text { Case } \\
\text { ID }\end{array}$ & \multicolumn{1}{c}{ Description } & \multicolumn{3}{c}{$\begin{array}{c}\text { HETP (in) } \\
\text { Liquid Vapor Overall }\end{array}$} \\
\hline \multirow{2}{*}{0.5} & 1 & experiment & - & -- & 0.50 \\
& 1a & simulation - falling film & 0.64 & 0.19 & 0.83 \\
& 1b & simulation - mesh flow & 0.49 & 0.18 & 0.66 \\
& & & & & \\
1.0 & 2 & experiment & -- & -- & 0.83 \\
& 2a & simulation - falling film & 0.68 & 0.38 & 1.05 \\
& 2b & simulation - mesh flow & 0.60 & 0.35 & 0.95 \\
\hline
\end{tabular}

Table 3-7. Run results for the experimental and simulated hexane-cyclohexane separation cases. (Experimental values were estimated using ChemCAD.)

Figure 3-6 shows three plots representing hexane concentration profiles for the low flow, falling film configuration:

a. at the interface,

b. in the cells adjacent to the interface,

c. as the difference between these values, representing the driving force for mass transfer along the channel length. 
Figure 3-6c shows that for this case, as for all cases considered, the vapor layer near the interface equilibrates very quickly to the interfacial composition. Given the ease of this equilibration, the ability of the vapor species to diffuse through the vapor layer becomes the limiting phenomenon.
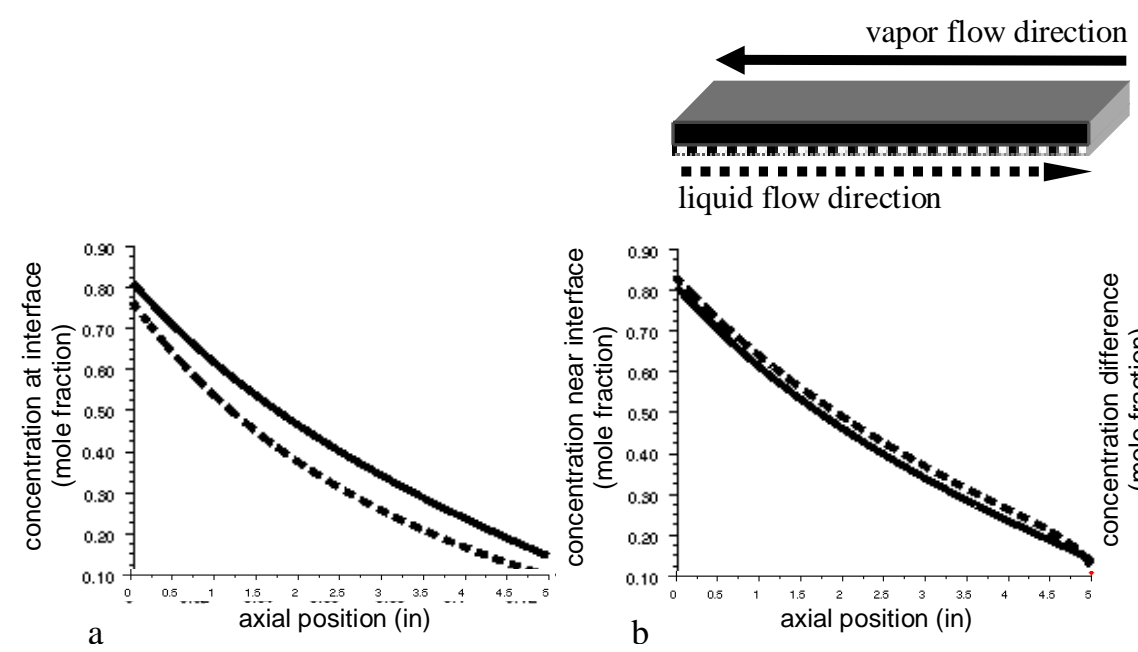

Figure 3-6. Representative hexane concentration profiles (mole fraction) as a function of axial position with respect to the channel top for simulated Case 1a (falling film). Dotted lines represent liquid-side, solid lines represent vapor-side profiles. A schematic of the channel, oriented horizontally to coincide with the plot axis, indicates liquid and vapor flow directions. Plot a presents interfacial concentrations, Plot $b$ presents concentrations in the cells adjacent to the interface, Plot $c$ shows the concentration difference driving the mass transfer at the interface (values in Plot b minus values in Plot a).

The profiles in Figure 3-7 show the relative area averaged (bulk) concentrations along the length of the distillation unit for Cases 1a and 2a (these concentration differences were used to calculate HETP values for the simulated runs). Although comparison of the two plots shows no difference in liquid-side concentration profiles, vapor-side concentration profiles show some dependence on flow velocity. At the higher flow rate, deviation between bulk and interfacial concentrations increased. Overall, since the vapor side controls mass transfer, the vapor-side HETP is more directly impacted by the change in flow rate. Although vapor-side control of the mass transfer seems counter-intuitive, this phenomenon becomes more evident by noting the points below.

1. As notable from the Schmidt Numbers, tabulated in Table 2, diffusive effects are more important than viscous effects in the vapor. The opposite is true in the liquid.

2. As notable from the Peclet Numbers, tabulated in Table $3 b$, convective mass transfer is more important than diffusive mass transfer for both phases, in all cases.

3. As notable by the ratio of the Peclet and Schmidt Numbers in the Table 3b, convective effects are significantly more important in the vapor than in the liquid phase, for all cases,. Furthermore, in the liquid, the relative importance of convective and viscous effects varies as a function of flow conditions.

Distillation is complex and its effectiveness depends on a variety of interacting phenomena.

\subsection{Conclusions to Task 3}

Enhanced distillation performance was demonstrated in microchannel devices using a surrogate mixture of $n$ hexane and cyclohexane. The measured HETP was less than 1 inch, which is an order of magnitude improvement in performance in comparison to conventional distillation columns. Numerical models were developed to predict 
the heat transfer and mass transfer in microchannel devices. A good agreement was achievement between the model predictions and experimental data. The models were qualified for future design for microchannel distillation applications.
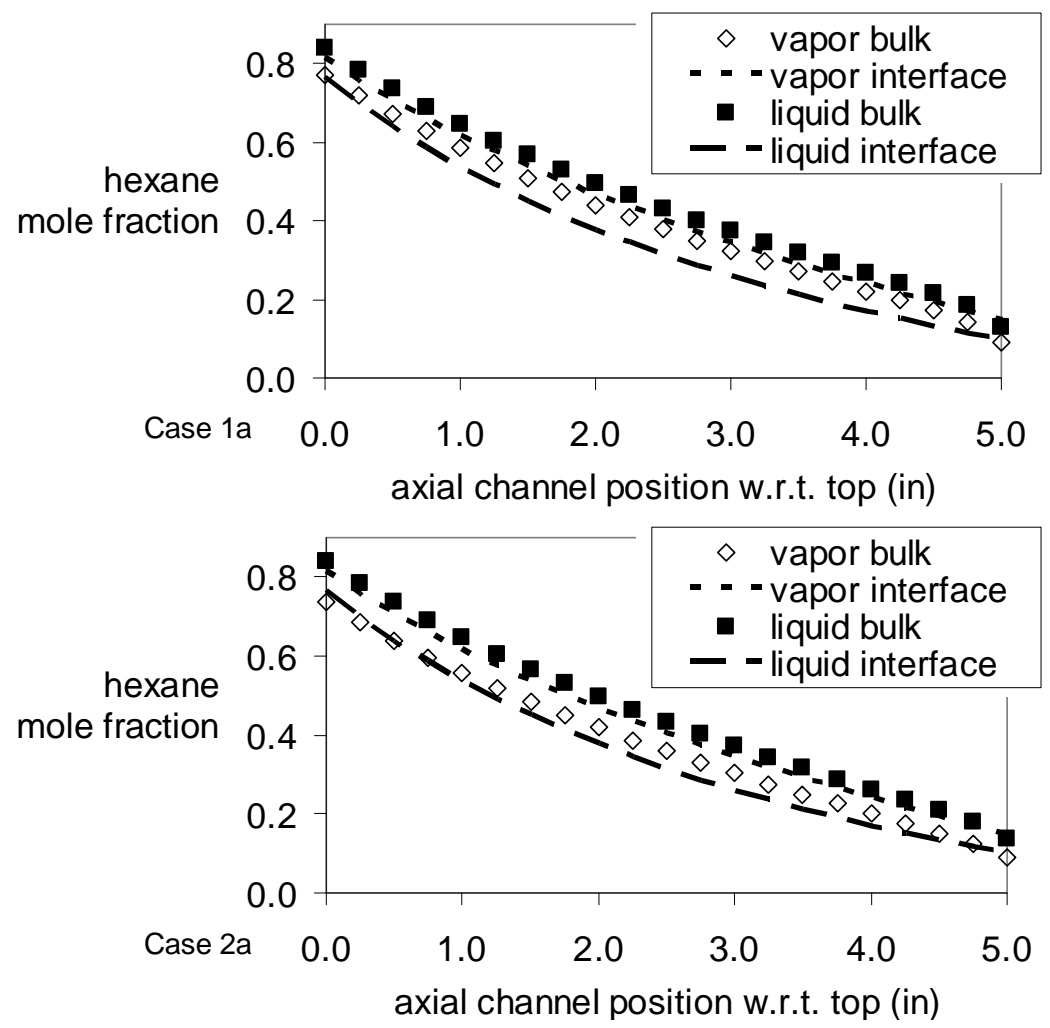

Figure 3-7. Representative surface area averaged concentration profiles and corresponding interfacial compositions for Cases $1 \mathrm{a}$ and $2 \mathrm{a}$. Area averaged (bulk) concentration profiles were used to determine HETP values for each of the simulated runs. 


\section{TASK 4 - VALIDATE DISTILLATION CODES BY FABRICATING AND OPERATING SINGLE-MICROCHANNEL DEVICES}

\subsection{Equipment and Functional Feature Designs}

An experimental device was specifically designed for these experimental trials intended to determine the applicability of MPT to ethylene distillation. The stainless steel distillation unit involved counter-currently flowing vapor and liquid phase mixtures of ethane and ethylene, separated by a laser-drilled porous screen. Liquid flowed vertically downward through a 0.010 in deep channel; vapor flowed upward through a channel of the same size. Figure 4-1 shows a picture and representative schematics of the device. Similarly to the first experimental system, this device was intended to study mass transfer over a stripping section of a distillation column, rather across a complete distillation unit. Small holes in the screen (Figure 14) allowed interfacial mass transfer while preventing breakthrough of one phase into the other. The 4-6 $\mu \mathrm{m}$ diameter holes were critical to effective performance. The capillary effects impacting operation are schematically shown in Figure 4-3. The gas phase was held at a slightly higher pressure relative to the liquid phase. As long as the pressure differential between phases did not exceed capillary pressure at the top or bottom of the device, gas and liquid phase separation was retained. Figure 4-2 shows measured pressure differentials for one of the cases consider.

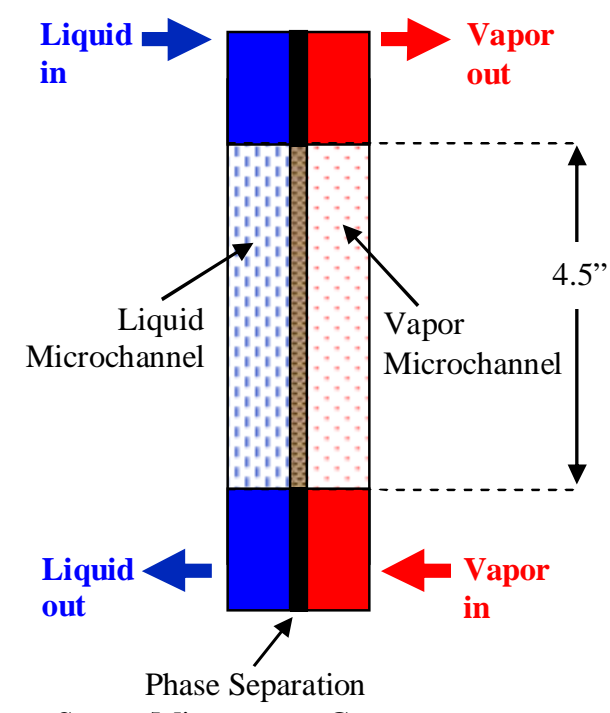

Screen/Microporous Contactor
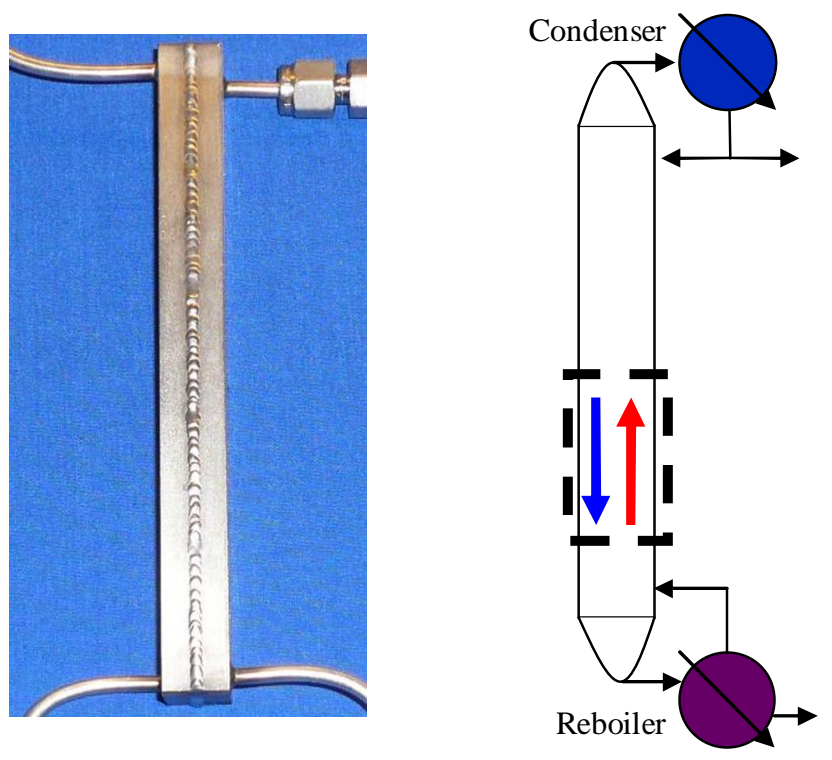

Figure 4-1. Microchannel distillation device used for ethane-ethylene separation. Flow channel width was 0.45 inch. 


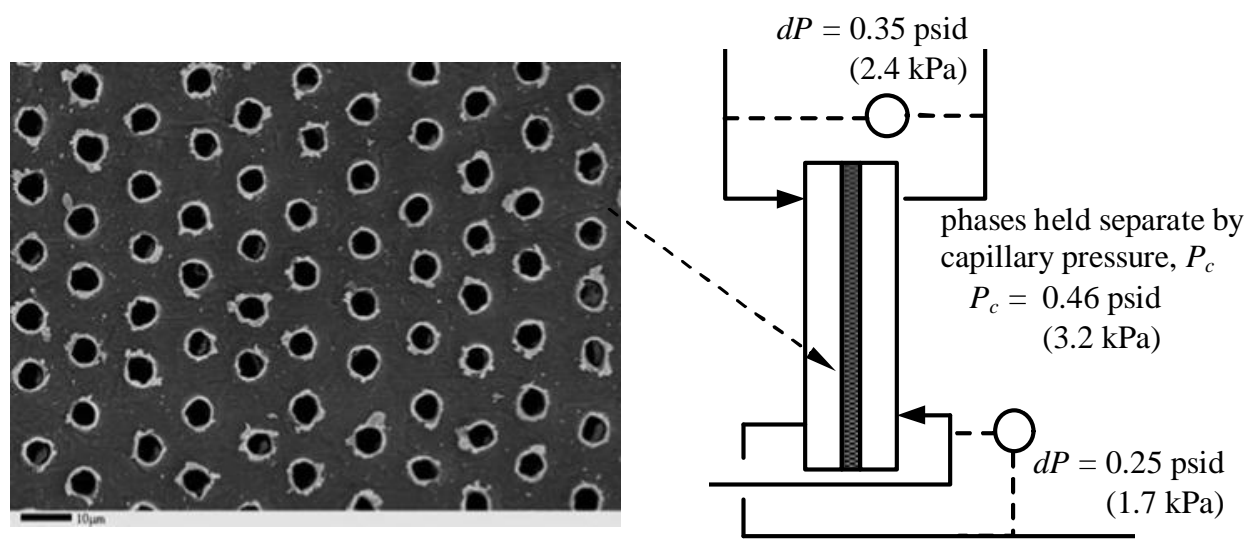

Figure 4-2. Phase separation screen/microporous contactor with 4-6 $\mu \mathrm{m}$ diameter laser drilled holes.

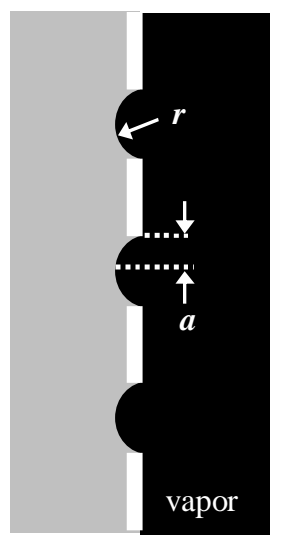

$$
\begin{aligned}
& \text { Young-Laplace equation } \quad P_{c}=\frac{2 \sigma}{r}=\frac{2 \sigma \cos \theta}{a} \\
& \text { for circular hole } \\
& \qquad \begin{aligned}
a & =\text { pore radius }(\mathrm{m}) \\
P_{c} & =\text { capillary/break-through pressure }(\mathrm{Pa}) \\
r & =\text { interfacial radius of curvature }(\mathrm{m}) \\
\theta & =\text { contact angle }\left({ }^{\circ}\right) \\
\sigma & =\text { vapor-liquid surface tension }(\mathrm{N} / \mathrm{m})
\end{aligned}
\end{aligned}
$$

counter-current flow without breakthrough

$$
\left(P_{\text {vapor }}-P_{\text {liquid }}\right)=d P<P_{c}
$$

Figure 4-3. Pressure differential for effective flow and interfacial interaction. Small holes in the screen allow interfacial contact and mass transfer while preventing breakthrough of one phase into the other.

\subsection{Experimental Set-up}

Experiments with the ethane-ethylene mixture required the purchase of a Thermotron cold box, to perform testing at constant temperature, under controlled conditions. The piping and instrumentation diagram for the test enclosure is shown in Figure 4-4; the Thermotron box limits are outlined by the dashed line in the figure. All system piping was stainless steel. Mass flow controllers were used to prepare vapor mixtures of the desired compositions. Both feed mixtures were let flow through refrigerant cooled heat exchangers to obtain the required condensation and temperature for the top feed and the desired vapor temperature for the bottom feed. Prior to entering the device, the condensed feed was collected in a surge tank whose level (measured with a specially designed and fabricated American Magnetics standard capacitance level sensor) controlled the liquid flow rate to the device. The vapor stream exiting the device was let pass through a needle valve upstream of a back pressure regulator. The needle valve was used to manually control the pressure differential across the perforated phase separation screen, as noted in Figure 4-2; pressure drop transducers verified the pressure differential in both upper and lower device sections. The back pressure regulator was used to control the global operating pressure of the device. Data were collected both manually and with Labview. 


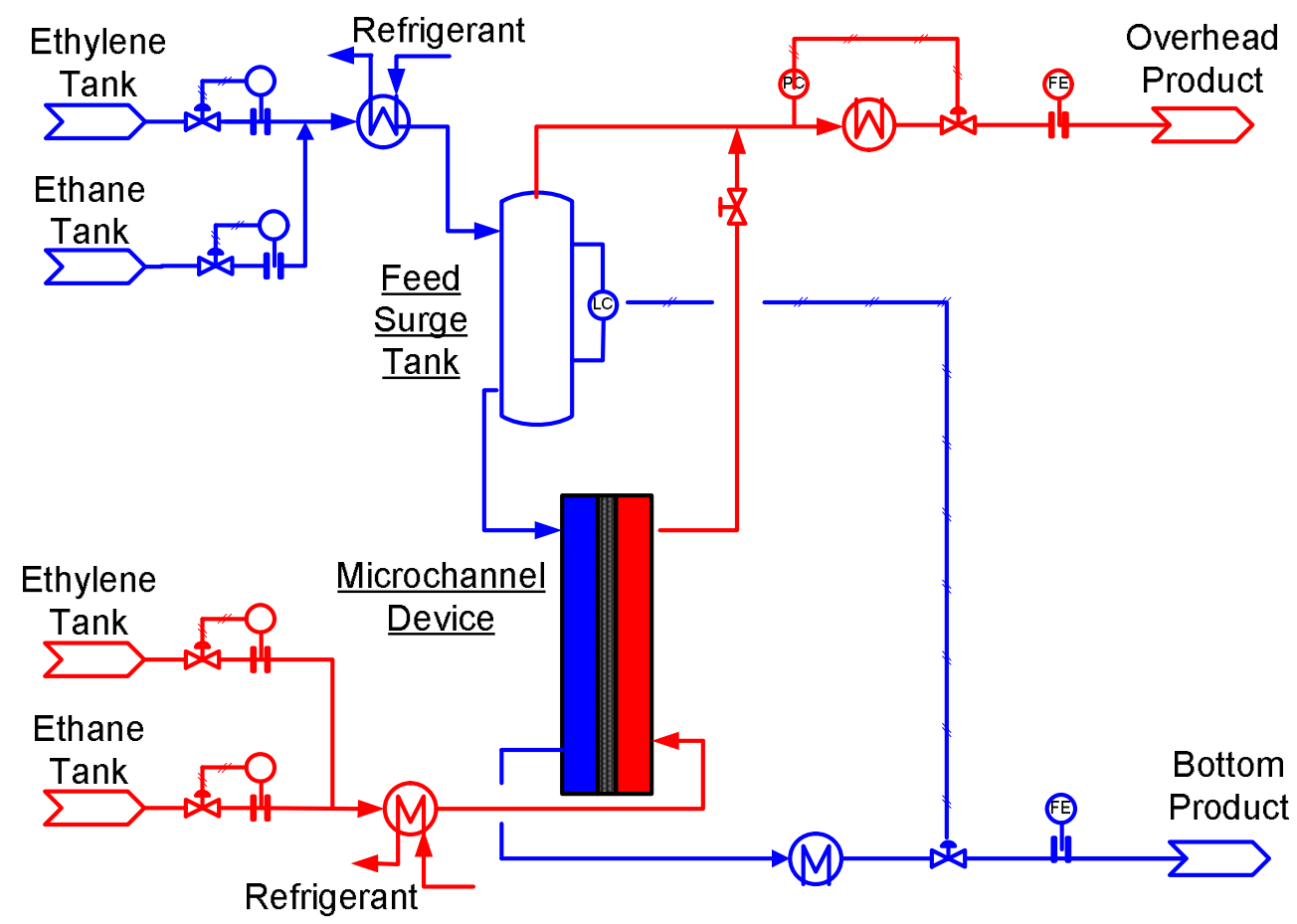

Figure 4-4. Simplified process and instrumentation diagram for the ethane-ethylene test stand.

\subsection{DISTILLATION EXPERIMENTS}

A limited set of experiments was run with the ethane-ethylene experimental system schematically shown in Figures 4-1 through 4-4. Table 4-1 lists the key run parameters. A rigorous ChemCAD distillation model was used to calculate the number of theoretical plates and HETP for the experimental runs. The distillation leads to the enrichment of the vapor phase with the lighter component (ethylene) as the vapor moves vertically upward through the column section.

\begin{tabular}{|c|c|c|c|c|c|c|c|c|c|c|}
\hline \multirow{3}{*}{$\begin{array}{l}\text { Run } \\
\text { Day }\end{array}$} & \multirow{3}{*}{$\begin{array}{l}\text { Flow } \\
\text { Ratio }\end{array}$} & \multicolumn{4}{|c|}{ Average Flow Rate $(\mathrm{sccm})$} & \multicolumn{4}{|c|}{ Average Ethylene Composition (mol\%) } & \multirow{3}{*}{$\begin{array}{c}\text { HETP } \\
\text { (in) }\end{array}$} \\
\hline & & \multicolumn{2}{|c|}{ Liquid } & \multicolumn{2}{|c|}{ Vapor } & \multicolumn{2}{|c|}{ Liquid } & \multicolumn{2}{|c|}{ Vapor } & \\
\hline & & in & out & in & out & in & out & in & out & \\
\hline 6 & 1.0 & 286 & 302 & 253 & 241 & 22.8 & 11.9 & 11.3 & 23.2 & 1.81 \\
\hline 4 & 1.3 & 373 & 392 & 330 & 331 & 22.8 & 11.9 & 11.2 & 23.4 & 1.85 \\
\hline 5 & $1.7^{*}$ & 492 & 508 & 434 & 442 & 22.3 & 12.1 & 11.3 & 22.8 & 1.70 \\
\hline
\end{tabular}

Table 4-1. Experimental run parameters and HETP values estimated using ChemCAD. 


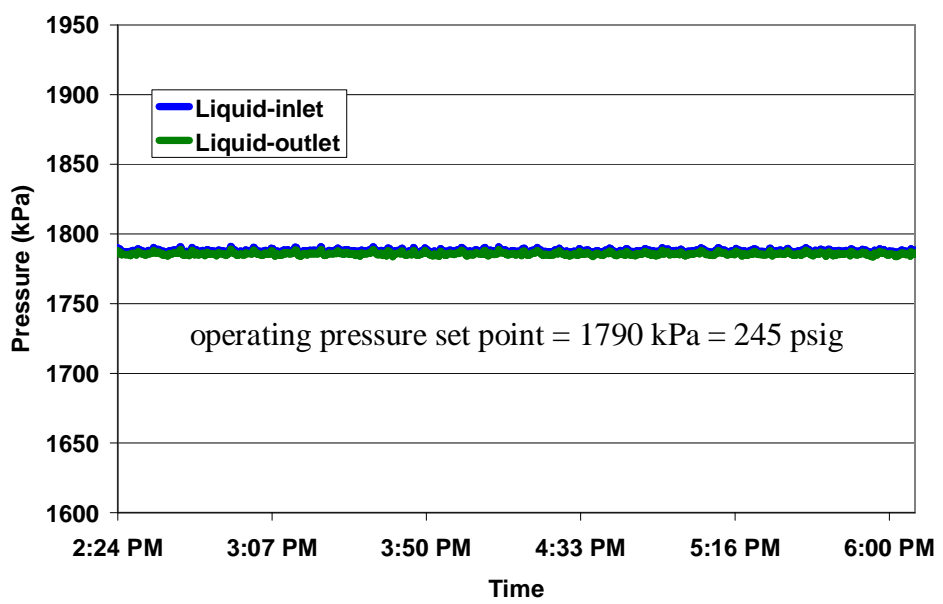

Figure 4-5. Steady profiles over an approximate 3 hour period for operation at a flow ratio of 1.7

As indicated in Figures 4-5 through 4-7, constant temperature, pressure, and composition profiles were achieved over the course of these experimental runs. Similar temperature profiles were noted on the liquid and vapor walls. As indicated in Table 4-1, HETP's smaller than 2 inches were estimated for all run conditions. Analyses with the 3-dimensional simulation developed for the $\mathrm{C} 6$ distillation took place to help gauge experimental observations and further check simulation validity. Details of the analysis are presented in the section that follows.
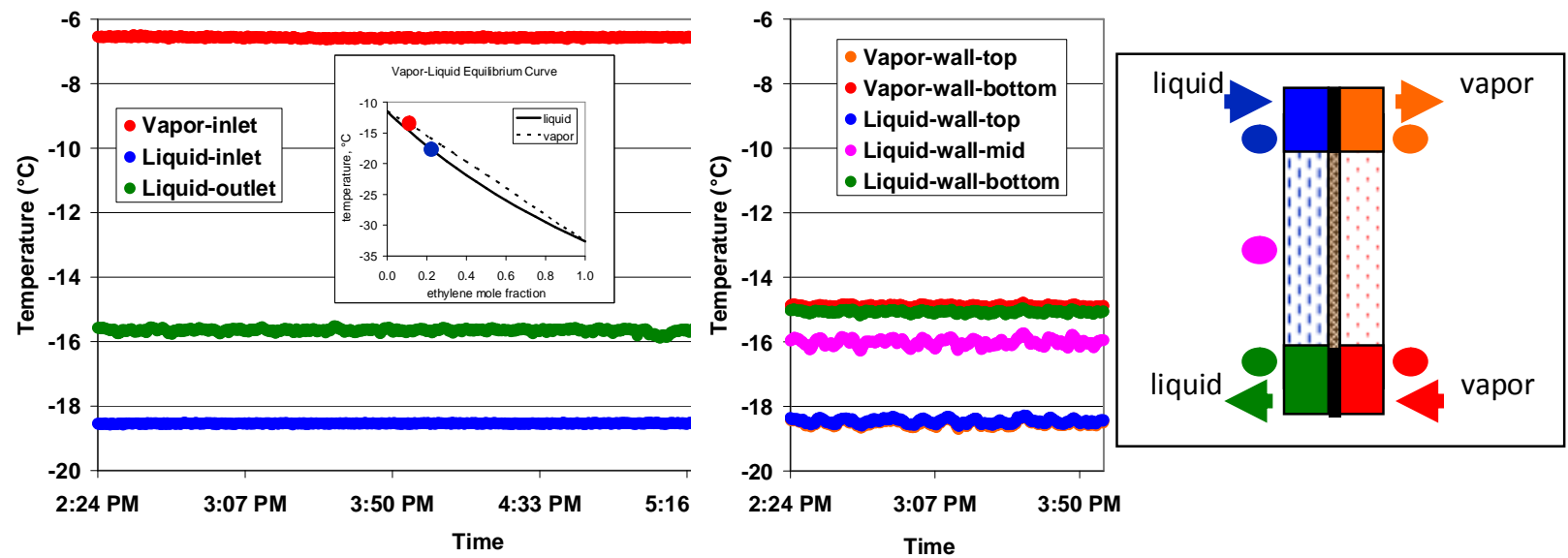

Figure 4-6. Steady temperature profiles over an approximate 3 hour period for operation at a flow ratio of 1.7. Color coding in the schematic corresponds to line color in the graphs. The temperature element at vapor outlet was malfunctioning and is not included in the graphs. 


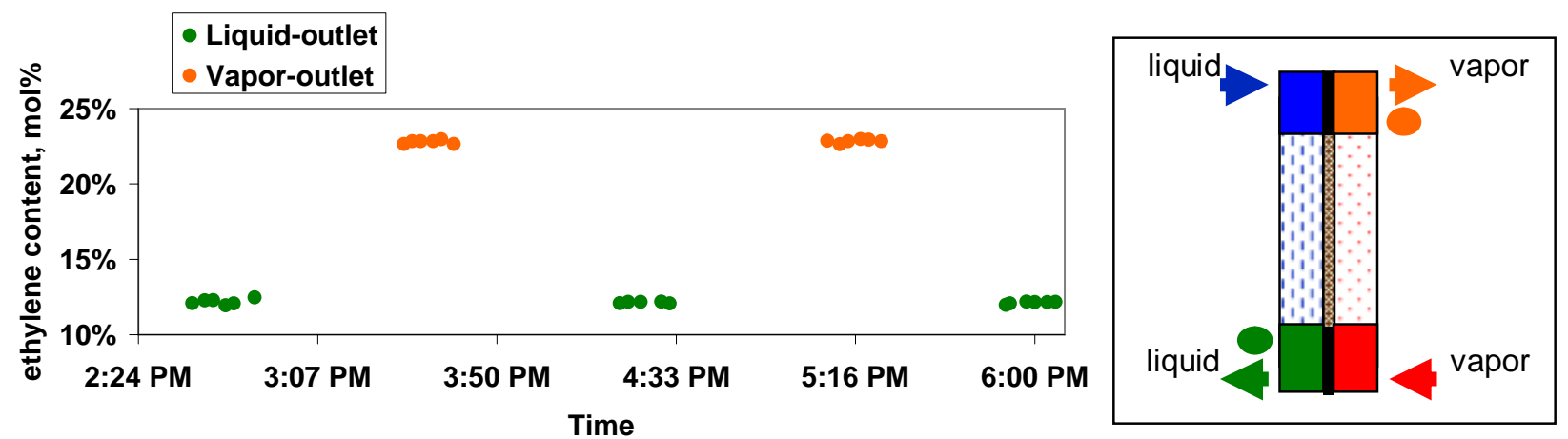

Figure 4-7. Steady outlet compositions measured over an approximate 3 hour period for operation at a flow ratio of 1.7 .

\subsection{Comparative CFD Simulation}

To help clarify experimental findings and further validate the accuracy of the Fluent ${ }^{\mathrm{TM}}$ CFD simulation methodology developed with the hexane-cyclohexane separation, experimental performance was compared to model projected estimates. As previously detailed, the adopted simulation approach involves assuming countercurrently flowing vapor and liquid phases undergoing mass transfer in response to equi-molar counter-diffusion at the vapor-liquid contact surface.

For direct comparison with experiment, the channel was modeled to include stacked volume layers, as shown in Figure 4-8. The 0.001 inch thick screen was directly sandwiched between the vapor-side and liquid-side feature plates, which were fully aligned with each other.

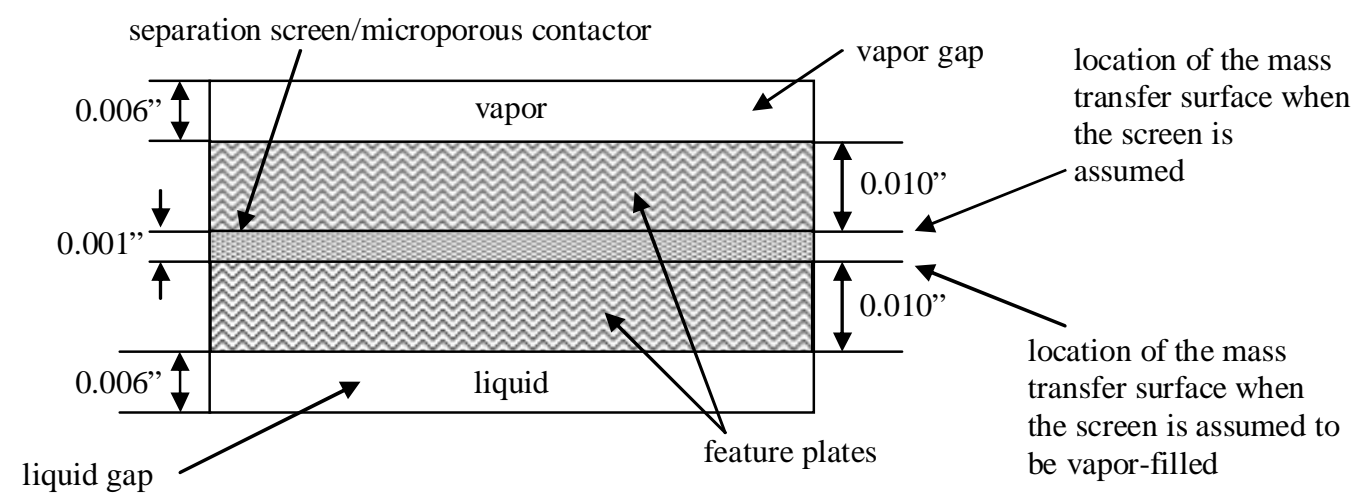

Figure 4-8. Cross sectional view of the microchannel distillation device used for ethane-ethylene separation.

Several steps were taken to allow most direct and expedient comparison between simulated and experimental systems.

- First, two 1 inch long channels, one spanning the total 0.45 inch channel width, the second spanning $1 / 5$ th of the total channel width, were built. Comparative cases were run to ensure consistent outcome for the same initial and operating conditions. These runs assumed a vapor-filled screen layer.

- Following acceptable comparisons, a narrow channel (1/5th as wide as the experimental channel) with the full, 4.5 inch experimental process length was built. Simulations were run to reflect the gambit of experimental conditions and estimate comparative performance. 
To clarify the sensitivity of the estimated distillation performance to the screen modeling approach, several simulation assumptions were considered. The screen was modeled:

- as a continuous stagnant liquid layer,

- as a continuous stagnant vapor layer,

- as a continuous liquid layer able to move in response to momentum transferred from the contiguous fluid layer of the same phase,

- as a continuous vapor layer able to move in response to momentum transferred from the contiguous fluid layer of the same phase.

The position of the interface was accordingly changed, depending on whether the screen was assumed to be vapor or liquid-filled (the location of the mass transfer surface for each case is noted in Figure 4-8). The interfacial surface was assumed to have no slip, reflecting the effect of the contact plate on fluid motion.

\subsubsection{Simulation Assumptions}

Material properties and interfacial compositions were estimated from pure ethane-ethylene ideal ChemCAD distillation column profiles (without intermediate stage heating) referenced for flowsheet modeling of the 245 psig process. These are tabulated in Table 4-2. Constant diffusivity, density and viscosity of the vapor and liquid phases were assumed throughout. For all experimental comparison cases, the mass transfer surface area was assumed to be $14 \%$ open to mass transfer (as estimated from SEM scans of the screen surface performed before the distillation experiments). Inlet concentrations and velocities were set to match experimental settings.

\begin{tabular}{ccc}
\hline Material Property & Liquid & Vapor \\
\hline density $\left(\mathrm{kg} / \mathrm{m}^{3}\right)$ & 449 & 32 \\
viscosity $(\mathrm{kg} / \mathrm{m} . \mathrm{s})$ & $7.13 \mathrm{E}-05$ & $9.0 \mathrm{E}-06$ \\
diffusivity $\left(\mathrm{m}^{2} / \mathrm{s}\right)$ & $1.1 \mathrm{E}-08$ & $5.6 \mathrm{E}-07$ \\
& & \\
\hline & Ethane & Ethylene \\
\hline molecular weight $(\mathrm{g} / \mathrm{mol})$ & $29(30$ actual) & 29 (28 actual) \\
distribution coefficients at the column top & 0.89616 & 1.37507 \\
distribution coefficients at the column bottom & 0.94730 & 1.45883 \\
\hline
\end{tabular}

Table 4-2. Material properties and interfacial parameters used in the simulation involving direct comparison with the ethane-ethylene experiments. Gas and liquid diffusivities were estimated adopting standard methodologies (Poling et al.).

\subsubsection{Detailed Simulation Results}

The key simulations and associated parameters are listed in Table 4-3. A short set of simulations was run in advance to confirm that a narrow channel counterpart was sufficiently similar to the wide/full channel system representation. The results for one of these simulations are included in the table to clarify the performance comparison noted in Figure 22.

- Runs 1-1a through 1-1d simulated the screen as a continuous vapor layer, able to move in response to momentum transferred from the contiguous fluid layer of the same phase.

- Runs 1-2a through 1-2d simulated the screen as a continuous liquid layer, able to move in response to momentum transferred from the contiguous fluid layer of the same phase.

- Run 1-3 simulated the screen as a continuous stagnant vapor layer.

- Run 1-4 simulated the screen as a continuous stagnant liquid layer. 


\begin{tabular}{|c|c|c|c|c|c|c|c|c|c|}
\hline $\begin{array}{c}\text { simulation } \\
\text { run } \\
\text { ID }\end{array}$ & $\begin{array}{l}\text { flow } \\
\text { ratio }\end{array}$ & $\begin{array}{l}\text { Fluid } \\
\text { in } \\
\text { screen }\end{array}$ & $\begin{array}{c}\text { inlet } \\
\text { liquid } \\
\text { flow rate } \\
\text { (sccm) }\end{array}$ & $\begin{array}{c}\text { inlet } \\
\text { vapor } \\
\text { flow rate } \\
\text { (sccm) }\end{array}$ & $\begin{array}{c}\text { inlet } \\
\text { liquid } \\
\text { velocity } \\
(\mathrm{m} / \mathrm{s})\end{array}$ & $\begin{array}{c}\text { inlet } \\
\text { vapor } \\
\text { velocity } \\
(\mathrm{m} / \mathrm{s})\end{array}$ & $\begin{array}{c}\text { liquid } \\
\text { HETP } \\
\text { (in) }\end{array}$ & $\begin{array}{c}\text { vapor } \\
\text { HETP } \\
\text { (in) }\end{array}$ & $\begin{array}{c}\text { overall } \\
\text { HETP } \\
\text { (in) }\end{array}$ \\
\hline $0-1 c$ & -- & Vapor & -- & -- & 0.00662 & 0.08300 & 0.59 & 0.33 & 0.90 \\
\hline $1-1 a$ & 1.0 & Vapor & 290 & 250 & 0.00673 & 0.08300 & 0.72 & 1.14 & 1.82 \\
\hline $1-1 b$ & 1.3 & Vapor & 370 & 330 & 0.00871 & 0.10749 & 0.91 & 1.23 & 2.09 \\
\hline $1-1 c$ & 1.7 & Vapor & 490 & 430 & 0.01143 & 0.14110 & 1.15 & 1.34 & 2.43 \\
\hline $1-1 d$ & 2.2 & Vapor & 630 & 560 & 0.01480 & 0.18260 & 1.42 & 1.47 & 2.82 \\
\hline $1-2 a$ & 1.0 & Liquid & 290 & 250 & 0.00673 & 0.08300 & 0.59 & 1.07 & 1.63 \\
\hline $1-2 b$ & 1.3 & Liquid & 370 & 330 & 0.00871 & 0.10749 & 0.74 & 1.15 & 1.85 \\
\hline $1-2 c$ & 1.7 & Liquid & 490 & 430 & 0.01143 & 0.14110 & 0.92 & 1.23 & 2.10 \\
\hline $1-2 d$ & 2.2 & Liquid & 630 & 560 & 0.01480 & 0.18260 & 1.12 & 1.32 & 2.38 \\
\hline $1-3$ & 1.7 & $\begin{array}{c}\text { stagnant } \\
\text { vapor }\end{array}$ & 490 & 430 & 0.01143 & 0.14110 & $1.15(1.00)$ & $1.34(1.00)$ & $2.43(1.00)$ \\
\hline $1-4$ & 1.7 & $\begin{array}{l}\text { stagnant } \\
\text { liquid }\end{array}$ & 490 & 430 & 0.01143 & 0.14110 & $1.10(1.19)$ & $1.31(1.07)$ & $2.35(1.12)$ \\
\hline
\end{tabular}

Table 4-3. Key parameters corresponding to the CFD simulations used to probe experimental system performance; inlet fluid velocities were defined to match experimental values. Run 0-1c corresponds to a preliminary run used to ensure adequate geometric configuration; this run has no direct experimental comparison. The preliminary run assumed an interfacial surface area $100 \%$ open to mass transfer; the latter runs assumed an interfacial surface area $14 \%$ open to mass transfer. The HETP's in the table reflect main channel values and are based on Hoy. Values in parenthesis for runs 1-3 and 1-4 correspond to the ratio of the stagnant to non-stagnant counterparts. All cases assumed a symmetric boundary condition at the channel sidewalls.

\subsubsection{Detailed Analysis and Discussion of Experimental and Simulated Results}

Results of the simulated runs intended for comparison with experimental measurements are tabulated in Table 4-3 and plotted in Figure 4-9, in terms of overall and vapor and liquid HETP, for easier interpretation. The reduced CFD flow rates relative to the experimental counterparts, shown in Table 7, reflect the reduced channel width of the model. Generally, overall HETP estimates were relatively insensitive to process conditions, ranging between 1.6 and 2.4 inches for all cases considered, increasing linearly with flow rate. The estimates were in the same range as those measured experimentally, although experimental estimates appeared to be even insensitive to flow rate. Given the similarity of the results, the CFD model is useful for predicting performance. Review of the results shows an apparently interesting and counterintuitive dependence of the HETP on the assumed screen configuration. Closer examination can help explain the observations. 

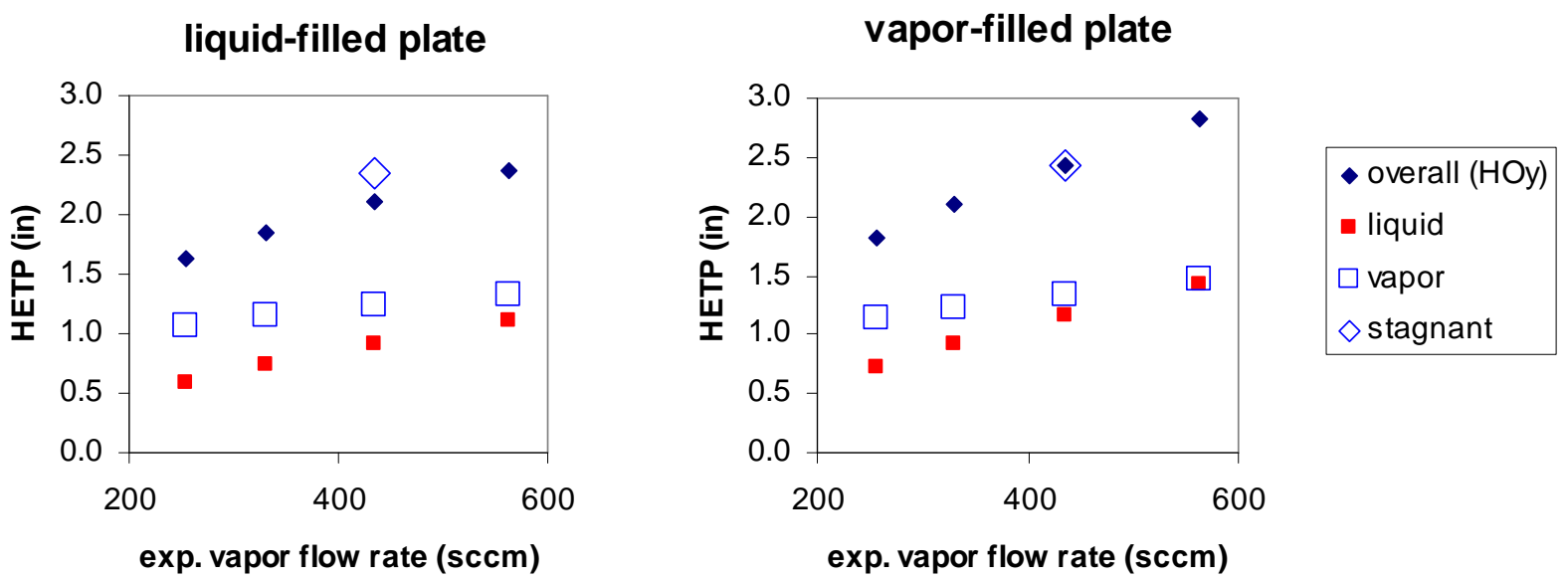

Figure 4-9. Plot of overall and vapor and liquid HETP's for the simulated cases as a function of the corresponding experimental vapor flow rates. The stagnant value is for the overall HETP.

From Figure 4-9, we can note a linear increase in HETP with flow rate for both vapor and liquid phases. This is expected. Lower sensitivity of the vapor phase HETP for both configurations is also noted by the shallower slope of the vapor curve relative to the liquid curve. This can be explained by the faster diffusive transport in the vapor phase relative to viscous transport in the same phase. The higher dependence of the liquid HETP on flow rate is similarly justified by a slower diffusive flux relative to the viscous counterpart in that same phase. These comparative rates can be better interpreted in terms of a Schmidt number for each phase, $S c=\frac{\mu}{\rho D}$, where $S c_{\text {vapor }}=0.5$ and $S c_{\text {liquid }}=14.4$.

As a ratio of the liquid to vapor values shows, in the liquid phase, the relative importance of viscous to diffusive transport is 30 times greater than in the vapor phase. In fact, when the screen is assumed to be liquid-filled and the layer is taken as stagnant (unable to respond to viscous momentum transfer), the HETP is noticeably increased. The same sensitivity is not seen when the screen is assumed to be filled with a stagnant vapor phase.

The Peclet number, $P e=\frac{L v}{D}$, can also provide additional insight into the results by quantifying the relative importance of convective to diffusive transport in each phase. Regardless of the absolute value, the ratio of the Peclet number in the two phases was held constant throughout the runs (the velocities were scaled by the same factor in both phases), and was 4 times higher in the liquid than in the vapor phase. Hence, once again, the liquid resistance (and therefore, the liquid HETP) is justifiably more dependent on flow rate than the vapor counterpart.

Finally, the more important viscous and convective transport effects of the liquid phase relative to the vapor phase can also justify performance enhancement noted when the screen is assumed to be filled with liquid instead of vapor. Additional graphs can clarify the observations.

Figures 4-10a, $b$, and $c$ show the light species concentration difference within each phase at the interface for two experimental comparison cases (where the surface area was assumed to be $86 \%$ obstructed by the solid 
part of the screen) and for one of the preliminary runs (where the surface area was assumed to be $100 \%$ open to mass transfer).

Figures 4-10a and $b$, where neither phase leads to a zero concentration difference at the interface, indicate that the species do not have enough surface area for mass transfer. In contrast, in Figure 4-10c, where the surface area is $100 \%$ open to mass transfer, concentration differences are zero in one phase or the other, depending on which one provides the greatest resistance. Hence, the occlusion provided by the screen is a big inhibitor to performance.

In addition, the larger difference in the vapor side interfacial concentration gradient when the screen is assumed to be filled with vapor (Run ID 1-1d, Figure 4-10a) rather than liquid (Run ID 1-2d, Figure 4-10b) shows that convection, momentum, and/or diffusive transfer within the vapor phase is limiting performance to a greater extent than transfer in the liquid counterpart (most likely because the lower velocity and momentum of the vapor do not allow motion of the species as effectively within the depths of the features in the feature plates). The importance of convection and viscous motion to the effectiveness of the liquid-side mass transfer can also be noted in the sharper, more distinct liquid-side concentration gradient peaks of Figure 4-10b. The stagnant chevron peaks correspond to the regions of least effective mass transfer.

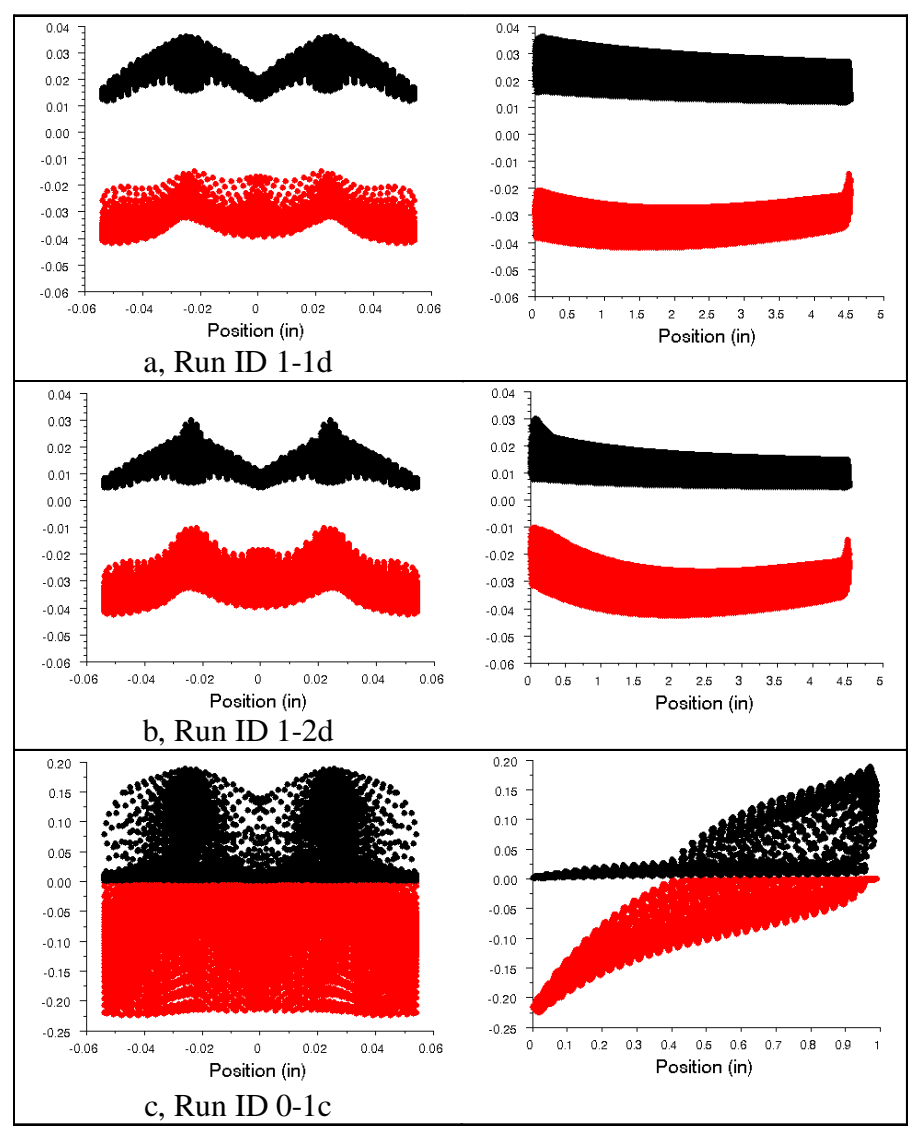

Figures 4-10. Representative profiles of the concentration difference (light species in the bulk minus light species in the interface) across the interface for Run ID's 1-1d (a), 1-2d (b), and 0-1c (c). Positive differences, shown in black, correspond to the liquid gradient, negative differences, shown in red, correspond to the vapor gradient. Left-most plots show profiles across the width of the channel; right- 
most plots show profiles across the length of the channel. Liquid moves in the positive axial direction. The concentration differences drive the mass transfer at the interface.

\subsubsection{Key Result Summary}

Fluent simulated performance estimates for the bench-scale distillation of the ethane-ethylene mixture were found to compare well with experimental measures of performance. Table 4-4 summarizes the comparisons, in terms of HETP's. Generally, CFD models of the experimental distillation system configuration correlated well with experimental results, either matching exactly experimental estimates or deviating by at most $43 \%$. Given the lack of fitting parameters of any sort, the agreement is a positive indication of model validity.

\begin{tabular}{ccccc}
\hline \multicolumn{2}{c}{ Experimental } & \multicolumn{3}{c}{ HETP estimate (in) } \\
Run Day & Flow Ratio & Experimental & Fluent & Difference \\
\hline 6 & 1.0 & 1.81 & $1.63-1.82$ & $1-10 \%$ \\
4 & 1.3 & 1.85 & $1.85-2.09$ & $0-13 \%$ \\
5 & 1.7 & 1.70 & $2.10-2.43$ & $24-43 \%$ \\
& & & & \\
\hline
\end{tabular}

Table 4-4. Comparisons of experimental and simulated model performance. Experimental HETP values were estimated using ChemCAD.

The CFD studies involved assuming that the 0.001 inch thick screen was either a vapor or a liquid layer (modeling the screen as a vapor layer corresponded to assuming that the screen pores were vapor-filled; modeling the screen as a liquid layer corresponded to assuming that the screen pores were liquid-filled). According to the CFD studies, it would appear as if having the screen filled with liquid, for the particular cases considered, leads to better performance than having it be filled with vapor. However, no experimental proof is available to confirm this finding.

Based on the relative insensitivity of the performance to changes in configuration and flow rate, and as corroborated by closer scrutiny of the concentration profiles across the phases, screen blockage is a significant detriment to performance. As would be expected, the more area is left open to mass transfer, the better the performance.

\subsection{Conclusions for Task 4}

A test facility was designed and assembled to evaluate C2 splitting performance, and a microchannel device was specifically designed and fabricated for the application. Data were collected over a 3-day period. The test facility performed as expected, achieving controllable and steady-state operation.

At this point in the project, the two microchannel distillation technology approaches adopted to date were reevaluated. The original design approach, demonstrated for C6 separation, was deemed useful for small-tomedium size distillation capacity ranges. The high productivity approach, demonstrated for C2 separation and deemed useful for high-throughput distillation applications, was found to require additional technology development compared to the original design approach. The primary challenge identified is the large number of microchannel distillation units required to perform the targeted separation. This raises the capital cost above current distillation solutions and necessitates pushing the market entry date beyond 2011, the year assumed in the Task 1 projections. 
The team proposed continuing with the original design approach, working with a single-channel test device with a single feed and integrated heat exchange. This approach was approved by DOE project management. Work with both C6 and C2 devices provided valuable learning used towards the design and implementation of the functional single-channel distillation device that followed. 


\section{TASK 5 - DESIGN, FABRICATE AND TEST INTEGRATED SINGLE-CHANNEL}

\section{DISTILLATION DEVICE}

Building on the learnings of the previous microchannel distillation experiments, a new design approach was selected for the development of a single-channel distillation device, incorporating integrated heat exchange and single feed, distillate, and bottom product streams. With functional validation, the concept can serve as a basis for the development of a scaled up commercial distillation unit. In addition, this integrated single channel device can be easily adopted for distillation experiments using additional mixtures of interest.

\subsection{Equipment and Functional Feature Design}

A third device configuration was designed and fabricated to maximize mass transfer while providing insight into methodologies for most direct extension to pilot and commercial scales. Unlike the other devices, which represented partial distillation column sections, the third device configuration consisted of a complete distillation unit, including integrated reboiler and condenser sections, a single liquid feed (split to enter and flow along the two, 1 inch wide sidewalls of the device), and single distillate and bottom product ports, as shown in Figure 5-1. Distillation was made possible by the intimate contacting of the downward flowing liquid films with the vapor stream flowing upward through the center of the device. The feed inlet, channel gap, and liquid drainage configurations (detailed in the inset of Figure 5-1) were specifically designed to maximize flows but prevent bridging and channel flooding. Uniform liquid film flow and distribution, important to effective and stable operation, were achieved by appropriate surfacing of the device sidewalls. Two devices of this type were fabricated and tested: the first with a 0.050 , the second with a 0.040 inch main channel gap size. The objective of the two designs was to scope the dimension that would enhance mass transfer rate while preventing the formation of liquid bridging and flooding at the flow rates of interest.

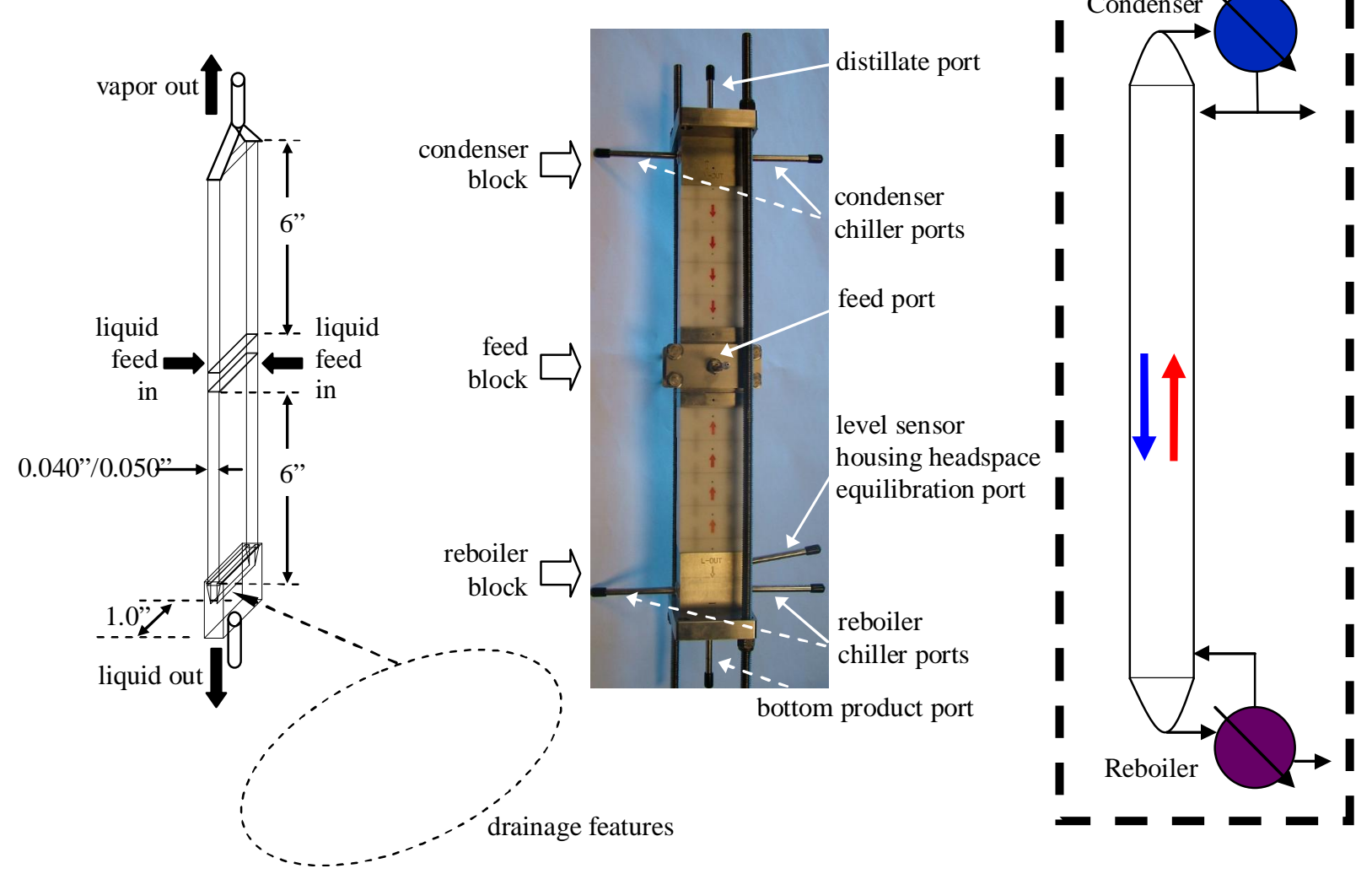

Page 32 of 63 
Figure5-1. Microchannel distillation device used for pentane-cyclopentane separation.

\subsection{Selection of a Chemical System}

A pentane-cyclopentane mixture was chosen for these evaluations. As shown in Figure 5-2, the vapor liquid equilibrium curve for this mixture of low relative volatility components was very similar to that of the ethaneethylene and hexane-cyclohexane systems of the previous trials. In addition, this species separation allowed the adoption of relatively low operating pressure, and a distillate to bottom product temperature differential greater than $10^{\circ} \mathrm{C}$.
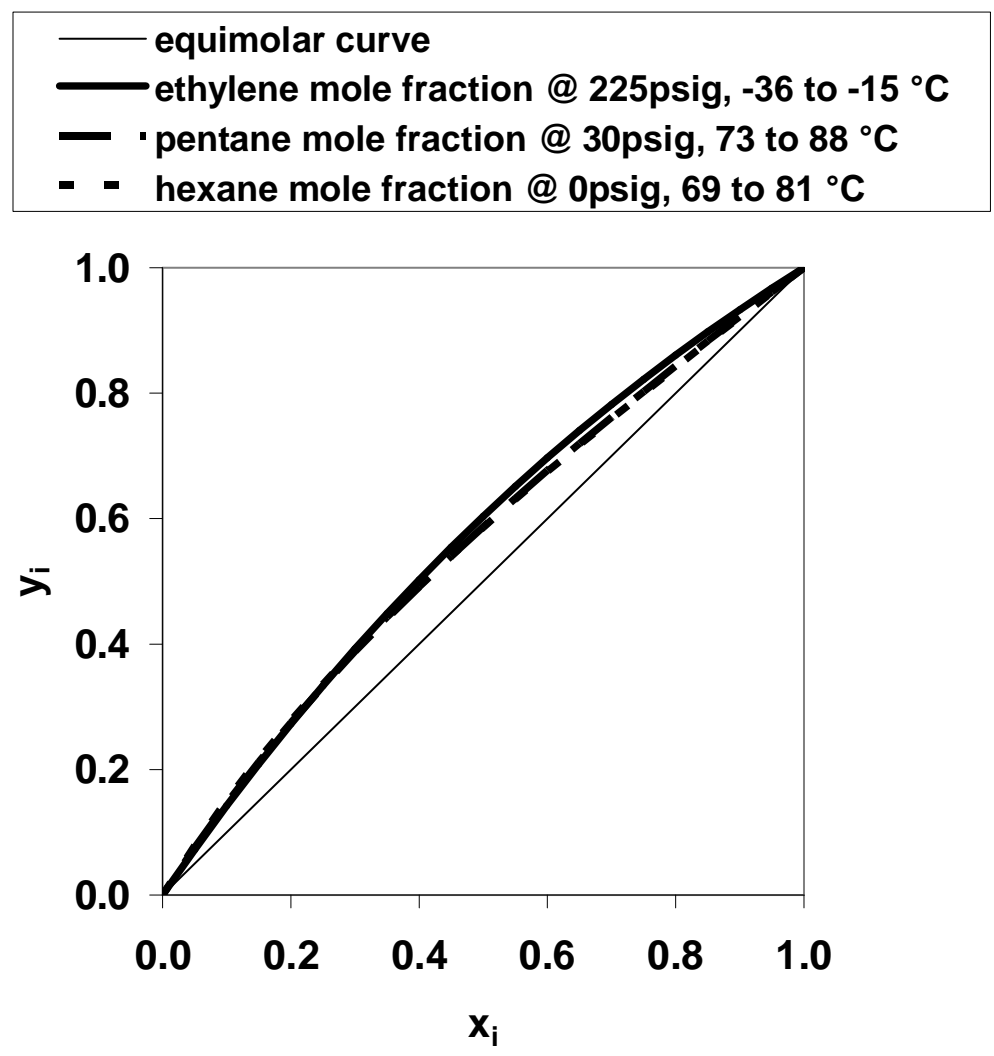

Figure 5-2. Superposition of the vapor liquid equilibrium curves for the three chemical separations experimentally tested with Velocys microchannel process technology. The curves coincide very closely, with the pentane and hexane systems having an exact overlap. As noted in the legend, temperature ranges for distillation of the analogous mixtures were very mild in comparison with the ethane distillation.

\subsection{Experimental Set-up}

The same Thermotron cold box used for the ethane-ethylene separation (Thermotron Industries, Model No. S27-3800) was used for testing with the pentane-cyclopentane mixture, helping to reduce heat losses to the environment and facilitate testing. The piping and instrumentation diagram for this test stand is shown in Figure 5-3; Thermotron box limits are delineated by dashed outline in this diagram, as well. Pictures of the insulated and bare device, mounted in the cold box, are also shown in Figure 5-4.

The pentane-cyclopentane feed mixture was prepared manually (by weight) and loaded into a dual $1000 \mathrm{cc}$ ISCO precision syringe pump, controlled by a Teledyne ISCO D-Series controller. The main stream from the pump was split into two feed streams; the uniformity of the streams was ensured with the inclusion of an orifice and 
needle valve in each line, adjusted to provide equal flows at both high and low flow rates. The feed streams were preheated prior to entering the device, just below vaporization temperature (to ensure a single-phase liquid feed at the inlet). Condenser and reboiler temperatures were adjusted using Alpha refrigeration units, with Syltherm as the heat transfer fluid. Syltherm flow rates were not controlled or monitored; thermocouples were placed in the Syltherm lines immediately upstream and downstream of the condenser and reboiler to provide insight into heat duties. System pressure was controlled with a back pressure regulator downstream of the distillate exit port. A control valve and a specially designed and fabricated American Magnetics standard capacitance level sensor regulated the bottom liquid product flow rate. A level sensor housing was specifically built and fabricated for the distillation trials. The sensor housing was directly connected and aligned with the reboiler section of the device and tested to ensure no impact on device operation or bottom product composition.

Thermowells allowed monitoring of device sidewall temperatures along the length of the device. A thermocouple inserted through the reboiler port allowed direct measurement of reboiler fluid temperature. A thermocouple inserted in the condenser exit line provided feedback on distillate temperature upstream of the back pressure regulator. Electric heat tapes placed between condenser port and back pressure regulator ensured that the vapor product did not condense and flow back into the device. These heat tapes allowed unhindered device operation but acted to mask the true temperature of the distillate vapor product. Bottom and distillate product streams were collected in a two-tier collection system, allowing long term collection in liter-size drums as well as short term collection into $10 \mathrm{ml}$ stainless steel tubes, for direct input into glass vials used for compositional analyses. The feed and product samples were analyzed by gas chromatography, adopting a specifically developed analytical protocol. Process data were collected both manually and with Labview. Canary software allowed instantaneous monitoring of process performance.

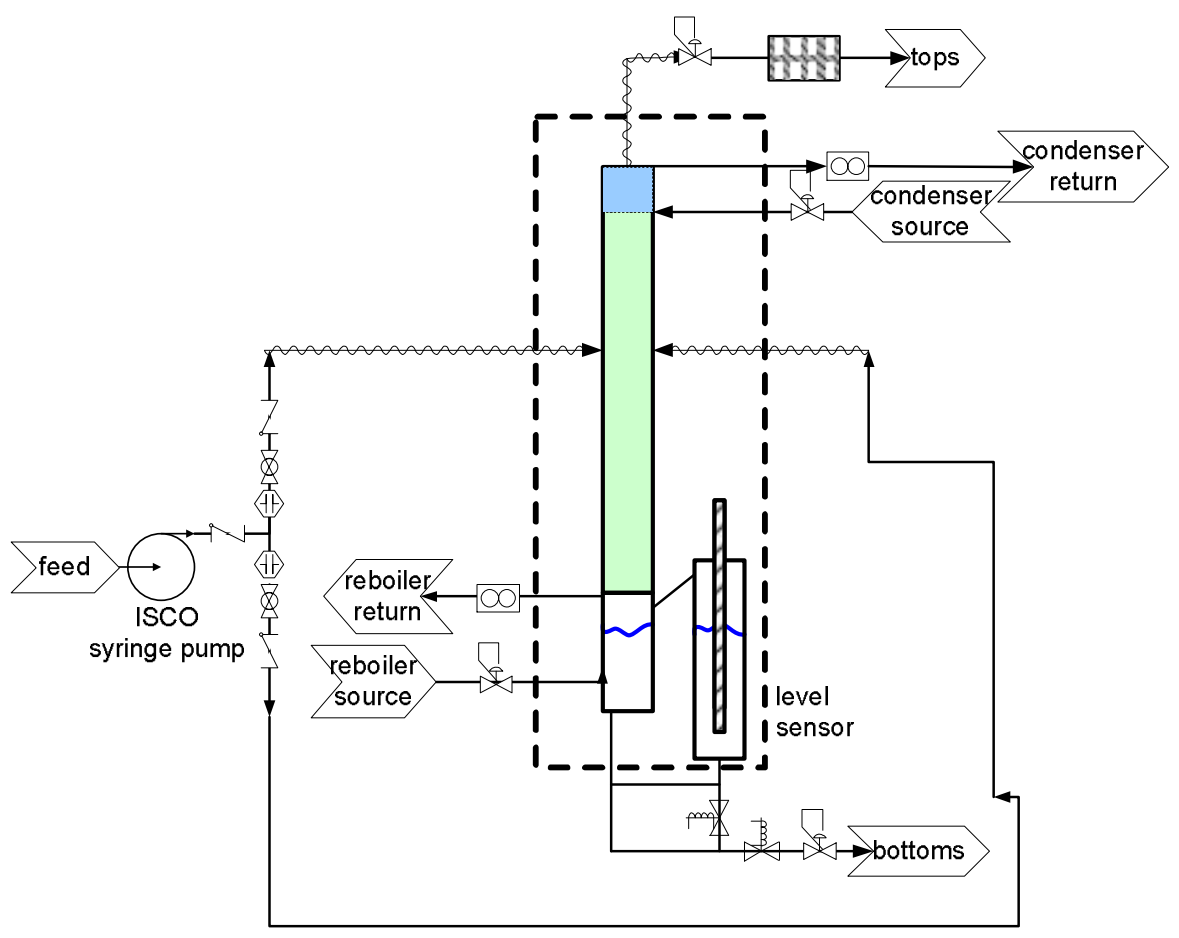

Figure 5-3. Simplified process and instrumentation diagram for the pentane-cyclopentane test stand. 

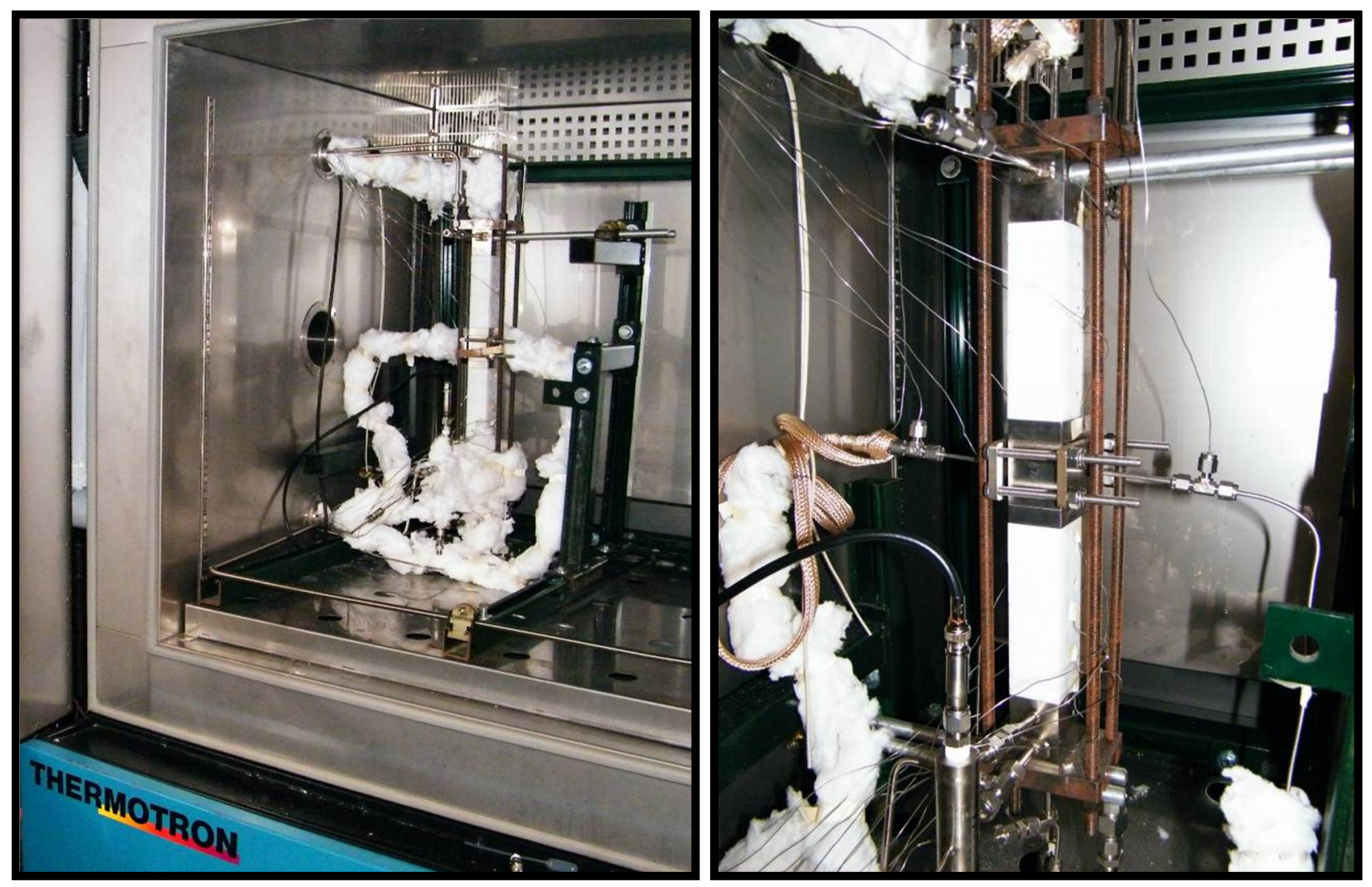

Figure 5-4. Pictures of the Flex Cell device mounted in the Thermotron cold box. Left-most picture shows the device with insulated level sensor housing, inlet and outlet lines. Right-most picture shows the same device with the insulation removed

\subsection{Distillation Experiments}

\subsubsection{Device Design and Experimental Operation}

The design flow rate for the system was determined by a semi-iterative process aimed at gauging the appropriate relationship between device gap size and internal traffic flow. Specifically, 30 psig was chosen as an adequate operating pressure, allowing a distillate to bottom product temperature differential greater than $10^{\circ} \mathrm{C}$ and minimal device pressure retention requirements. Liquid down flow along the 1.0 inch wide sidewalls was selected to provide good internal traffic flow with minimal active volume penalty.

The design approach involved the following steps:

1. Running a preliminary ChemCAD simulation to determine desired operating mode and parameter ranges at 30psig for a nominal feed rate.

- Assuming

- a 0.5 species mole fraction feed stream entering at the column center,

- a 12 inch column with HETP as small as 0.25 inch (for approximately 50 total stages),

○ a 0.99 mole fraction top product purity,

- a partial condenser.

- Varying vapor boil-up/bottom product ratio to obtain

- relatively linear and smooth temperature and composition profiles,

- maximum bottom product purity. 
2. Estimating the required falling film flows and condenser and reboiler duties at the operating conditions of interest, and iterating to find the vapor gap size needed to avoid flooding.

- Having verified that stable laminar film flow requires a liquid Reynolds number $\left(\operatorname{Re}_{\max }\right)<10$ (per analytical expressions describing falling film flow (Bird et al.) and experiments with ethyl and isopropyl alcohol over a flat wall), use ChemCAD provided liquid properties for a representative lower column plate (viscosity, $\mu$, and density, $\rho$ ) to determine the maximum allowable liquid traffic flow $\left(Q_{\max }\right)$ over the lower column section wall ( $W$ in width),

$$
Q_{\text {max }}=\frac{\operatorname{Re}_{\text {max }}}{4} \frac{W \mu}{\rho}
$$

- Scale all external and internal ChemCAD-calculated vapor and liquid flows so as to have the liquid traffic flow in the lower column section meet the required maximum value, $Q_{\max }$.

- Iterate to find the vapor gap size required to accommodate the internal traffic without flooding. For this purpose, refer to expressions for countercurrent flow through monoliths (Heibel et al.), which lead to the following expression for the gap size needed to avoid flooding, $d_{\mathrm{h}}$,

$$
d_{h}=\frac{1}{g} \frac{\rho_{G}}{\rho_{L}-\rho_{G}}\left[\frac{u_{G}}{\left(0.12\left(\frac{u_{L}}{u_{G}} \sqrt{\frac{\rho_{L}}{\rho_{G}}}\right)^{-0.475}-0.025\right) \varepsilon}\right]^{2}
$$

where densities and viscosities of the gas and vapor phases are given by the following symbols: , $\rho_{G}, \rho_{L}$, $\mu_{\mathrm{G}}, \mu_{\mathrm{L}}$ and the void fraction, assumed to be 1.0 for the calculations, is given by $\varepsilon$.

Table 5-1 summarizes some of the key results of the iteration process, indicating a 0.045 inch gap size as appropriate for the prevention of flooding in the simulated 50 stage column operated to achieve a $99 \mathrm{~mol} \%$ distillate purity. The gap of the 1st and 2 nd generation devices, 0.050 and 0.040 inch, respectively, was chosen slightly larger and smaller than the correlation estimate, to allow a safety margin in the first case, and to push the operating and design window in the second case. The experimental design point, for a feed flow rate of 0.34 $\mathrm{g} / \mathrm{min}$, was chosen with the intent of obtaining the highest bottom product purity for the projected top purity at similar operating conditions. 


\begin{tabular}{|c|c|c|c|c|}
\hline \multicolumn{5}{|c|}{ scaled ChemCAD operating parameters to maintain bottom stage Re and avoid flooding } \\
\hline feed stage temperature & ${ }^{\circ} \mathrm{C}$ & 78.4 & 77.6 & 77.5 \\
\hline bottom stage temperature & ${ }^{\circ} \mathrm{C}$ & 79.7 & 84.1 & 87.0 \\
\hline feed flow & $\mathrm{ccm}(\mathrm{g} / \mathrm{min})$ & $1.09(0.68)$ & $0.58(0.36)$ & $0.54(0.34)$ \\
\hline top product flow & $\mathrm{ccm}(\mathrm{g} / \mathrm{min})$ & $8.36(0.07)$ & $16.73(0.14)$ & $19.29(0.16)$ \\
\hline bottom product flow & $\mathrm{ccm}(\mathrm{g} / \mathrm{min})$ & $0.97(0.61)$ & $0.33(0.22)$ & $0.26(0.17)$ \\
\hline bottom c-C5 composition, liquid product & $\mathrm{mol} / \mathrm{mol}$ & 0.56 & 0.82 & 0.96 \\
\hline $\mathrm{R} / \mathrm{D}$, liquid reflux/distillate & mass/mass & 8.05 & 7.27 & 7.14 \\
\hline V/B, vapors/bottoms, as specified & mass/mass & 1.00 & 5.01 & 7.00 \\
\hline \multicolumn{5}{|c|}{ bottom stage fluid properties and operating parameters to avoid flooding } \\
\hline liquid $\operatorname{Re}_{\max }$, set to avoid flooding & & 8 & 8 & 8 \\
\hline liquid property ratio, $\mu / \rho$ & $\mathrm{m} 2 / \mathrm{s}$ & $3.23 E-07$ & $3.33 \mathrm{E}-07$ & $3.40 \mathrm{E}-07$ \\
\hline liquid flow over one wall, $Q_{\max }$ & $\mathrm{ccm}$ & 0.99 & 1.02 & 1.04 \\
\hline liquid film thickness & in & 0.0016 & 0.0016 & 0.0016 \\
\hline liquid velocity, $u_{L}$ & $\mathrm{~m} / \mathrm{s}$ & 0.016 & 0.016 & 0.016 \\
\hline vapor velocity, $u_{G}$ & $\mathrm{~m} / \mathrm{s}$ & 0.063 & 0.089 & 0.096 \\
\hline main channel gap to avoid flooding & in & 0.034 & 0.043 & 0.045 \\
\hline
\end{tabular}

Table 5-1. Representative iterative design point calculations to size experimental column flows and gap dimensions. For the ChemCAD simulations, the feed stream and top stage temperatures were consistently held at 78.8 and $73{ }^{\circ} \mathrm{C}$, respectively. These values corresponded to pre-set $49 \mathrm{~mol} \%$ and $99 \mathrm{~mol} \%$ pentane feed and distillate compositions. Bottom stage temperatures was let fluctuate to achieve the predefined boil-up ratio and distillate purity. For the falling film calculations, void fraction was assumed to be 1.0 in all cases, the wall, perpendicular to the ground, was assumed to have a width of 1.0 inch.

\subsubsection{1st GenerationDevice Operation}

Much of the operation for the 1st generation MPT distillation device, nicknamed 'Flex Cell', was centered about the design flow rate. To ensure proper distribution, the feed stream was fed as a subcooled liquid at a consistent $75^{\circ} \mathrm{C}$, immediately upstream of the device. Operating parameters were varied with the following key intent:

- to troubleshoot the stand and device operation and ascertain operational functionality

- adopting low condenser temperature for high distillate purity

- adopting low condenser and high reboiler temperatures for equal product flow split

- to obtain high distillate purity

- setting the condenser temperature to correspond to pure normal pentane boiling temperature at operating pressure and lowering reboiler temperature

- to obtain high bottom product purity

- setting the reboiler temperature to pure cyclopentane boiling temperature and increasing condenser temperature.

Higher feed flow rates (1.5 and 2.0 times the design point value) were also adopted for a short run time to scope operational constraints related to bridging and parameter effects. 
Test parameters and results for the 1st generation Flex Cell are summarized in Tables 10 through 12 for the three flow rates considered. Process-side reboiler fluid temperature and condenser chiller feed temperature (measured immediately upstream of the integrated condenser) were the key control parameters for the operation, as noted in the section detailing the experimental set-up for the device. A 50mol\% pentane feed stream was used in all cases. Feed streams were sampled and checked by GC (using an Agilent Technologies $6890 \mathrm{~N}$ gas chromatograph with a 7683 autosampler) each time product samples were gathered, to ensure valid calculations and to capture slight time dependent feed variations in the premixing.

For each GC analysis, the measured compositions were normalized by their sum, to obtain $100 \%$ total stream composition values. To gauge distillation performance, each stable run condition was analyzed graphically with a McCabe-Thiele diagram (McCabe et al.). Because a 100\% mole balance closure was required for the analysis, a corrected bottom stream composition was calculated and compared against measured values. Agreement was good for most run conditions, with the exception of the first two troubleshooting runs, where the mass balance closure was less than $95 \mathrm{~mol} \%$. Overall mass balance was very good for other cases, ranging between 95 and 104 mol\%. 


\begin{tabular}{|c|c|c|c|c|c|c|c|c|c|c|}
\hline \multicolumn{2}{|l|}{$\begin{array}{l}\text { Flow rate } \\
\text { relative to design }\end{array}$} & \multicolumn{9}{|c|}{$1.0 x$} \\
\hline \multirow{2}{*}{\multicolumn{2}{|c|}{ Distillation Run Sequence }} & \multicolumn{2}{|c|}{ Troubleshooting } & \multicolumn{3}{|c|}{$\Delta$ Trbl @ low Tcnd } & \multicolumn{4}{|c|}{$\Delta$ Tond @ high Trbl } \\
\hline & & 1 & 2 & 3 & 4 & 5 & 6 & 7 & 8 & 9 \\
\hline Condenser $\mathbf{T}$ & ${ }^{\circ} \mathrm{C}$ & 72 & 73 & 73 & 73 & 73 & 73 & 74 & 75 & 77 \\
\hline Reboiler T & ${ }^{\circ} \mathrm{C}$ & 86 & 91 & 86 & 85 & 84 & 88 & 88 & 88 & 88 \\
\hline Condenser chiller feed $\mathrm{T}$ & ${ }^{\circ} \mathrm{C}$ & 72.2 & 72.7 & 73.0 & 72.8 & 72.8 & 73.1 & 73.7 & 74.7 & 76.8 \\
\hline Reboiler chiller feed T & ${ }^{\circ} \mathrm{C}$ & 90.3 & 98.7 & 89.5 & 87.7 & 86.8 & 93.4 & 93.6 & 93.5 & 93.6 \\
\hline Reboiler liquid product $\mathbf{T}$ & ${ }^{\circ} \mathrm{C}$ & 85.7 & $90.8 \S$ & 85.8 & 84.8 & 84.3 & 87.5 & 87.7 & 87.7 & 87.7 \\
\hline Condenser fluid dT & ${ }^{\circ} \mathrm{C}$ & 0.30 & 0.34 & 0.29 & 0.30 & 0.30 & 0.32 & 0.32 & 0.30 & 0.25 \\
\hline Reboiler fluid dT & ${ }^{\circ} \mathrm{C}$ & 0.48 & 0.71 & 0.40 & 0.30 & 0.30 & 0.54 & 0.55 & 0.53 & 0.53 \\
\hline Feed T & ${ }^{\circ} \mathrm{C}$ & 72.4 & 74.4 & 74.8 & 74.7 & 74.7 & 74.8 & 74.8 & 74.8 & 74.9 \\
\hline Feed flow rate & $\mathrm{g} / \mathrm{min}$ & 0.34 & 0.34 & 0.34 & 0.34 & 0.34 & 0.34 & 0.34 & 0.34 & 0.34 \\
\hline Distillate flow rate & $\mathrm{g} / \mathrm{min}$ & 0.05 & 0.15 & 0.05 & 0.03 & 0.01 & 0.12 & 0.13 & 0.15 & 0.18 \\
\hline Bottom product flow rate & $\mathrm{g} / \mathrm{min}$ & 0.27 & 0.17 & 0.28 & 0.32 & 0.33 & 0.21 & 0.22 & 0.19 & 0.15 \\
\hline $\begin{array}{l}\text { nC5 feed composition } \\
\text { (measured \& normalized) }\end{array}$ & $\mathrm{mol} \%$ & 0.50 & 0.48 & 0.47 & 0.47 & 0.47 & 0.48 & 0.48 & 0.48 & 0.49 \\
\hline $\begin{array}{l}\text { nC5 distillate composition } \\
\text { (measured \& normalized) }\end{array}$ & $\mathrm{mol} \%$ & 0.91 & 0.79 & 0.91 & 0.92 & 0.95 & 0.87 & 0.85 & 0.80 & 0.74 \\
\hline $\begin{array}{l}\text { nC5 bottom composition } \\
\text { (measured \& normalized) }\end{array}$ & $\mathrm{mol} \%$ & $0.38 *$ & $0.17^{*}$ & 0.38 & 0.43 & 0.45 & 0.28 & 0.24 & 0.21 & 0.18 \\
\hline $\begin{array}{l}\text { nC5, bottom composition } \\
\text { (for } 100 \% \text { balance) }\end{array}$ & $\mathrm{mol} \%$ & $0.44 *$ & $0.24 *$ & 0.40 & 0.43 & 0.45 & 0.28 & 0.25 & 0.23 & 0.20 \\
\hline Overall mole balance (out/in) & & $93 \% * *$ & $94 \% * *$ & $96 \%$ & $103 \%$ & $100 \%$ & $97 \%$ & $104 \%$ & $100 \%$ & $98 \%$ \\
\hline \multicolumn{11}{|l|}{ Rectification } \\
\hline Stages around $\min$. reflux & & 14 & 8 & 14 & 14 & 19 & 11 & 10 & 8 & 5 \\
\hline Stages at total reflux & & 8 & 5 & 8 & 9 & 10 & 7 & 6 & 5 & 4 \\
\hline HETP around min. reflux & in & 0.43 & 0.75 & 0.43 & 0.43 & 0.32 & 0.55 & 0.60 & 0.75 & 1.2 \\
\hline HETP at total reflux & in & 0.67 & 1.0 & 0.67 & 0.60 & 0.55 & 0.75 & 0.86 & 1.0 & 1.2 \\
\hline \multicolumn{11}{|l|}{ Stripping } \\
\hline Stages around $\min$. reflux & & 2 & 5 & 2 & 1 & 0 & 4 & 5 & 6 & 7 \\
\hline Stages at total reflux & & 1 & 2 & 1 & 0 & 0 & 2 & 3 & 3 & 3 \\
\hline HETP around min. reflux & in & 3.0 & 1.2 & 3.0 & 6.0 & 0 & 1.5 & 1.2 & 1.0 & 0.86 \\
\hline HETP at total reflux & in & 6.0 & 3.0 & 6.0 & 0 & 0 & 3.0 & 2.0 & 2.0 & 2.0 \\
\hline $\begin{array}{ll}\S & \text { Measurement } \\
& \text { sidewalls. } \\
* & \text { Measured and } \\
* * & \text { Mass balance }\end{array}$ & was dee & $\begin{array}{l}\text { centratic } \\
\text { ss than } p\end{array}$ & $\begin{array}{l}\text { t; reboile } \\
\text { on differe } \\
\text { referable. }\end{array}$ & $\begin{array}{l}\text { excee } \\
\text { O pum }\end{array}$ & $\begin{array}{l}\text { ed } 3 m \\
\text { leak }\end{array}$ & as repo & & way frc & the & \\
\hline
\end{tabular}

Table 5-2. Pentane-cyclopentane distillation run summary for the 1st generation Flex Cell operated at a feed flow rate 1.0 times the design point. $T$ and $\mathrm{dT}$ correspond to temperature and temperature differentials, respectively. 


\begin{tabular}{|c|c|c|c|c|c|c|c|c|c|c|}
\hline \multirow{3}{*}{$\begin{array}{l}\text { Flow rate } \\
\text { relative to design } \\
\text { Distillation Run Sequence }\end{array}$} & & \multicolumn{9}{|c|}{$1.5 X$} \\
\hline & & \multicolumn{2}{|c|}{ high tower T's } & \multicolumn{2}{|c|}{ low tower T's } & \multicolumn{5}{|c|}{$\Delta$ Trbl @ low Tend } \\
\hline & & 10 & 11 & 12 & 13 & 14 & 15 & 16 & 17 & 18 \\
\hline Condenser $\mathbf{T}$ & ${ }^{\circ} \mathrm{C}$ & 77 & 77 & 73 & 73 & 72 & 72 & 72 & 72 & 72 \\
\hline Reboiler T & ${ }^{\circ} \mathrm{C}$ & 87 & 88 & 85 & 84 & 83 & 84 & 85 & 86 & 87 \\
\hline Condenser chiller feed $\mathrm{T}$ & ${ }^{\circ} \mathrm{C}$ & 76.6 & 76.5 & 72.6 & 72.6 & 71.9 & 71.9 & 72.0 & 72.1 & 72.0 \\
\hline Reboiler chiller feed T & ${ }^{\circ} \mathrm{C}$ & 93.4 & 95.4 & 91.4 & 89.7 & 87.8 & 92.3 & 94.2 & 96.1 & 97.8 \\
\hline Reboiler liquid product $\mathrm{T}$ & ${ }^{\circ} \mathrm{C}$ & 86.7 & 87.9 & 84.9 & 83.8 & 82.7 & 84.4 & 85.2 & 86.1 & 86.9 \\
\hline Condenser fluid dT & ${ }^{\circ} \mathrm{C}$ & 0.28 & 0.28 & 0.33 & 0.32 & 0.33 & 0.35 & 0.35 & 0.39 & 0.39 \\
\hline Reboiler fluid dT & ${ }^{\circ} \mathrm{C}$ & 0.56 & 0.62 & 0.54 & 0.48 & 0.43 & 0.61 & 0.64 & 0.73 & 0.79 \\
\hline Feed T & ${ }^{\circ} \mathrm{C}$ & 75.0 & 75.0 & 74.6 & 74.7 & 74.6 & 74.6 & 74.7 & 74.8 & 74.7 \\
\hline Feed flow rate & $\mathrm{g} / \mathrm{min}$ & 0.51 & 0.51 & 0.51 & 0.51 & 0.51 & 0.51 & 0.51 & 0.51 & 0.51 \\
\hline Distillate flow rate & $\mathrm{g} / \mathrm{min}$ & 0.27 & 0.31 & 0.14 & 0.08 & 0.02 & 0.13 & 0.20 & 0.24 & 0.26 \\
\hline Bottom product flow rate & $\mathrm{g} / \mathrm{min}$ & 0.24 & 0.20 & 0.35 & 0.43 & 0.46 & 0.37 & 0.30 & 0.26 & 0.25 \\
\hline $\begin{array}{l}\text { nC5 feed composition } \\
\text { (measured } \& \text { ormalized) }\end{array}$ & $\mathrm{mol} \%$ & 0.49 & 0.48 & 0.49 & 0.49 & 0.49 & 0.49 & 0.49 & 0.49 & 0.49 \\
\hline $\begin{array}{l}\text { nC5 distillate composition } \\
\text { (measured \& ormalized) }\end{array}$ & $\mathrm{mol} \%$ & 0.72 & 0.69 & 0.86 & 0.88 & 0.91 & 0.84 & 0.82 & 0.78 & 0.75 \\
\hline $\begin{array}{l}\text { nC5 bottom composition } \\
\text { (measured \& ormalized) }\end{array}$ & $\mathrm{mol} \%$ & 0.21 & 0.16 & 0.36 & 0.40 & 0.47 & 0.37 & $0.32 *$ & $0.28 *$ & 0.23 \\
\hline $\begin{array}{l}\text { nC5, bottom composition } \\
\text { (for } 100 \% \text { balance) }\end{array}$ & $\mathrm{mol} \%$ & 0.23 & 0.17 & 0.35 & 0.42 & 0.47 & 0.37 & $0.29 *$ & $0.23 *$ & 0.23 \\
\hline $\begin{array}{l}\text { Overall mole balance } \\
\text { (out/in) }\end{array}$ & $\begin{array}{l}\mathrm{mol} / \\
\mathrm{mol}\end{array}$ & $100 \%$ & $99 \%$ & $97 \%$ & $99 \%$ & $96 \%$ & $99 \%$ & $99 \%$ & $100 \%$ & $101 \%$ \\
\hline \multicolumn{11}{|l|}{ Rectification } \\
\hline Stages around $\min$. reflux & & 5 & 4 & 10 & 11 & 13 & 9 & 8 & 7 & 6 \\
\hline Stages at total reflux & & 4 & 3 & 7 & 7 & 8 & 6 & 6 & 5 & 4 \\
\hline HETP around min. reflux & in & 1.2 & 1.5 & 0.60 & 0.55 & 0.46 & 0.67 & 0.75 & 0.86 & 1.0 \\
\hline HETP at total reflux & in & 1.2 & 1.5 & 0.75 & 0.75 & 0.67 & 0.86 & 0.86 & 1.0 & 1.2 \\
\hline \multicolumn{11}{|l|}{ Stripping } \\
\hline Stages around $\min$. reflux & & 6 & 8 & 4 & 2 & 1 & 4 & 5 & 6 & 6 \\
\hline Stages at total reflux & & 3 & 4 & 1 & 1 & 0 & 1 & 2 & 3 & 3 \\
\hline HETP around min. reflux & in & 1.0 & 0.75 & 1.5 & 3.0 & 6.0 & 1.5 & 1.2 & 1.0 & 1.0 \\
\hline HETP at total reflux & in & 2.0 & 1.5 & 6.0 & 6.0 & 0 & 6.0 & 3.0 & 2.0 & 2.0 \\
\hline
\end{tabular}

Measured and corrected concentration difference exceeded 3mol\%.

Table 5-3. Pentane-cyclopentane distillation run summary for the 1st generation Flex Cell operated at a feed flow rate 1.5 times the design point. T and $\mathrm{d} T$ correspond to temperature and temperature differentials, respectively. 


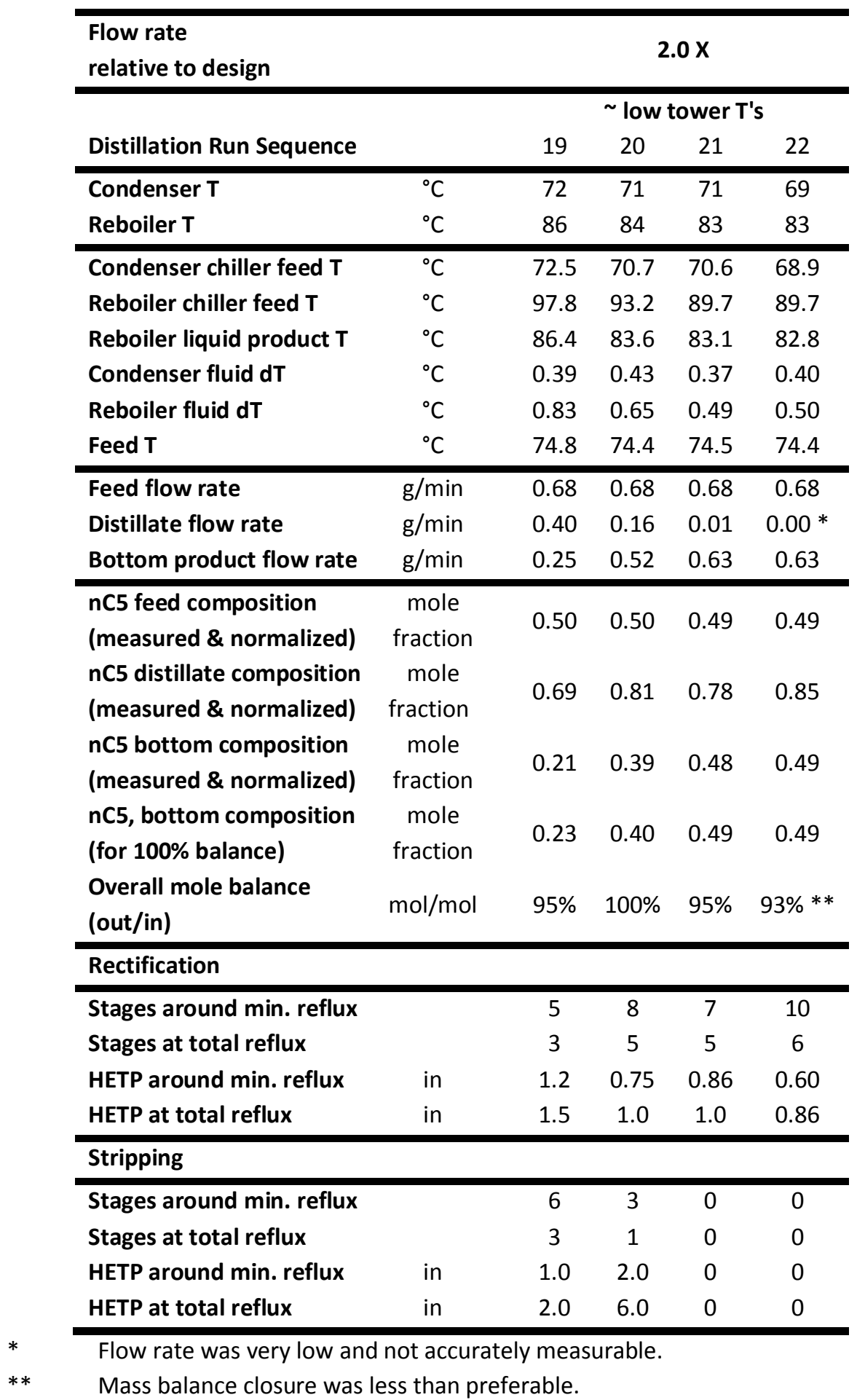

Table 5-4. Pentane-cyclopentane distillation run summary for the 1st generation Flex Cell operated at a feed flow rate 2.0 times the design point. $T$ and $d T$ correspond to temperature and temperature differentials, respectively.

Process pressure and temperature profiles were instantaneously monitored using the software program Canary. Process stability was gauged by ensuring that process temperatures and pressures were stable over the course 
of at least 2 full hours of operation. Table 5-5 shows some key comparative measures for three extended or replicated runs over the course of the experiments. In many cases, a re-equilibration to new process conditions was noted in minutes. Although the stand was designed to minimize downstream line volumes, the minimum achieved turnover time in the course of operation at the design flow rate was $45 \mathrm{~min}$. In some cases, for the lowest output rates, as much as a day of stable operation was required to collect a sample after a single turnover. Longer run times for these extreme conditions might have resulted in higher product purity. Figures 55 and 5-6 are representative parameter profiles for tower operation over a 6-hour period. The plotted information is detailed in the figures to clarify observations.

\begin{tabular}{|c|c|c|c|c|c|c|c|}
\hline \multirow{2}{*}{$\begin{array}{l}\text { Flow rate } \\
\text { relative to design } \\
\text { Distillation Run Sequence * }\end{array}$} & & \multicolumn{2}{|c|}{$\begin{array}{c}1.0 \mathrm{X} \\
\text { (extended run) }\end{array}$} & \multicolumn{2}{|c|}{$\begin{array}{c}1.0 \mathrm{X} \\
\text { (replicated run) }\end{array}$} & \multicolumn{2}{|c|}{$\begin{array}{c}1.5 \mathrm{X} \\
\text { (extended run) }\end{array}$} \\
\hline & & a 5 & 5 & 8 & $8 a$ & a 11 & 11 \\
\hline Condenser $\mathrm{T}$ & ${ }^{\circ} \mathrm{C}$ & 73 & 73 & 75 & 75 & 77 & 77 \\
\hline Reboiler T & ${ }^{\circ} \mathrm{C}$ & 84 & 84 & 88 & 88 & 88 & 88 \\
\hline Condenser chiller feed T & ${ }^{\circ} \mathrm{C}$ & 72.8 & 72.8 & 74.7 & 74.7 & 76.7 & 76.5 \\
\hline Reboiler liquid product $\mathbf{T}$ & ${ }^{\circ} \mathrm{C}$ & 84.2 & 84.3 & 87.7 & 87.5 & 87.7 & 87.9 \\
\hline Feed T & ${ }^{\circ} \mathrm{C}$ & 75.1 & 74.7 & 74.8 & 74.7 & 75.0 & 75.0 \\
\hline Feed flow rate & $\mathrm{g} / \mathrm{min}$ & 0.34 & 0.34 & 0.34 & 0.34 & 0.51 & 0.51 \\
\hline Distillate flow rate & $\mathrm{g} / \mathrm{min}$ & 0.01 & 0.01 & 0.15 & 0.14 & 0.33 & 0.31 \\
\hline Bottom product flow rate & $\mathrm{g} / \mathrm{min}$ & 0.33 & 0.33 & 0.19 & 0.17 & 0.19 & 0.20 \\
\hline $\begin{array}{l}\text { nC5 feed composition } \\
\text { (measured \& normalized) }\end{array}$ & $\begin{array}{l}\text { mole } \\
\text { fraction }\end{array}$ & 0.47 & 0.47 & 0.48 & 0.49 & 0.48 & 0.48 \\
\hline $\begin{array}{l}\text { nC5 distillate composition } \\
\text { (measured \& normalized) }\end{array}$ & $\begin{array}{l}\text { mole } \\
\text { fraction }\end{array}$ & 0.94 & 0.95 & 0.80 & 0.79 & 0.68 & 0.69 \\
\hline $\begin{array}{l}\text { Overall mole balance } \\
\text { (out/in) }\end{array}$ & $\mathrm{mol} / \mathrm{mol}$ & $100 \%$ & $100 \%$ & $100 \%$ & $92 \% * *$ & $102 \%$ & $99 \%$ \\
\hline
\end{tabular}

Table 5-5. Some key comparative run measures for pentane-cyclopentane distillation in the 1st generation Flex

Cell. Data indicate long term and repeatable operating responses for the column. T indicates temperature.

For the pressure and sensor level profiles of Figure 5-5, one can note that

- the bottom control valve opens as the liquid level rises, leading to relatively regular oscillations in the profiles;

- the flow fluctuations follow the liquid level control valve (bottom flow is highest when the liquid level is highest);

- fluctuations are long term periodic, following the fluctuations in liquid level and flow, with the top pressure lower than the bottom pressure, due to hydrostatic effects;

- pressure fluctuations follow liquid level and flow.

For the temperature profiles of Figure 5-6, although fluctuations are noticeable, these are generally stable, following the trends of the pressure fluctuations. It is interesting to note that large tower operation does not typically reflect such immediate thermal response. The open microchannel configuration is likely to minimize 
response delays and more clearly show the direct link between pressure and temperature throughout the system. Generally, one can note that

- condenser and reboiler fluid temperatures changes are small (flow rates were not monitored);

- tower temperature increases towards the bottom;

- the temperature of the level sensor housing is lower than the reboiler temperature and follows the same fluctuations noted in the tower;

- the Thermotron cold box temperature is recorded manually (reported as $77^{\circ} \mathrm{C}$ ).
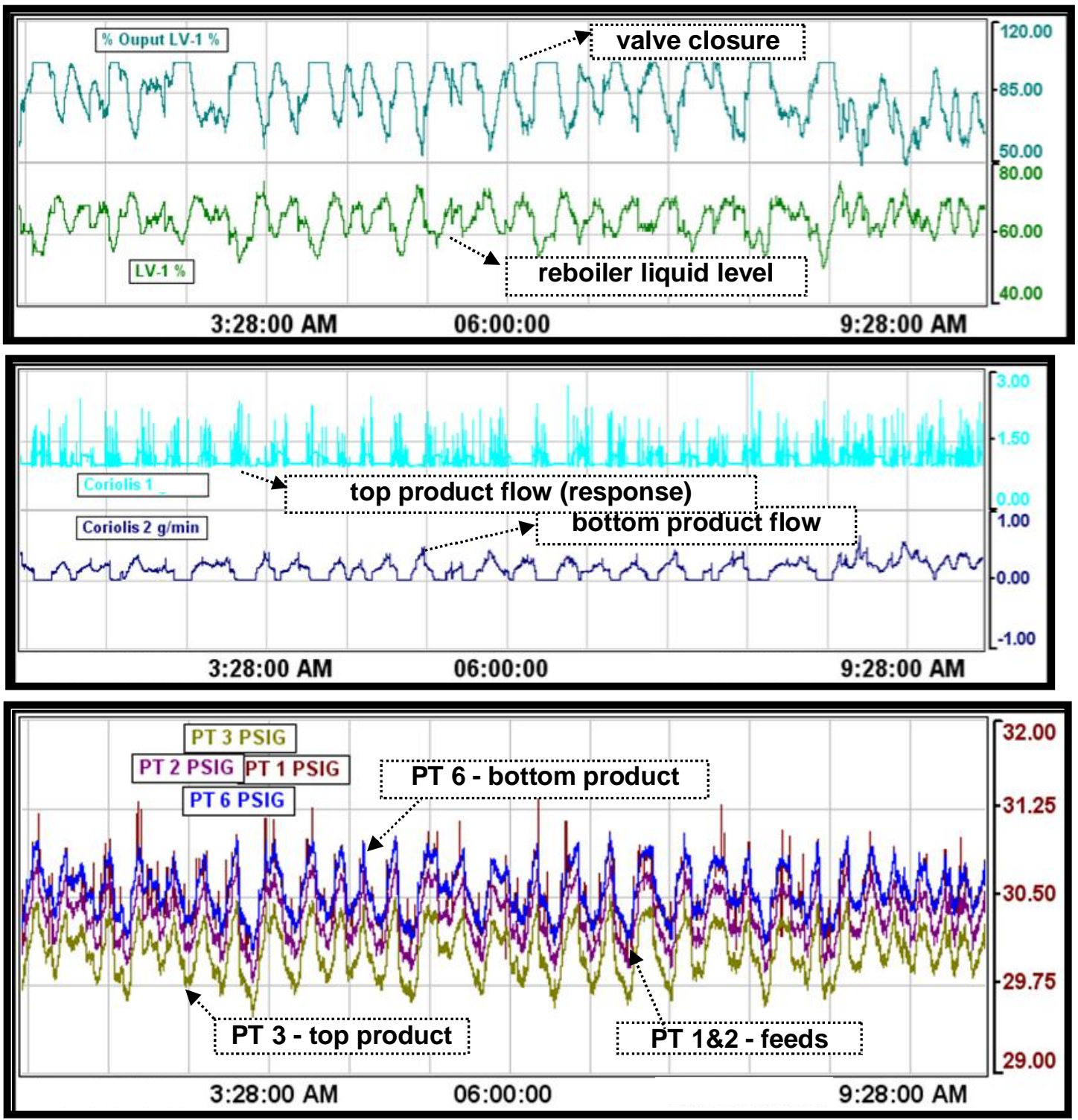

Figure 5-5. Time dependent level sensor, Coriolis flowmeter, and pressure profiles for operation over a 6 hour period at 1.0x flow rate. Profiles correspond to the 1st generation Flex Cell distillation run 1. 


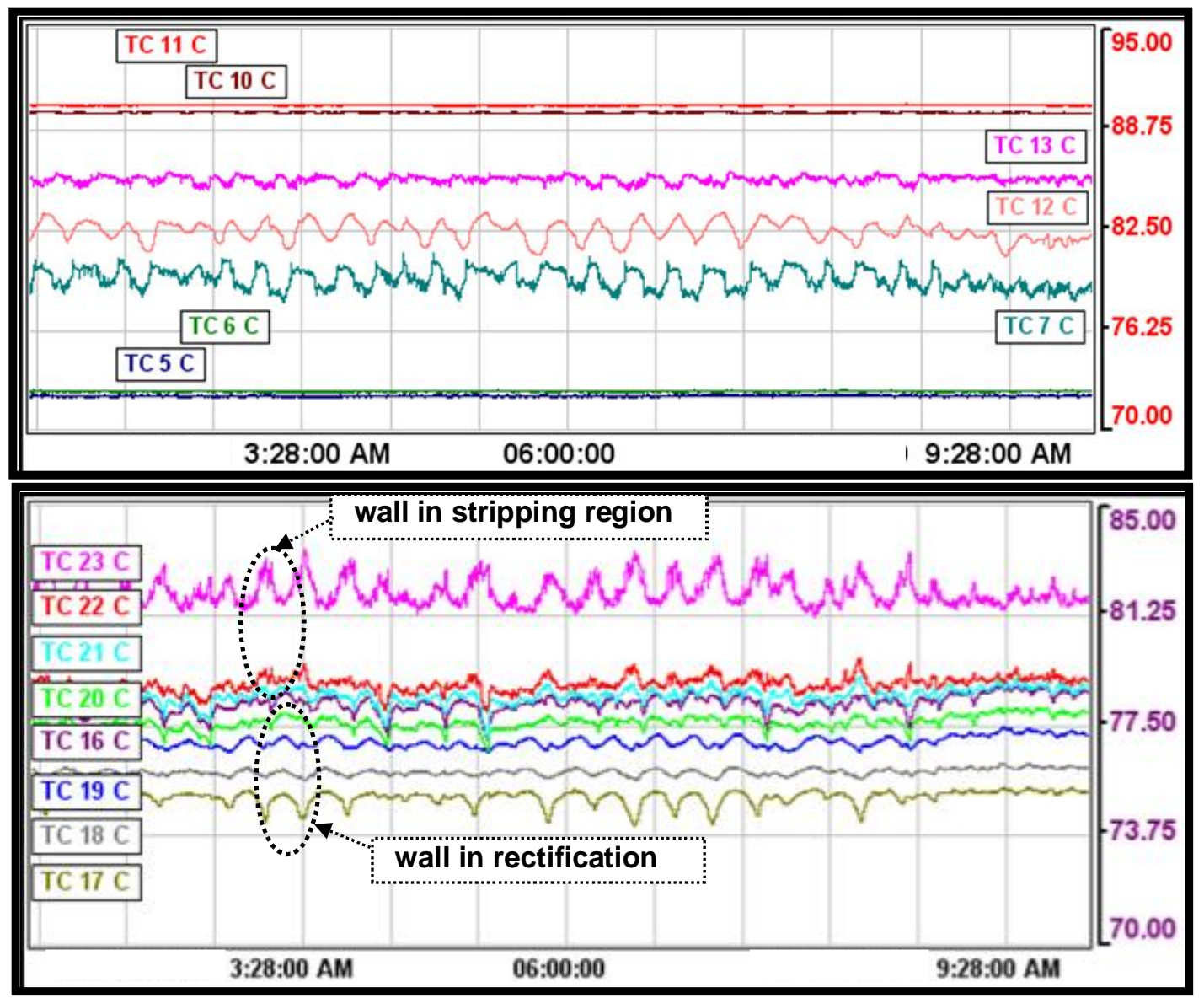

Figure 5-6. Time dependent temperature profiles for operation over a 6 hour period at 1.0x flow rate. Profiles correspond to the 1st generation Flex Cell distillation run 1.

It should be noted that the level sensor, with a maximum measurement stroke of 1 inch, was calibrated and tested to ensure functionality in advance of the testing. Its response was also checked throughout the course of the run. Its calibration required the use of the pentane cyclopentane mixture itself. A series of brief tests was performed to ensure that the bottom product concentration was not affected by the liquid in the level sensor housing.

Tower operation was stable at all three flow conditions scoped in the testing, with more consistent and periodic fluctuations in the level sensor and bottom control valve at the higher flow rates. This response appeared to be accompanied by higher frequency fluctuations in the tower pressures and temperatures, as well. Figure 5-7 shows the impact of increased flow rate on level sensor and control valve response, temperature and pressure profiles for three cases run at similar reboiler and condenser temperatures. 

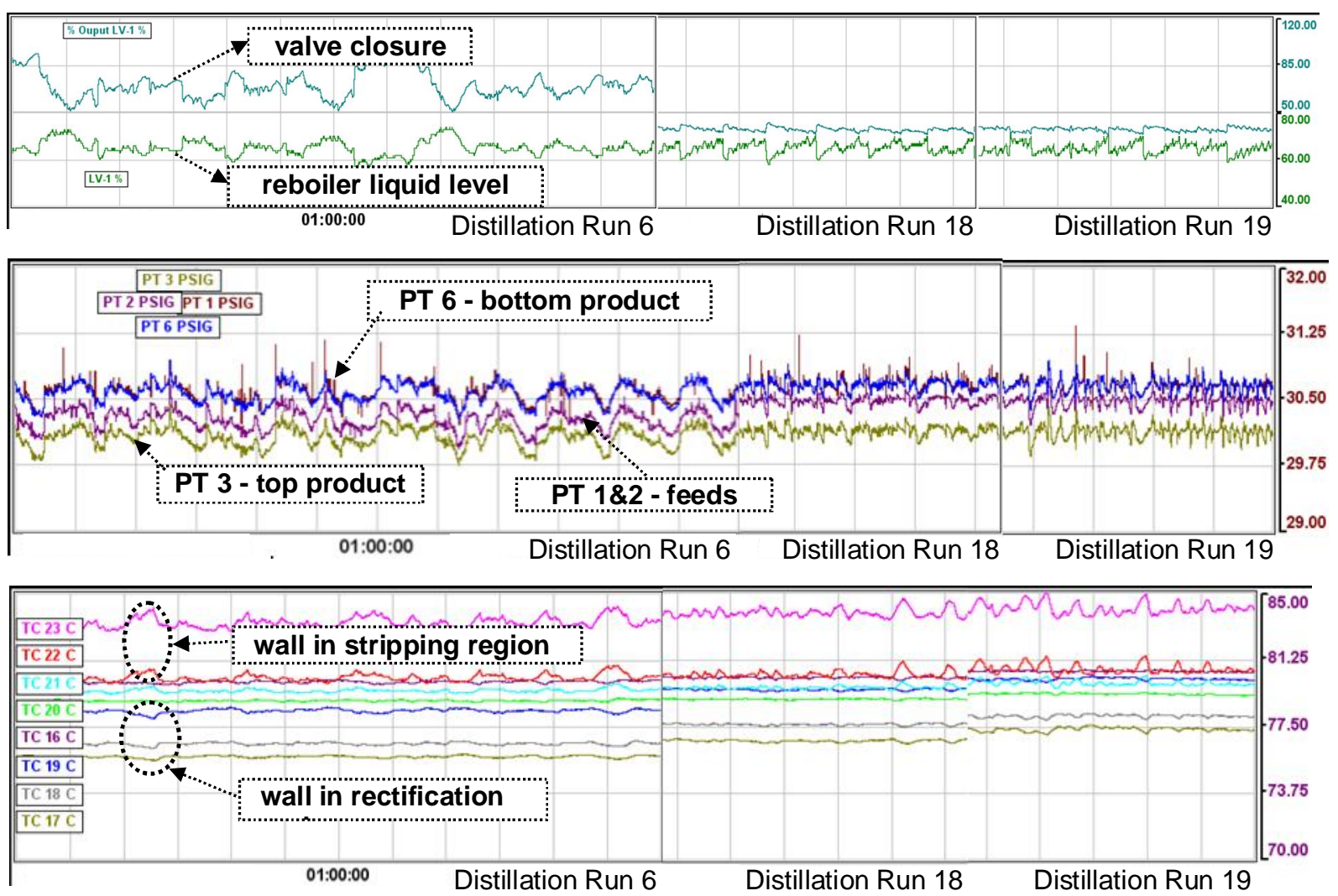

Figure 5-7. Time dependent sensor and valve response, pressure and temperature profiles for operation of the 1st generation Flex Cell over a 1 hour period at 1.0, 1.5, and 2.0x flow rates. Profiles correspond to the distillation runs of $8: 45,5 / 226,8: 42,6 / 2518$, and 16:00,6/2519, operated with condenser and reboiler temperatures ranging from 72 to $73^{\circ} \mathrm{C}$ and 86 to $88^{\circ} \mathrm{C}$, respectively.

Typically, as the flow rate increased, chiller fluid temperatures to obtain similar separation and product distribution tended to become more extreme, an indication of the higher reboiler and condenser duties. A gradual degradation in the level sensor performance was noted as the operation progressed, and an electrical connector to the level sensor had to be replaced after operation of the 1st generation Flex Cell to continue operation with the 2nd generation device. Whether because of the higher feed flow rates or because of problems with the level sensor connection, the later runs were accompanied by occasional sudden decreases in operating pressure. Although not confirmed, it is possible that the combined instability in the level sensor operation and the higher internal traffic may have led to some tower "flooding", liquid bridging that might promote film coalescence and reduce the upflow of gas needed to stabilize and maintain process and flow through the pressure control valve.

\subsubsection{Data Analyses and Performance Estimates}

Performance for each run case was quantified in terms of achieved separation stages. Because reboiler and condenser heat duties were not expressly measured during operation, and since the integrated reboiler and condenser did not allow direct measurement of reflux, it was not possible to determine the exact number of separation stages in the distillation column. Hence, a performance range was calculated for each run condition, bracketed between infinite and minimum reflux. Specifically, using McCabe-Thiele analyses (assuming constant molal overflow),

- worst case estimates were calculated by assuming operation at infinite reflux ratio; 
- close to best case estimates were calculated by assuming operation with a reflux ratio close to (1.5 times) minimum.

Results of this calculation are tabulated in Tables 5-2, 5-3, 5-4, and 5-5 for all key experimental cases.

Hence, as representatively shown in Figure 5-8 (left), knowing the compositions of the feed and products, the minimum number of rectification and stripping stages were determined. For reference, the maximum HETP for the stripping section was also estimated, by dividing the height of the section ( 6 inches) by the corresponding number of stages. The maximum HETP for the rectifying section was calculated in a similar manner, assuming an additional separation stage to account for the fact that a top product was in fact distilled. In all cases, the feed stage was assumed to be a part of the stripping section.
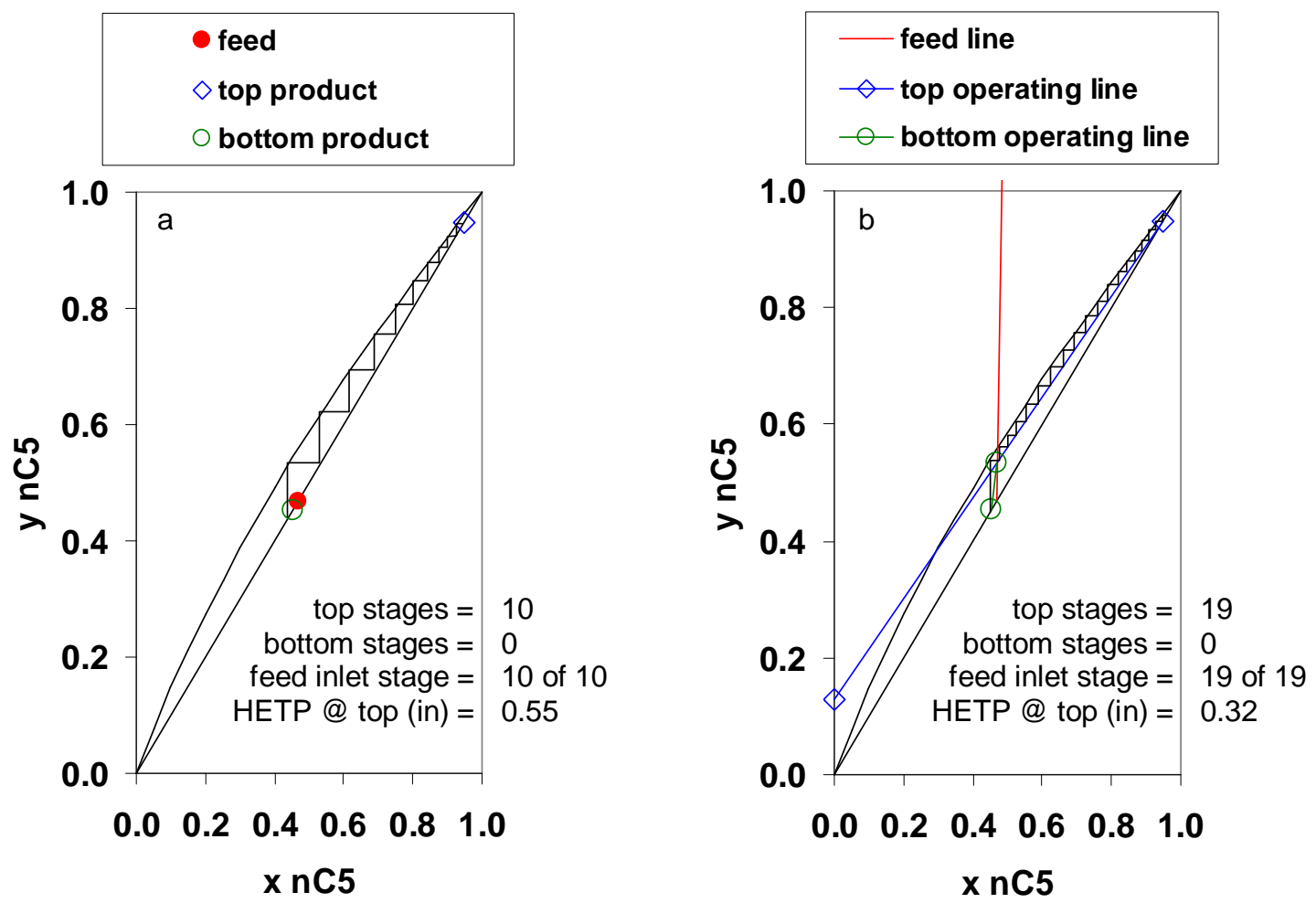

Figures 5-8. McCabe-Thiele analysies plots for a representative 1st generation Flex Cell distillation caserun (5), run operated at the design flow rate on 5/20, at 10:55. Estimated stage numbers and HETP's are also shown, for clarification. a) Infinite reflux approximation. b) Approximation based on a reflux ratio 1.5 times minimum.

Figure 5-8 (right) shows the McCabe-Thiele diagram used to estimate the maximum number of stages for the same representative case, with operation close to minimum reflux ratio. For this approximation, the minimum reflux ratio was calculated from the intersection of the feed line with the equilibrium curve and multiplied by 1.5 to locate the top and bottom operating lines. HETP's were calculated, similarly to the infinite reflux case, without assuming an additional separation stages in either section. Hence, as is shown in Figure 5-8, between 11 (one stage above infinite reflux) and 19 stages of separation were achieved over the 6 inch rectifying length of the column. For this particular run case, the stripping section was essentially ineffective. 


\subsubsection{Results for Operation at the Design Feed Flow Rate}

The first two troubleshooting runs at this flow rate were valuable to ascertaining tower response and noting the importance of appropriate reboiler thermocouple positioning. Comparison of distillation runs 2 through 6 shows a clear dependence of reboiler temperature on process (with the same condenser temperature in place), with increased reboiler temperature leading to decreased distillate purity (from 95 to $79 \mathrm{~mol} \%$ ) and increased bottom product purity (from 45 to approximately 20 mol\%). The latter runs, 6 through 9, highlight the impact of condenser temperature on performance. Increasing condenser temperature for the same reboiler temperature leads to increased flow rate out the top, decreasing top purity, and increasing bottom product purity. As the performance estimates at the bottom of Table 5-2 verify, for the test conditions considered, separation was generally most effective in the rectifying section of the column, leading to HETP's in the order of 0.5 inch.

\subsubsection{Results for Operation at 1.5 of the Design Feed Flow Rate}

Performance at this intermediate feed flow rate, for distillation runs 10 through 13 , verified relatively high bottom product purities at high tower temperatures and high top product purities at relatively low tower temperatures. The low condenser temperature runs, 14 through 18, clarified the trend, with increased reboiler temperature at the same condenser temperature leading to increased bottom product purity at the detriment of distillate purity. There would seem to have been some minor change in operation immediately before distillation run 14, since comparison before and after this run is not direct. The difference could be attributed to the temperature of the line immediately downstream of the condenser, which was later noted to impact device operation. The decrease in chiller temperature may have required an increase in line temperature to prevent vapor re-condensation in the device, causing an effective increase in upper tower temperature, as verified by the relatively high distillate flow rates of distillation run 18 relative to run 10 and distillation runs 14 through 17 relative to runs 12 and 13 . As the performance estimates at the bottom of Table 5-3 verify, for these test conditions considered, separation was generally most effective in the rectifying section of the column. At high column temperatures, the stripping section seemed to surpass rectification performance.

\subsubsection{Results for Operation at 2.0 of the Design Feed Flow Rate}

Performance at the high feed flow rate of distillation runs 19 through 22 showed the same general trends as the lower feed flow rate cases. However, the trends were a bit confounded, given that run 21 did not align with expected behavior. Also, the distillate flow rate of run 22 was too low to measure accurately with the available flowmeter. Progressively worse electrical spikes in the level sensor caused frequent system interruptions and process instability, confounding potential liquid bridging.

\subsubsection{1st Generation MPT Distillation Flex Cell, Flow Rate Comparisons}

Operation of the 1st generation Flex Cell was very successful, verifying operation in line with typical distillation processes. Lower condenser temperatures led relatively consistently to higher distillate product purity, higher reboiler temperatures led to consistently higher bottom product purity. Scoping operation at the different flow rates showed that, as expected, increasing feed flow rate for the same processing conditions leads to a decrease in separation performance. Exact comparisons cannot be made across all run conditions, but some of the most ready comparative runs, involving similar reboiler and chiller fluid feed temperatures, are listed in Table 5-6. Generally, condenser chiller temperatures tend to decrease for the increased feed flow rates, due to increased duties associated with the higher flows. A key indicator of changes in distillation performance is the distillate purity, which is noted to consistently decrease with the increased flow rate. The bottom composition for these particular runs appears less sensitive to flow. Graphical McCabe-Thiele diagrams for one set of comparative cases are also shown in Figure 5-9. 


\begin{tabular}{|c|c|c|c|c|c|c|c|c|c|}
\hline Flow rate relative to design & $\begin{array}{c}1.0 \\
x\end{array}$ & $\begin{array}{c}1.5 \\
x\end{array}$ & $\begin{array}{c}2.0 \\
x\end{array}$ & $\begin{array}{c}1.0 \\
x\end{array}$ & $\begin{array}{c}1.5 \\
x\end{array}$ & $\begin{array}{c}2.0 \\
x\end{array}$ & $\begin{array}{c}1.0 \\
x\end{array}$ & $\begin{array}{c}1.5 \\
x\end{array}$ & $\begin{array}{c}2.0 \\
x\end{array}$ \\
\hline Distillation Run Sequence & 5 & 15 & 20 & 6 & 18 & 19 & 5 & 14 & 22 \\
\hline Condenser chiller feed $\mathrm{T}\left({ }^{\circ} \mathrm{C}\right)$ & 72.8 & 71.9 & 70.7 & 73.1 & 72.0 & 72.5 & 72.8 & 71.9 & 68.9 \\
\hline Reboiler product $\mathrm{T}\left({ }^{\circ} \mathrm{C}\right)$ & 84.3 & 84.4 & 83.6 & 87.5 & 86.9 & 86.4 & 84.3 & 82.7 & 82.8 \\
\hline nC5 feed composition (mole fraction) & 0.47 & 0.49 & 0.50 & 0.48 & 0.49 & 0.50 & 0.47 & 0.49 & 0.49 \\
\hline nC5 distillate composition (mole fraction) & 0.95 & 0.84 & 0.81 & 0.87 & 0.75 & 0.69 & 0.95 & 0.91 & 0.85 \\
\hline $\begin{array}{l}\text { nC5 bottom composition for } 100 \% \text { balance (mole } \\
\text { fraction) }\end{array}$ & 0.45 & 0.37 & 0.40 & 0.28 & 0.23 & 0.23 & 0.45 & 0.47 & 0.49 \\
\hline
\end{tabular}

Table 5-6. Comparative pentane-cyclopentane distillation performance for the 1st generation Flex Cell operated at varying feed flow rates. Details pertaining to each run can be found in Tables 10, 11, and 12.
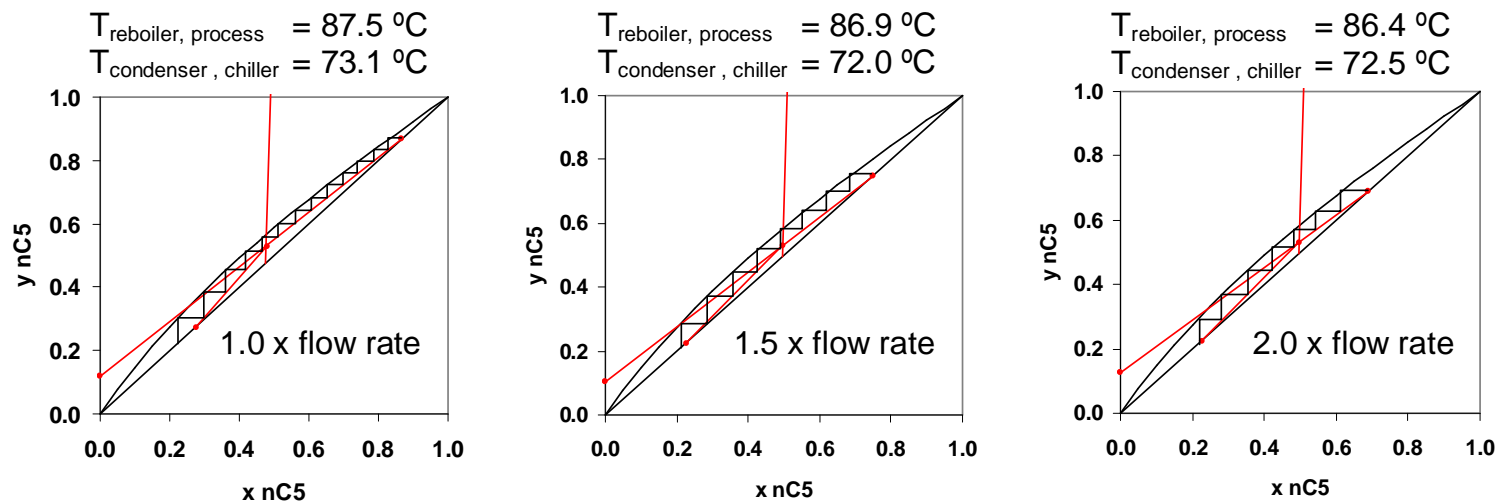

Figure 5-9. McCabe-Thiele analyses diagrams for three representative distillation runs $(6,18$, and 19$)$ involving similar feed composition, reboiler and condenser temperatures but varying feed flow rates. Although performance of the stripping section of the tower was unchanged, the rectification performance was impacted by the change in process conditions, as is typical of standard distillation tower operation. Operation was stable and controllable for all conditions. Details can be found in Tables 5-2 through 5-5.

\subsubsection{2nd Generation Flex Cell Operation and Performance Comparisons}

A very limited number of tests were performed with the 2nd generation MPT distillation Flex Cell. Stable operation was achieved at the design feed flow rate, but increasing the feed flow rate to 1.5 times the design point led to unstable operation. The reduced gap size is believed to lead to earlier onset of bridging. To allow some insight into feed flow effects, as single run was performed at a flow rate 0.8 times the design value. Because the cross sectional area of the 2 nd generation Flex Cell is 0.8 times that of the 1st generation device, the reduced feed rate was also intended to allow comparison of the performance of the 1st and 2nd generation devices at the same flux.

Table 5-7 lists the test parameters and results for the 2 nd generation Flex Cell as well as comparative results obtained with the 1st generation device. Reboiler temperature is noted to have the expected impact on product purities. However, little to no difference in separation performance is noted between the two devices operating at the same conditions. In fact, a slight decrease in rectifying section performance for the 2 nd generation Flex Cell is accompanied by a slight increase in stripping section performance relative to the 1st generation device. The two effects could be considered to balance out. However, operation at the same internal flux, with the 
lower feed flow rate, seems to lead to similar rectification performance and improved stripping section performance for the 2 nd generation Flex Cell relative to the 1st. The 2 nd generation device operating at these conditions would indicate a slight overall performance improvement. Additional run points are required to draw more definite conclusions.

\begin{tabular}{|c|c|c|c|c|c|c|c|c|}
\hline \multicolumn{2}{|l|}{ Flex Cell Device } & \multicolumn{3}{|c|}{$1^{\text {st }}$} & \multicolumn{3}{|c|}{$2^{\text {nd }}$} & \multirow{2}{*}{$\frac{2^{\text {nd }}}{0.8 x}$} \\
\hline $\begin{array}{l}\text { Flow rate } \\
\text { relative to design }\end{array}$ & & & $1.0 x$ & & & $1.0 x$ & & \\
\hline Distillation Run Sequence & & 3 & 4 & 6 & 2 & 1 & 3 & 4 \\
\hline Condenser $\mathrm{T}$ & ${ }^{\circ} \mathrm{C}$ & 73 & 73 & 73 & 73 & 73 & 73 & 73 \\
\hline Reboiler T & & 86 & 85 & 87 & 86 & 85 & 87 & 87 \\
\hline Condenser chiller feed T & ${ }^{\circ} \mathrm{C}$ & 73.0 & 72.8 & 73.1 & 73.1 & 73.0 & 73.1 & 73.1 \\
\hline Reboiler chiller feed T & ${ }^{\circ} \mathrm{C}$ & 89.5 & 87.7 & 93.4 & 93.4 & 88.1 & 94.8 & 94.7 \\
\hline Reboiler liquid product $T$ & ${ }^{\circ} \mathrm{C}$ & 85.8 & 84.8 & 87.5 & 86.2 & 84.5 & 87.2 & 87.3 \\
\hline Condenser fluid dT & ${ }^{\circ} \mathrm{C}$ & 0.29 & 0.30 & 0.32 & 0.33 & 0.28 & 0.36 & 0.34 \\
\hline Reboiler fluid dT & ${ }^{\circ} \mathrm{C}$ & 0.40 & 0.30 & 0.54 & 0.67 & 0.45 & 0.73 & 0.66 \\
\hline Feed T & ${ }^{\circ} \mathrm{C}$ & 74.8 & 74.7 & 74.8 & 75.1 & 75.2 & 75.1 & 75.1 \\
\hline Feed flow rate & $\mathrm{g} / \mathrm{min}$ & 0.34 & 0.34 & 0.34 & 0.34 & 0.34 & 0.34 & 0.27 \\
\hline Distillate flow rate & $\mathrm{g} / \mathrm{min}$ & 0.05 & 0.03 & 0.12 & 0.09 & 0.03 & 0.12 & 0.11 \\
\hline Bottom product flow rate & $\mathrm{g} / \mathrm{min}$ & 0.28 & 0.32 & 0.21 & 0.24 & 0.29 & 0.21 & 0.15 \\
\hline $\begin{array}{l}\text { nC5 feed composition } \\
\text { (measured \& normalized) }\end{array}$ & mol\% & 0.47 & 0.47 & 0.48 & 0.49 & 0.51 & 0.50 & 0.49 \\
\hline $\begin{array}{l}\text { nC5 distillate composition } \\
\text { (measured \& normalized) }\end{array}$ & $\mathrm{mol} \%$ & 0.91 & 0.92 & 0.87 & 0.86 & 0.92 & 0.85 & 0.87 \\
\hline $\begin{array}{l}\text { nC5 bottom composition } \\
\text { (measured \& normalized) }\end{array}$ & mol\% & 0.38 & 0.43 & 0.28 & 0.33 & 0.45 & 0.29 & 0.23 \\
\hline $\begin{array}{l}\text { nC5, bottom composition } \\
\text { (for } 100 \% \text { balance) }\end{array}$ & $\mathrm{mol} \%$ & 0.40 & 0.43 & 0.28 & 0.35 & 0.47 & 0.30 & 0.25 \\
\hline Overall mole balance (out/in) & $\mathrm{mol} / \mathrm{mol}$ & $96 \%$ & $103 \%$ & $97 \%$ & $99 \%$ & $94 \% * *$ & $98 \%$ & $97 \%$ \\
\hline \multicolumn{9}{|l|}{ Rectification } \\
\hline Stages around $\min$. reflux & & 14 & 14 & 11 & 10 & 14 & 9 & 11 \\
\hline Stages at total reflux & & 8 & 9 & 7 & 6 & 8 & 6 & 7 \\
\hline HETP around min. reflux & in & 0.43 & 0.43 & 0.55 & 0.60 & 0.43 & 0.67 & 0.55 \\
\hline HETP at total reflux & in & 0.67 & 0.60 & 0.75 & 0.86 & 0.67 & 0.86 & 0.75 \\
\hline \multicolumn{9}{|l|}{ Stripping } \\
\hline Stages around $\min$. reflux & & 2 & 1 & 4 & 4 & 1 & 5 & 5 \\
\hline Stages at total reflux & & 1 & 0 & 2 & 2 & 1 & 2 & 2 \\
\hline HETP around min. reflux & in & 3 & 6 & 1.5 & 1.5 & 6 & 1.2 & 1.2 \\
\hline HETP at total reflux & in & 6 & 0 & 3 & 3 & 6 & 3 & 3 \\
\hline
\end{tabular}

Mass balance closure was less than preferable.

Table 5-7. Pentane-cyclopentane distillation run summary for the 2 nd generation Flex Cell operated at feed flow rates 0.8 and 1.0 times the design point. Comparative results for the 1st generation device are also included, for reference. 
Closer scrutinizing of chiller, reboiler, and operating temperature differentials across all run points, shown in Figures 5-10a through c, highlights potential reasons for the apparent lack of overall performance improvement of the 2 nd generation device relative to the 1st. Smaller diffusion distances in the vapor phase are expected to lead to faster equilibration time and increased separation stages; yet, there was no clear evidence of this effect.

Since the calculated temperature drop across condenser and reboiler chiller lines for all run cases was less than $0.8^{\circ} \mathrm{C}$, and since the thermocouples used to collect the data had an accuracy of $\pm 0.5^{\circ} \mathrm{C}$, this differential could not be dependably used to gauge relative reboiler and condenser duties. More significant temperature differentials were evident between the reboiler chiller feed line and the reboiler process fluid. Hence, in Figure 5-10a, these were plotted as a function of distillate purity over the course of stand operation. The temperatures of the chiller feed line and reboiler process fluid during stand operation were plotted on the same basis, as well (Figure 510b). As Figure 5-10a highlights, most runs reflect very strong distillate purity dependence on the temperature differential between reboiler process liquid and chiller fluid temperature. With the exception of what is deemed to have been a questionable run (operation at 2.0X), only those experiments which took place prior to the 1st generation Flex Cell distillation run 9 deviated significantly from this trend, showing a clear and unconfounded dependence on chiller feed and reboiler fluid temperature (recall that the reboiler temperature measurement above $90^{\circ} \mathrm{C}$ was deemed to have been incorrectly affected by the reboiler sidewall temperature). In fact, soon after run 9, insulation was added to the reboiler and liquid level sensor housing to reduce losses to the device surroundings, leading to an effective increase in tower temperature. As was confirmed though distillation experiments, increased tower temperature leads to decreased distillate purity. Although difficult to implement without disrupting tower operation, a direct measure of condenser process fluid temperature would be very helpful to ensuring consistent process conditions, allowing more direct and true performance comparisons.
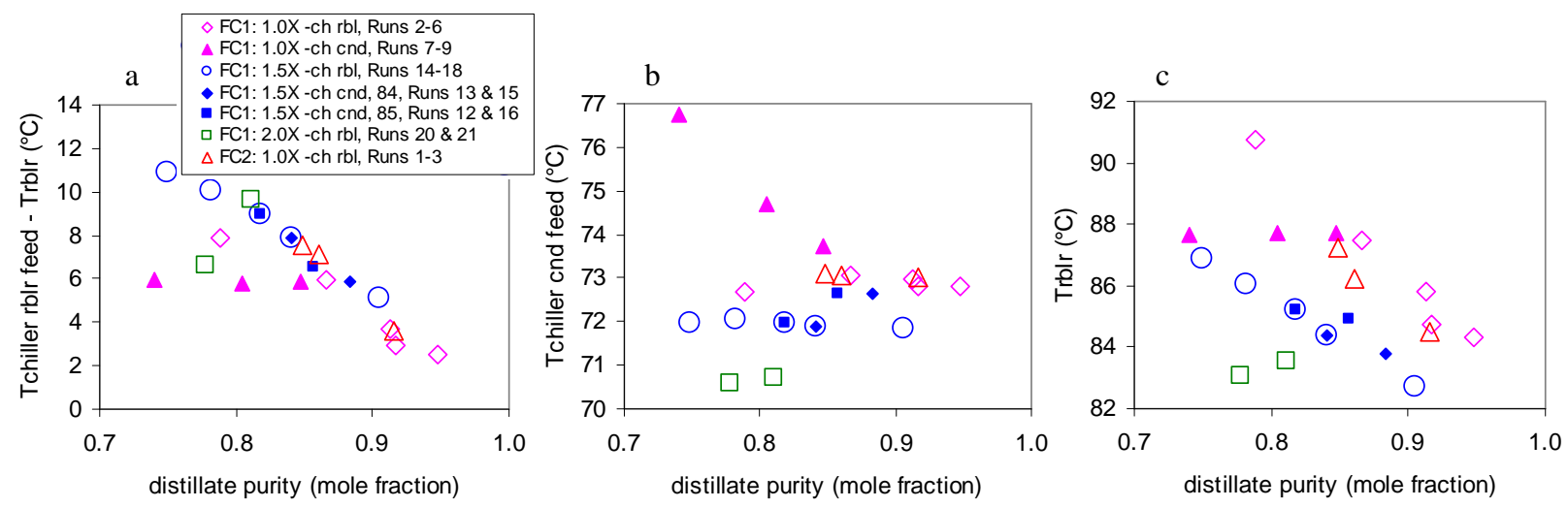

Figure 5-10. Plots of differential chiller feed and reboiler temperatures, and condenser chiller feed and reboiler process fluid temperatures as a function of distillate product purity. Measurements spanned the total operation period, including both the $1^{\text {st }}$ generation and $2^{\text {nd }}$ generation Flex Cells, FC1 and FC2, respectively. The label indicates the feed flow rate relative to the design point value (1.0X, 1.5X, 2.0X), whether the run set involved variation in reboiler or condenser temperature (ch $\mathrm{rbl}$ or ch cnd, respectively), and the collection dates for the data.

\subsection{Conclusions for Task 5}

Low relative volatility component separation in an integrated microchannel device was proven through experiments with the 1st and 2 nd generation Flex Cell devices, using a single equimolar feed mixture of pentane 
and cyclopentane to obtain single purified distillate and bottom product streams. Tower operation was controlled by changing feed flows and reboiler and condenser temperatures. A distillate product purity of $95 \%$ was achieved at the design feed flow rate. As expected, distillate product purity increased with decreased tower operating temperature and decreased feed flows. Overall mass balance was consistently close to $100 \%$. In addition, operation was stable and controllable over a wide range of internal traffic rates and feed flows. Of the two device gap sizes considered, the larger gap size of the 1st generation Flex Cell allowed greater flexibility in operating window with no evident detriment in performance. However, additional testing is needed to more fully characterize the relative performance of the two devices at comparable operating conditions. Adding measurement of chiller fluid flows and process-side condenser temperature would be beneficial to future testing.

Performance was quantified in terms of achieved separation stages. Because reboiler and condenser heat duties were not expressly measured during operation, and since the integrated reboiler and condenser did not allow direct measurement of reflux, the number of stages in the distillation column was gauged by bracketing performance between infinite and minimum reflux. Hence, for the design flow rate case, between 11 (one stage above infinite reflux) and 19 stages of separation were achieved over a 6 inch length. These values are very promising and remarkably small in comparison to conventional distillation towers, whose stage heights are measured in terms of feet rather than fractions of inches. With the high mass transfer efficiency of microchannel distillation, small increments in tower height could provide significant increase in tower performance. In addition, the combined process efficiency and integrated heat transfer bear great promise for significant operational energy savings in industrial settings.

This device configuration proved the viability of implementing microchannel units for separations that extend beyond the laboratory, not only allowing order of magnitude processing height reductions relative to typical commercial operations, but also verifying that the process, with single feed, distillate, and bottom product streams, can take place within a compact and integrated device. 


\section{TASK 6 - MPT BENCH-SCALE DESIGN}

With the intent of planning for full scale design, the investigation detailed below was performed to identify and develop a methodology for providing uniform and consistent feed distribution to the full scale device.

\subsection{Flow Distribution for Full-scale}

A developed method aimed to distribute feed gas in the microchannel device with sufficient uniformity. The working of the distribution strategy was shown for a simulated full scale design with some practical assumptions. The developed distribution method can be applied to the final full scale design after the geometry of the microchannels is finalized for obtaining a sufficient flow distribution.

The flow is delivered to the microchannel device through an external pipe. The flow in the external pipe is distributed into the shims that comprise the device. The main challenge is to distribute the flow into the microchannel uniformly. This work involved developing a strategy to design an internal manifold in the shims to distribute for uniform flow distribution in the microchannels. A general schematic of an internal manifold in a shim that connects external pipe to microchannels is shown in Figure 6-1. The flow from the delivery pipe is delivered to the internal manifold that distributes the flow into microchannels.

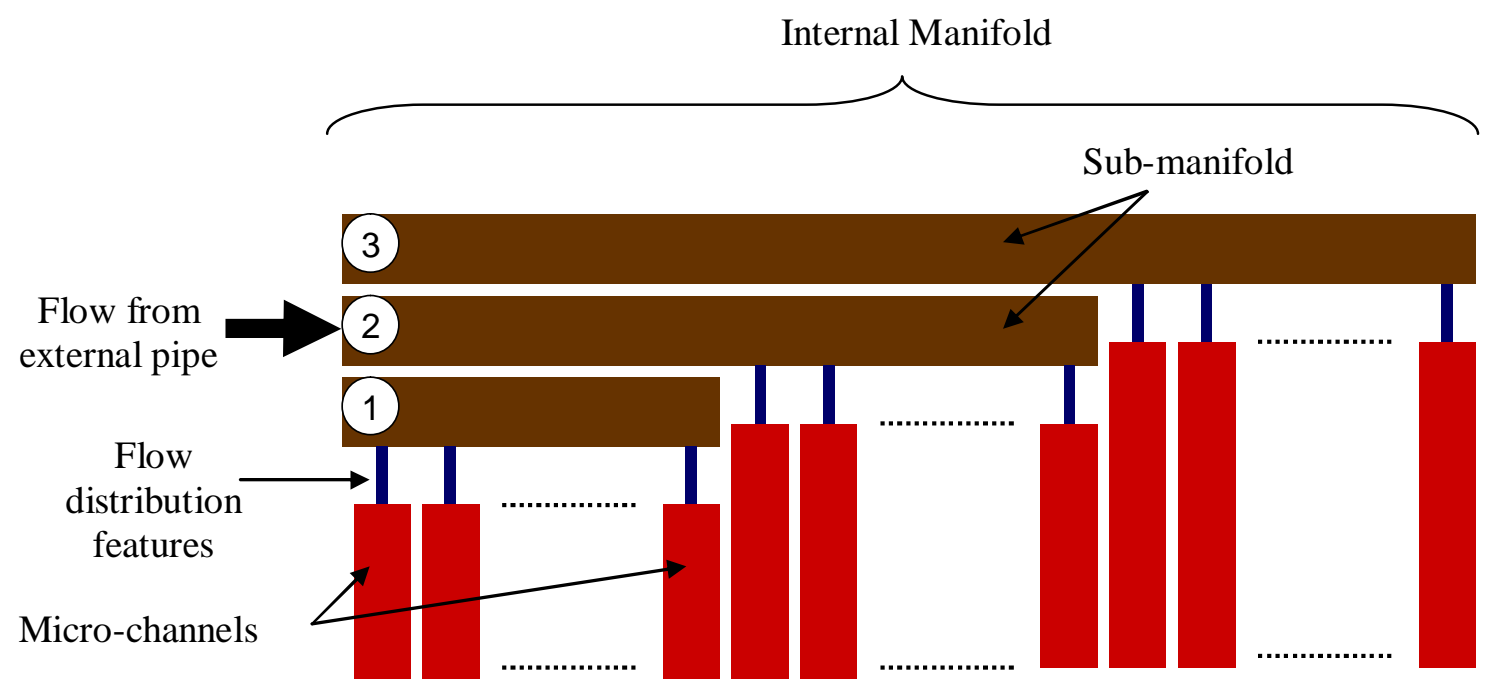

Figure 6-1. Schematic of an internal manifold and microchannels.

Since the geometry of microchannels has not been finalized, only the internal manifold at the inlet was considered. All the microchannels were assumed to exit at constant outlet pressure. The internal manifold consisted of sub-manifolds and flow distribution features as shown in Figure 32. Every microchannel is connected to a sub-manifold by a flow distribution feature. The uniformity in flow distribution is achieved by designing the flow distribution features appropriately.

An analysis was done to estimate the total feed flow rate in a shim for 2,000,000,000 lb/hr plant capacity. The feed flow rate per microchannel was estimated to be $0.5 \mathrm{~kg} / \mathrm{hr}$ approximately. The feed composition was assumed to be $75.5 \%$ ethylene and $24.5 \%$ ethane at 245 psig and $-26.8^{\circ} \mathrm{C}$. Total number of parallel microchannels in a shim was 100 . Since the microchannel geometry was not finalized, it was assumed that at the nominal flow rate of $0.5 \mathrm{~kg} / \mathrm{hr}$, the pressure drop in the channel was 1 psi and pressure drop in the microchannels was a linear function of the mass flow rate. 
Flow distribution features are placed upstream of the distillation channels to dampen the sensitivity that fluctuations may pose to the overall flow distribution. The flow distribution features are based on turning the flow to increase the pressure drop. Modifying the number of turns enables sufficient flow distribution across the width of a shim.

\subsubsection{Results}

A numerical model was developed to simulate the flow through the distribution features. The model was based on flow resistances connected in series and parallel. Total number of sub-manifolds in the geometry was 5 . Each sub-manifold was connected to 20 microchannels by flow distribution features. The dimensions and number of sub-manifold were arbitrary chosen to show that the flow distribution can be controlled by number of the turns in the flow distribution features. Table 16 summarizes the dimensions used in the numerical model.

\begin{tabular}{rc}
\hline \multicolumn{1}{c}{ Geometry Feature } & Dimensions \\
\hline Sub-manifolds & $0.8^{\prime \prime} \times 0.015^{\prime \prime}$ \\
Sub-manifold 1 & $0.8^{\prime \prime} \times 0.015^{\prime \prime}$ \\
Sub-manifold 2 & $1.3^{\prime \prime} \times 0.015^{\prime \prime}$ \\
Sub-manifold 3 & $1.3^{\prime \prime} \times 0.015^{\prime \prime}$ \\
Sub-manifold 4 & $1.5^{\prime \prime} \times 0.015^{\prime \prime}$ \\
Sub-manifold 5 & \\
\hline Flow Distribution Feature & $0.03^{\prime \prime} \times 0.015^{\prime \prime}$ \\
Cross-section & Variable \\
Number of turns & $0.2^{\prime \prime} \times 0.015^{\prime \prime}$ \\
Cross-section & Length N/A (Nominal pressure drop of 1 psi was assumed) \\
\hline
\end{tabular}

Table 6-1. Dimensions used in the numerical model to simulate flow through distribution features.

The quality of flow distribution was calculated by Quality Index Factor (Q) as follow:

Where,

$\mathrm{Q}=$ Quality Index Factor (\%)

= Maximum mass flow rate through channel $(\mathrm{kg} / \mathrm{s})$

$=$ Minimum mass flow rate through channel $(\mathrm{kg} / \mathrm{s})$

In case of perfect distribution, $Q=0 \%$ and in case of no flow through a microchannel, $Q=100 \%$.

The model was used to estimate number of turns in every flow distribution feature. The target $Q$ was less than $5 \%$. Figure 6-2 shows the requirement for number of turns for flow distribution features. There were total 100 flow distribution features (same as number of microchannels). Channel 1 was closest to the inlet and Channel 100 was farthest from the inlet. 


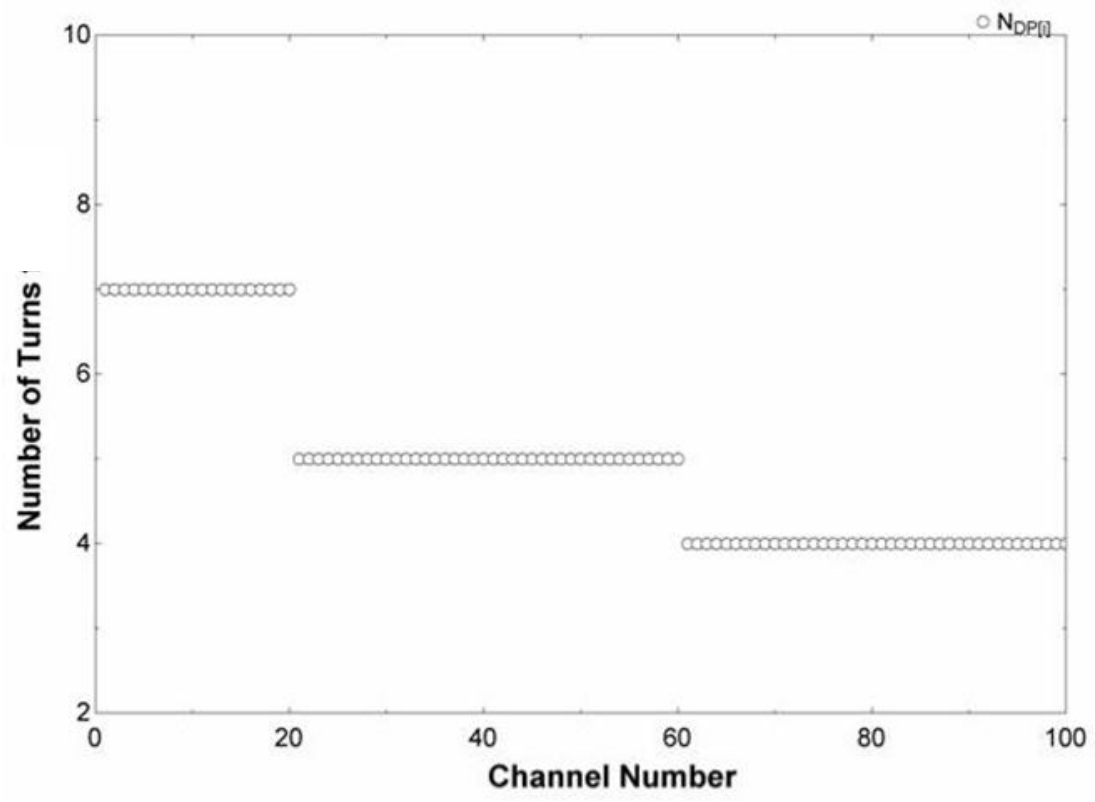

Figure 6-2. Number of turns in flow distribution features.

The designed number of turns for flow distribution feature as shown in Figure 6-2 gave a $Q=4.5 \%$ for microchannel. When the definition of Quality Index Factor was applied to flow distribution in sub-manifolds, the $\mathrm{Q}$ was $2.3 \%$. The total pressure drop was estimated to be 5.9 psi. The channel-to-channel flow rate is shown in Figure 6-3.

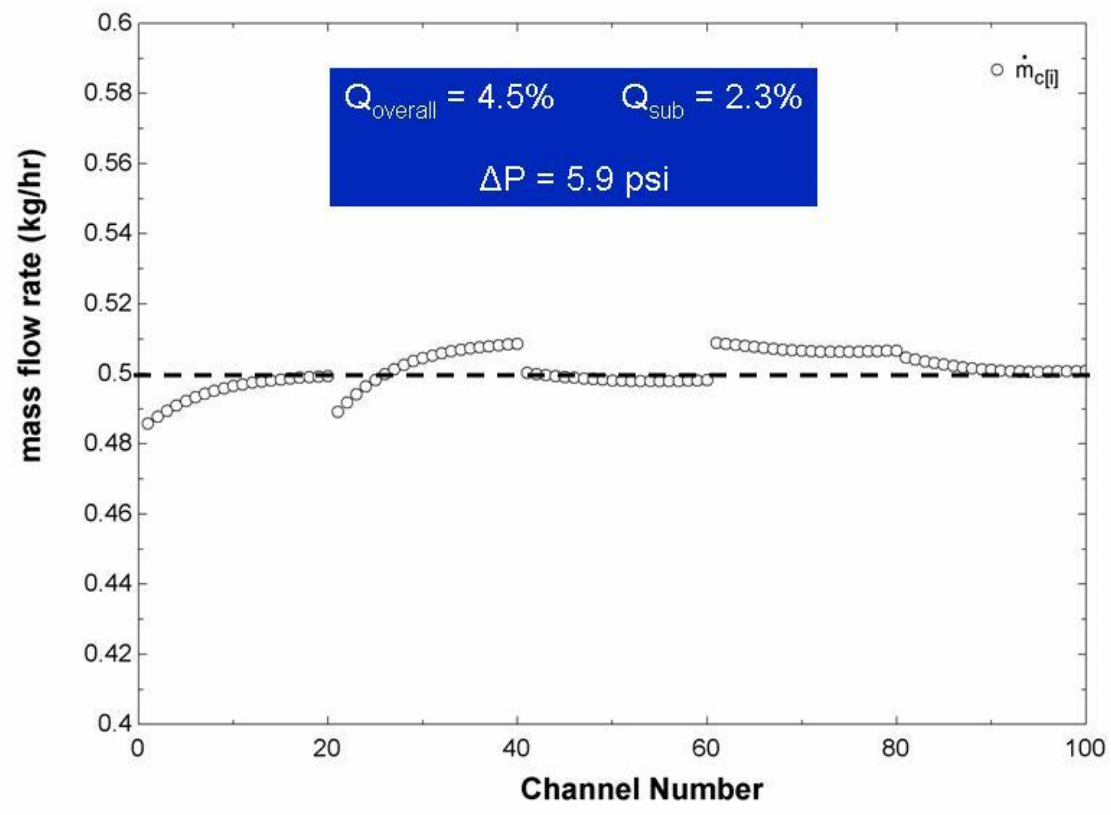

Figure 6-3. Predicted flow distribution in microchannels.

Many times due to irregularities in the channel geometry, for the same flow rate through the microchannel, the channel pressure drop may vary. The variation in channel pressure drop would lead to mal-distribution. A study was done to see the effect of pressure drop variation in the channel on flow distribution. $A \pm 5 \%$ variation in the 
channel pressure drop was applied in the model. The applied channel pressure drop profile is shown in Figure 64.

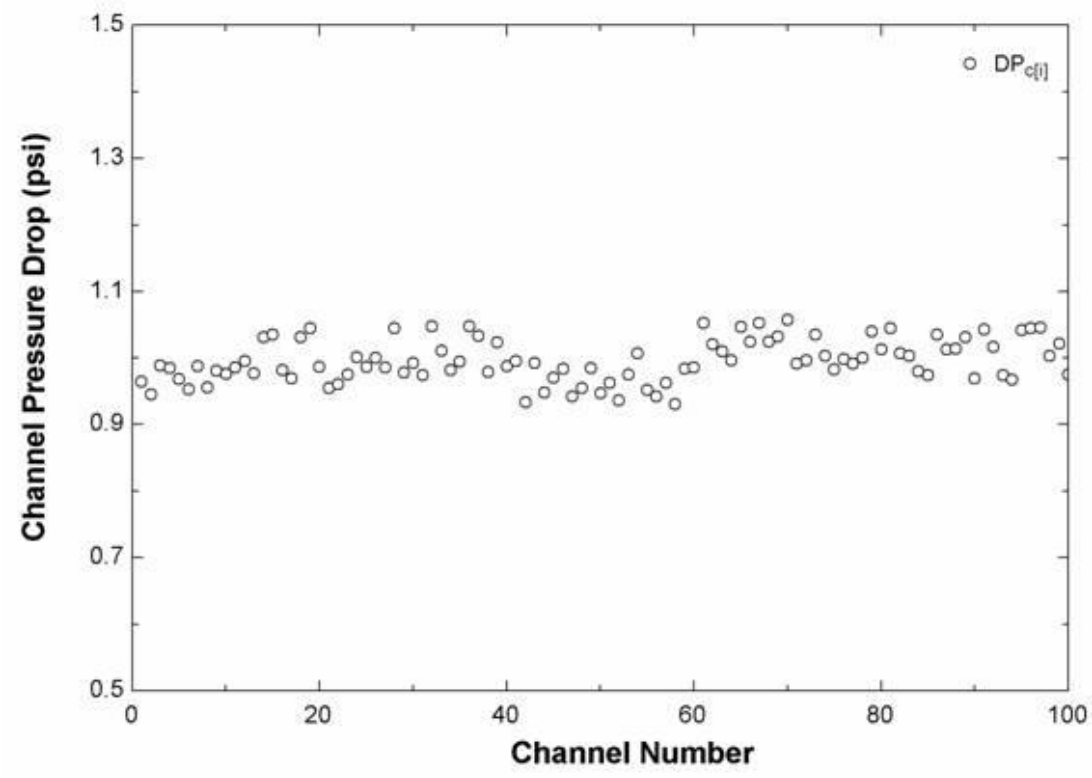

Figure 6-4. Channel pressure drop variation for design sensitivity analysis.

The Quality Index Factor for microchannel was $6.2 \%$ which is very close to flow distribution without channel pressure drop variation. The overall pressure drop was 5.8 psi. The Quality Index Factor for sub-manifold was $4.9 \%$. Figure 36 shows the mass flow distribution across the microchannels.

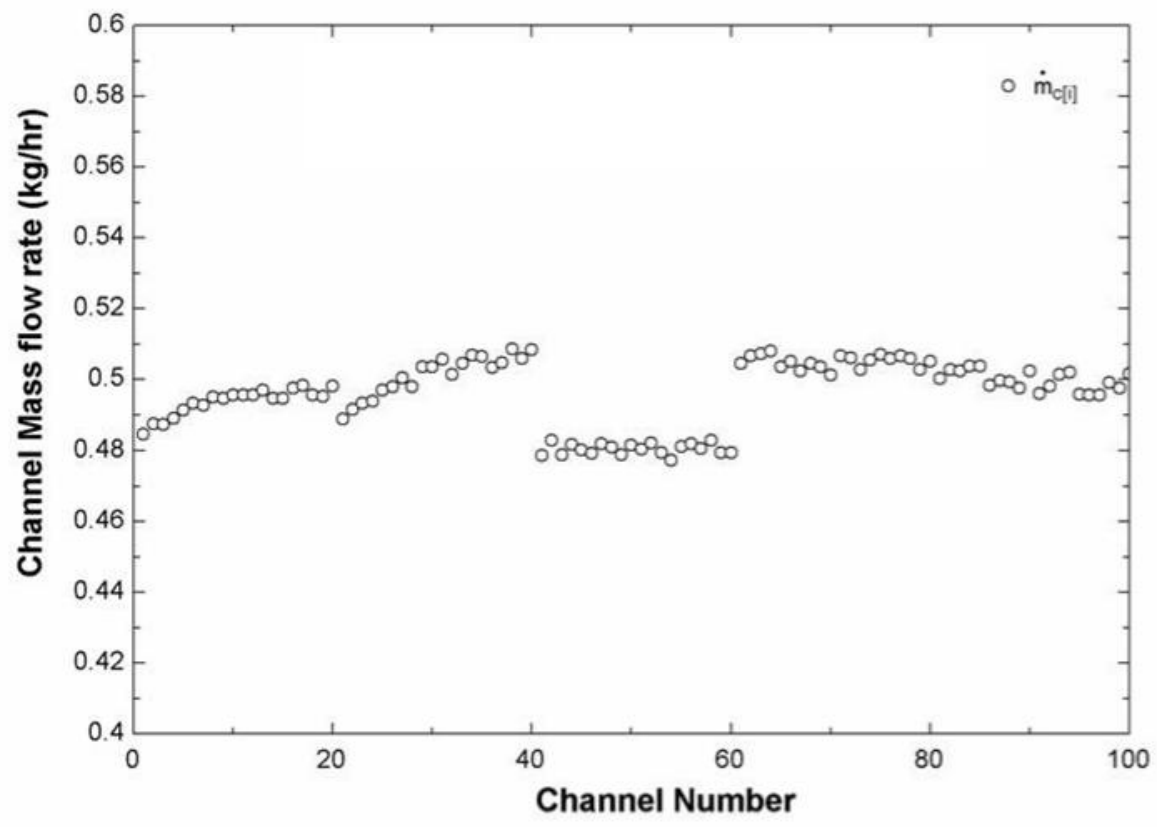

Figure 6-5. Mass flow distribution for design sensitivity analysis. 
The results shows that the number of turns in the flow distribution features provide control to obtain sufficient flow distribution. In the example, the only the number of turns in the flow distribution features were used as a variable to obtain an acceptable flow distribution. However, the overall mal-distribution can be further reduced by modifying the sub-manifold dimensions as well as flow distribution feature dimensions, thus making the design strategy flexible enough to apply to different systems.

To account for performance change due to mal-distribution in the microchannels, the final design will overdesign the number of stages in the device to ensure that the overall product purity may be achieved. For $6 \%$ mal-distribution, $10 \%$ more stages can be added to the device which would result in about 2 " increase of overall length of the channels. 


\section{CONCLUSIONS}

In the course of this five year project, a breakthrough distillation process using Microchannel Process Technology (MPT) was successfully developed, with proven potential for advancement to the next implementation step. This step must be chosen carefully to address applications that can benefit from MPT distillation.

Development progressed from experiments and models considering sections of a full scale device to the design, fabrication, and operation of a single-channel distillation unit involving integrated heat transfer, and single feed, distilled and bottom products.

Early work involved flowsheet analyses to discern the economic viability of ethane-ethylene MPT distillation and develop strategies for maximizing its impact on the economics of the process. Experiments were performed with three low relative volatility mixtures, ethane-ethylene, the targeted system, cyclohexane-hexane, and cyclopentane-pentane. Devices and test stands were specifically designed for these efforts. Simulations and numerical models were paired with experiments in the process of developing this platform technology. Computational Fluid Dynamics (CFD) simulations were developed and validated to help discern the process dynamics and guide future design work.

Experimental trials demonstrated steady and controllable operation for a variety of process conditions. Values of Height-to-an-Equivalent Theoretical Plate (HETP) ranging from less than 0.5 inch to a few inches were experimentally proven, demonstrating a ten-fold performance enhancement relative to conventional distillation. This improvement, while substantial, is not sufficient to displace very large scale distillation trains, due to the capital cost of an MPT solution at the current state of design and manufacturing technology. However, its modularity does offer advantages for smaller scale facilities, such as flowsheet flexibility that would be prohibitively expensive with conventional distillation towers. For this reason, it is unlikely that MPT distillation will be applied to large-scale ethane-ethylene separation, the target of this project. However, the efforts on this project have allowed scoping of technical hurdles that are key to making MPT distillation a commercial reality for other applications. Talks with multiple potential partners are on-going. Their outcome will also help determine the path ahead for MPT distillation. 


\section{REFERENCES}

1. Battelle Memorial Institute, Improved Conditions for fluid separations in microchannels, capillary-driven fluid separations, and laminated devices capable of separating fluids. International Patent No. WO 03/049835 A1, 2003.

2. Battelle Memorial Institute, Conditions for fluid separations in microchannels, capillary-driven fluid separations, and laminated devices capable of separating fluids. U.S. Patent No. 6,875,247 B2, 2005.

3. Battelle Memorial Institute, Methods of contacting substances and microsystem contactors. U.S. Patent No. US 6,869,462 B2, 2005.

4. Bird, R.B., Stewart, W.E., Lightfoot, E.N., Transport Phenomena, John Wiley \& Sons: NY, 1960, pp. 36-41.

5. Heibel, A.K., Jamison, J.A., Woehl, P., Kapteijn, F., Moulijn, J.A., "Improving Flooding Performance for Countercurrent Monolith Reactors," Ind. Eng. Chem. Res., 43, pp. 4848-4855, 2004.

6. McCabe, W.L., Smith, J.C., Harriott, P., Unit Operations of Chemical Engineering, 4th edition, McGrawHill Book Company: New York, 1985.

7. Poling, B.E., Prausnitz, J.M., O'Connell, J.P., The Properties of Gases and Liquids, 5th ed., McGraw-Hill Book Company: New York, 2001.

8. Taylor, R., Krishna, R., Multicomponent Mass Transfer, John Wiley \& Sons: New York, 1993. 


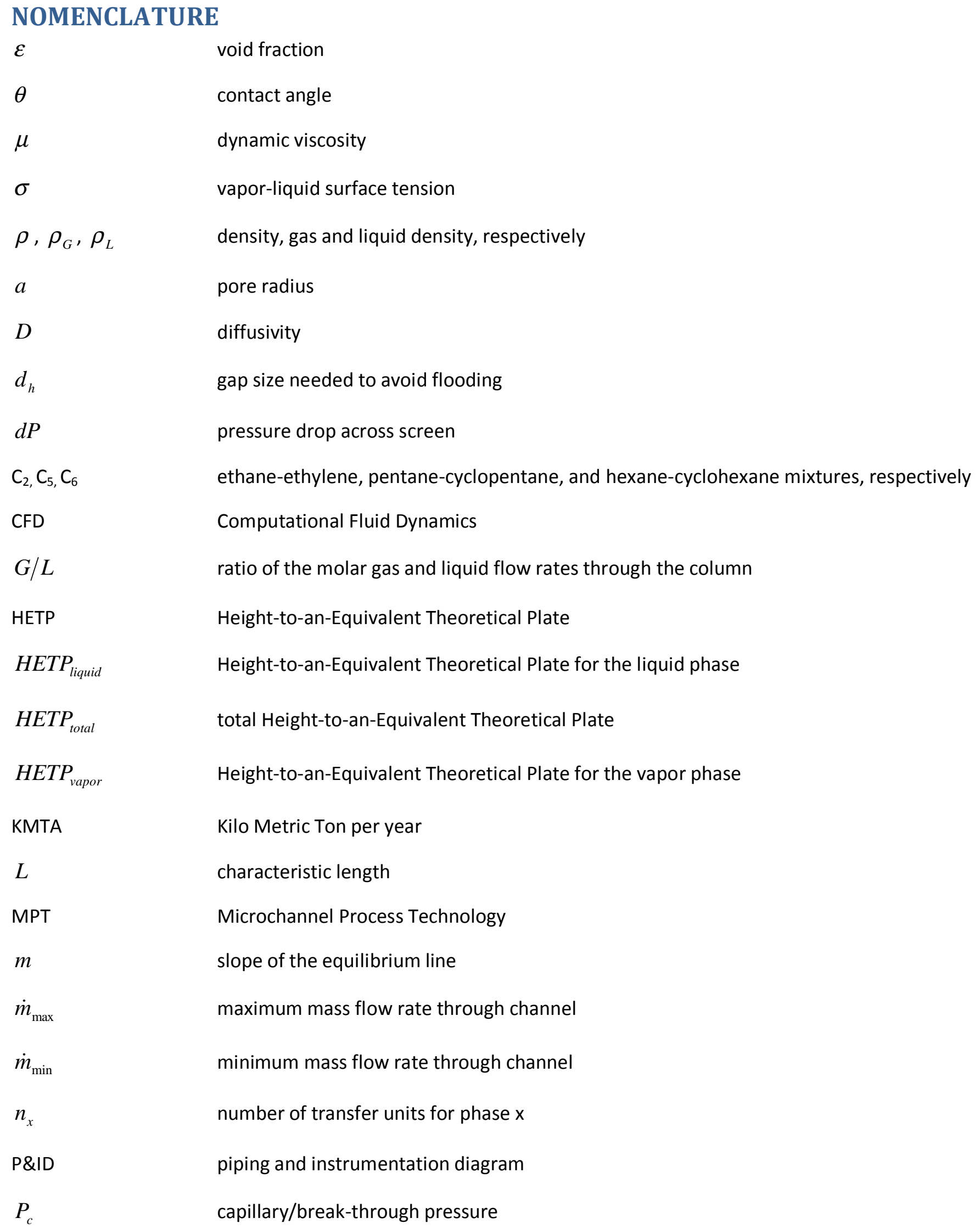




$\begin{array}{ll}P_{\text {vapor }}, P_{\text {liquid }} & \text { vapor-side and liquid-side pressure, respectively } \\ P e & \text { Peclet number, } \frac{L v}{D} \\ Q_{\max } & \text { maximum allowable liquid flow for a falling film } \\ Q & \text { Quality Index Factor } \\ r & \text { interfacial radius of curvature } \\ \mathrm{Re} & \text { Reynolds number } \\ \mathrm{R} / \mathrm{D} & \text { liquid reflux to distillate product ratio } \\ S c, S c_{\text {vapor }}, S c_{\text {liquid }} & \text { Schmidt number, } \frac{\mu}{\rho D} \\ \mathrm{~T} \mathrm{Btu/yr} & \text { Trillion British Thermal Units per year } \\ u_{G}, u_{L} & \text { gas and liquid velocity, respectively } \\ v & \text { velocity } \\ \mathrm{V} / \mathrm{B} & \text { vapor boil up to bottom product ratio } \\ W & \text { width of wall over which falling film flows } \\ x_{i}, y_{i} & \text { length of the mass transfer channel } \\ Z_{\text {tot }} & \end{array}$




\section{COSTS}

\begin{tabular}{|c|c|c|c|c|c|c|c|}
\hline \multicolumn{8}{|c|}{ Project Spending and Estimate of Future Spending } \\
\hline Quarter & From & To & $\begin{array}{l}\text { Estimated } \\
\text { Federal } \\
\text { Share of } \\
\text { Outlays* }\end{array}$ & $\begin{array}{l}\text { Actual Federal } \\
\text { Share of } \\
\text { Outlays }\end{array}$ & $\begin{array}{l}\text { Estimated } \\
\text { Recipient } \\
\text { Share of } \\
\text { Outlays* }\end{array}$ & $\begin{array}{l}\text { Actual } \\
\text { Recipient } \\
\text { Share of } \\
\text { Outlays }\end{array}$ & Cumulative \\
\hline & Start & $12 / 31 / 2004$ & Note 1 & $\$ \$ 123,440$ & Note 1 & $\$ 52,903$ & $\$ 176,342$ \\
\hline $2 \mathrm{Q} 05$ & $1 / 1 / 2005$ & $3 / 31 / 2005$ & & $\$ 273,182$ & & $\$ 117,078$ & $\$ 566,603$ \\
\hline $3 \mathrm{Q} 05$ & $4 / 1 / 2005$ & $6 / 30 / 2005$ & & $\$ 268,083$ & & $\$ 114,893$ & $\$ 949,579$ \\
\hline $4 \mathrm{Q} 05$ & $7 / 1 / 2005$ & $9 / 30 / 2005$ & & $\$ 366,242$ & & $\$ 156,961$ & $\$ 1,472,782$ \\
\hline $1 \mathrm{Q} 06$ & $10 / 1 / 2005$ & $12 / 31 / 2005$ & & $\$ 241,231$ & & $\$ 103,385$ & $\$ 1,817,397$ \\
\hline $2 \mathrm{Q} 06$ & $1 / 1 / 2006$ & $3 / 31 / 2006$ & & $\$ 348,563$ & & $\$ 149,384$ & $\$ 2,315,345$ \\
\hline 3Q06 & $4 / 1 / 2006$ & $6 / 30 / 2006$ & & $\$ 194,455$ & & $\$ 83,338$ & $\$ 2,593,138$ \\
\hline $4 \mathrm{Q} 06$ & $7 / 1 / 2006$ & $9 / 30 / 2006$ & & $\$ 163,743$ & & $\$ 70,175$ & $\$ 2,827,056$ \\
\hline 1Q07 & $10 / 1 / 2006$ & $12 / 31 / 2006$ & & $\$ 117,481$ & & $\$ 50,349$ & $\$ 2,994,885$ \\
\hline $2 \mathrm{Q} 07$ & $1 / 1 / 2007$ & $3 / 31 / 2007$ & & $\$ 142,558$ & & $\$ 61,096$ & $\$ 3,198,539$ \\
\hline $3 \mathrm{Q} 07$ & $4 / 1 / 2007$ & $6 / 30 / 2007$ & & $\$ 65,004$ & & $\$ 27,859$ & $\$ 3,291,402$ \\
\hline $4 \mathrm{Q} 07$ & $7 / 1 / 2007$ & $9 / 30 / 2007$ & & $\$ 46,589$ & & $\$ 19,967$ & $\$ 3,357,957$ \\
\hline 1Q08 & $10 / 1 / 2007$ & $12 / 31 / 2007$ & & $\$ 78,939$ & & $\$ 33,831$ & $\$ 3,470,728$ \\
\hline 2Q08 & $1 / 1 / 2008$ & $3 / 31 / 2008$ & & $\$ 88,773$ & & $\$ 38,046$ & $\$ 3,597,546$ \\
\hline $3 \mathrm{Q} 08 * *$ & $4 / 1 / 2008$ & $6 / 30 / 2008$ & & $\$ 25,425$ & & $\$ 10,896$ & $\$ 3,633,867$ \\
\hline $4 Q 08$ & $7 / 1 / 2008$ & $9 / 30 / 2008$ & & $\$ 50,026$ & & $\$ 21,440$ & $\$ 3,705,332$ \\
\hline 1Q09 & $10 / 1 / 2008$ & $12 / 31 / 2008$ & & $\$ 50,001$ & & $\$ 21,429$ & $\$ 3,776,761$ \\
\hline $2 \mathrm{Q} 09$ & $1 / 1 / 2009$ & $3 / 31 / 2009$ & & $\$ 21,615$ & & $\$ 9,263$ & $\$ 3,807,639$ \\
\hline $3 \mathrm{Q} 09$ & $4 / 1 / 2009$ & $6 / 30 / 2009$ & & $\$ 101,482$ & & $\$ 43,492$ & $\$ 3,952,613$ \\
\hline $4 \mathrm{Q} 09$ & $7 / 1 / 2009$ & $9 / 30 / 2009$ & & $\$ 91,028$ & & $\$ 39,012$ & $\$ 4,082,653$ \\
\hline 1Q10 & $10 / 1 / 2009$ & $12 / 31 / 2009$ & & $\$ 19,775$ & & $\$ 8,475$ & $\$ 4,110,903$ \\
\hline 2Q10*** & $1 / 1 / 2010$ & $2 / 12 / 2010$ & & $\$ 472.8$ & & $\$ 203$ & $\$ 4,111,579$ \\
\hline Totals & & & & $\$ 2,878,105$ & & $\$ 1,233,474$ & $\$ 4,111,579$ \\
\hline
\end{tabular}

** An indirect rate adjustment from 4th Quarter FY07, that had previously been omitted, is accounted for here in the amount of $\$ 15,202.79$.

*** Additional costs may be incurred beyond this date, but within the quarter, to finalize the reporting. Final costs will be reported in the Final Financial Status Report.

Note 1: Leave blank. Only the actual DOE/Cost Share amounts spent through 6/30/04 are needed.

Note 2: Amount for this quarter and subsequent quarters should be updated as necessary on a quarterly basis. Estimates need to be provided for the entire project. If spending for a given quarter is different than estimated, then the remaining quarter's estimates should be updated to account for the difference. Total DOE and Cost Share amounts should be the same as the Award amount. 


\section{PATENTS}

The following patent applications have been filed in the US, as well as in the PCT office:

1. Distillation Process Using Microchannel Technology, filed 7/8/05 (11/177,941)

2. Multiphase Contacting Process Using Microchannels, filed $7 / 7 / 06(11 / 483,136)$ 


\section{PUBLICATIONS AND PRESENTATIONS}

1. "Separation of Ethane-Ethylene in High Flux Microchannel" was presented at the AIChE Spring 2008 meeting, April 7-10, New Orleans. Authors: Ravi Arora, Anna Lee Tonkovich, Maddalena Fanelli, Laura Silva, Jennifer Marco, Daniel Weidert, Jeff Marco, Paul Neagle, and Thomas Hickey.

2. "Advanced Separations, Including Distillation, Using Microchannel Architecture for Process Intensification," was presented at the European Congress of Chemical Engineering (ECCE-6), September 2007, Copenhagen, Denmark. Authors: Laura Silva, Ravi Arora, Anna Lee Tonkovich, Amanda Glass, Daniel Weidert, Maddalena Fanelli, Dongming Qiu, Robert Litt.

3. "Micro-scale distillation - I: simulation," was presented at the Multiphase Flow 2007 Conference, June 13, 2007, Bologna, Italy. The proceedings paper was published in Computational Methods in Multiphase Flow IV, A.A. Mammoli, C.A. Brebbia, pp. 205-213, 2007. Authors: Maddalena Fanelli, Ravi Arora, Amanda Glass, Robert Litt, Dongming Qiu, Laura Silva, Anna Lee Tonkovich, and Daniel Weidert.

4. "High Mass Transfer Efficiency with Integrated Heat Transfer," was presented at the AIChE Spring 2005 meeting, April 2005, Atlanta, GA. Authors: Laura Silva, Ravi Arora, Anna Lee Tonkovich, Thomas Hickey.

5. Velocys has received inquiries from chemical producers interested in applications of microchannel distillation beyond ethylene plants. Velocys has followed up with inquiries and continues to respond to requests for information. 
APPENDIX A - ABB LUMUS TASK 1 REPORT (NON-CONFIDENTIAL) 